Florida International University FIU Digital Commons

$10-24-2011$

\title{
Interactions of Toxic Metals with Algal Toxins Derived from Harmful Algal Blooms
}

Shuo Li

Florida International University, sli011@fiu.edu

DOI: $10.25148 /$ etd.FI11120206

Follow this and additional works at: https://digitalcommons.fiu.edu/etd

\section{Recommended Citation}

Li, Shuo, "Interactions of Toxic Metals with Algal Toxins Derived from Harmful Algal Blooms" (2011). FIU Electronic Theses and Dissertations. 478.

https://digitalcommons.fiu.edu/etd/478 


\section{FLORIDA INTERNATIONAL UNIVERSITY}

Miami, Florida

INTERACTIONS OF TOXIC METALS WITH ALGAL TOXINS

DERIVED FROM HARMFUL ALGAL BLOOMS

A thesis submitted in partial fulfillment of the

requirements for the degree of

MASTER OF SCIENCE

in

CHEMISTRY

by

Shuo Li

2011 
To: Dean Kenneth Furton

College of Arts and Sciences

This dissertation, written by Shuo Li and entitled Interactions of Toxic Metals with Algal Toxins Derived from Harmful Algal Blooms, having been approved in respect to style and intellectual content, is referred to you for judgment.

We have read this dissertation and recommend that it be approved.

Kathleen Rein

Jose Almirall

Yong Cai, Major Professor

Date of Defense: October 24, 2011

The dissertation of Shuo Li is approved.

Dean Kenneth Furton
College of Arts and Sciences

Interim Dean Kevin O'Shea

University Graduate School

Florida International University, 2011 


\section{DEDICATION}

I dedicate this thesis to my parents. Without their understanding, patience, support, and most of all love, the completion of this work would not have been possible. I also dedicate to my ex-girlfriend, Yongxia, who made me stronger than ever since we were separated from each other one year ago. 


\section{ACKNOWLEDGMENTS}

First of all, I would like to thank my major professor, Dr. Yong Cai, for his support, guidance, and patience. He is not only an excellent research advisor but also my mentor in both my work and life. Sincere gratitude is also extended to other committee members, Dr. Jose Almirall and Dr. Kathleen Rein, for their critical comments and suggestions. Special thanks must go to Dr. Guangliang Liu for his kind and professional help throughout the research project.

I would like to extend acknowledgement to Dr. Kathleen Rein' research group for their algal toxins supplies. I would like to thank the members from Dr. Rein' group, Daisy and Pengfei, for their great help with the Karenia brevis culture experiments.

Special thanks must go to Szabina Stice and Dr. Zheng Wang, for their kindness to help me to revise my thesis paper. I would like to thank my friends, Dr. Yanbin Li, Dionne, Zhiwei and Dr. Sen Chen who have been working or have worked with me for more than two years in Dr. Cai's group.

I would like to thank Dr. Yaru Song for her help with the usage and maintenance of the LC/MS using for toxin determination.

A very great thank you goes to my uncle, Rengao and my cousin, David, who offered me great support not only in the form of financial help but in the form of spiritual help to make me more confident.

I would like to thank University Graduate School and Department of Chemistry \& Biochemistry at Florida International University for the financial support. 


\section{ABSTRACT OF THE THESIS \\ INTERACTIONS OF TOXIC METALS WITH ALGAL TOXINS \\ DERIVED FROM HARMFUL ALGAL BLOOMS}

by

\section{Shuo Li}

Florida International University, 2011

Miami, Florida

\section{Professor Yong Cai, Major Professor}

The purposes of this study were to characterize the complexation of toxic metals with algal toxins and to determine the effects of arsenic and copper on the growth of Karenia brevis under specific experimental conditions.

Microcystins, pahayokolides, brevetoxins and okadaic acid were used as representatives of algal toxins while arsenic, copper, cadmium, cobalt, iron, manganese and mercury were selected as typical toxic metals (including metalloids here) in the aquatic environment. The stabilities of the toxin-metal complexes were determined using equilibrium dialysis and/or centrifugal ultrafiltration technique. A direct exposure of arsenic and copper to the $K$. brevis was carried out to determine the effects of these metals to the growth of the algal cell.

The results indicated that $\mathrm{Cu}^{2+}, \mathrm{Hg}^{2+}, \mathrm{Co}^{2+}, \mathrm{Cd}^{2+}$ and $\mathrm{Fe}^{2+}$ were capable of complexing with the algal toxins. Moreover, the exposure experiments demonstrated that the high concentration of arsenic and copper could affect the growth of the K. brevis. 


\section{TABLE OF CONTENTS}

CHAPTER

PAGE

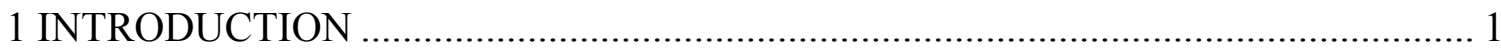

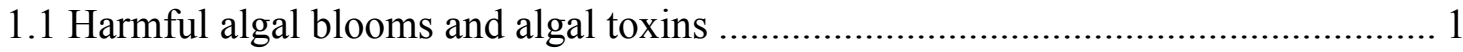

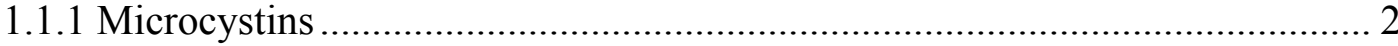

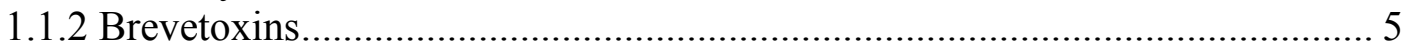

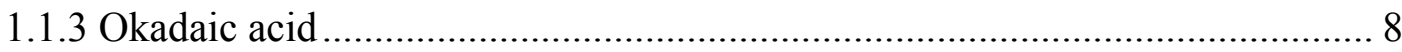

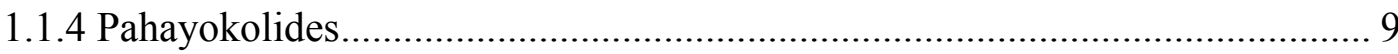

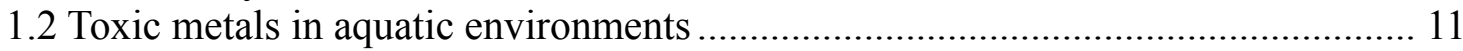

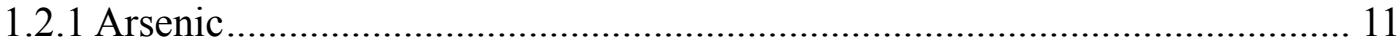

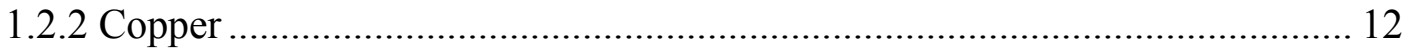

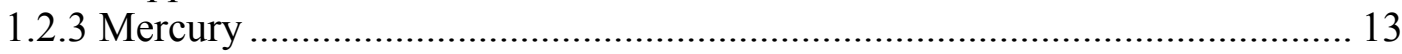

1.3 Interactions between algal toxins and toxic metals ............................................... 15

1.3.1 The effects of toxic metals on the growth of algae species and toxin

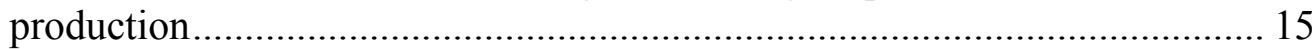

1.3.2 The complexation of algal toxins with metals.......................................... 17

1.3.3 Indirect interactions between algal toxins with metal .................................... 18

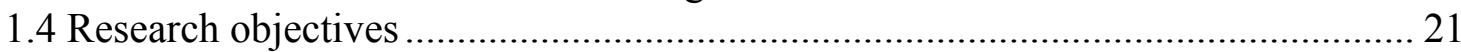

2 DETERMINATION OF CONDITIONAL STABILITY CONSTANTS

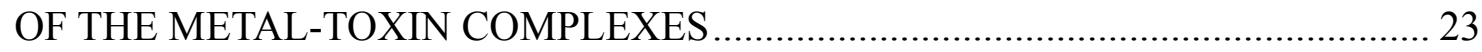

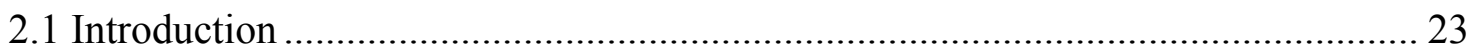

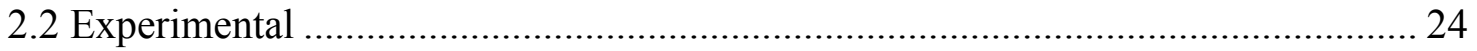

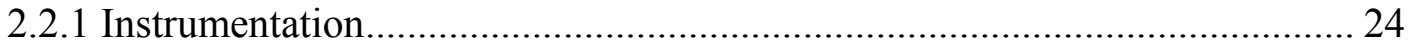

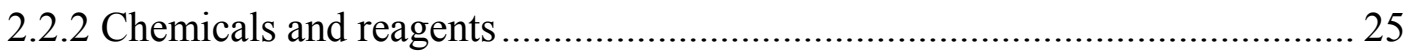

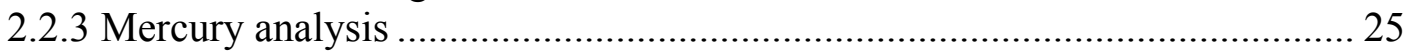

2.2.4 Total metal analysis (except for mercury) …………...................................... 27

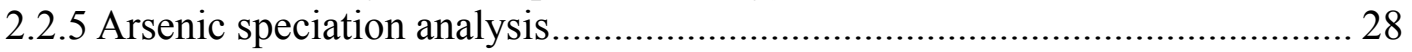

2.3 Determination of time required for equilibrium dialysis ..................................... 29

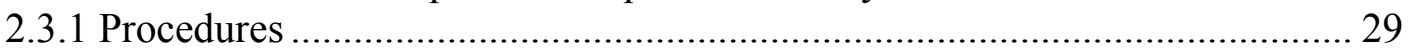

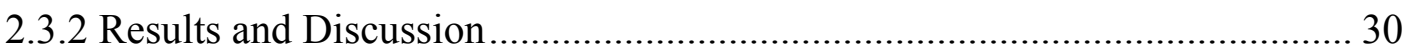

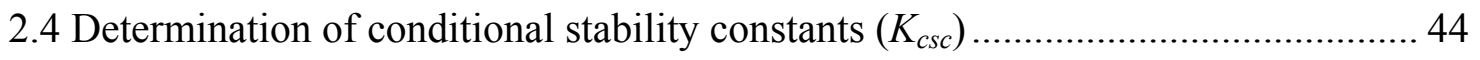

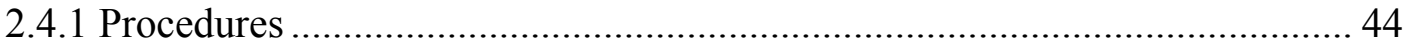

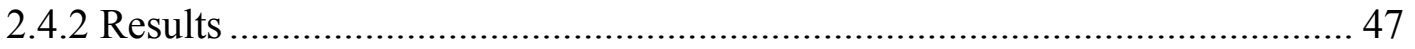

2.5 Determination of distribution ratio of iron using ultrafiltration technique ............. 51

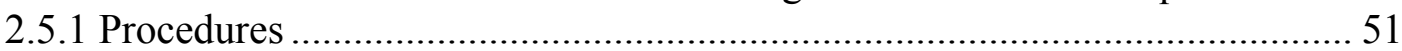

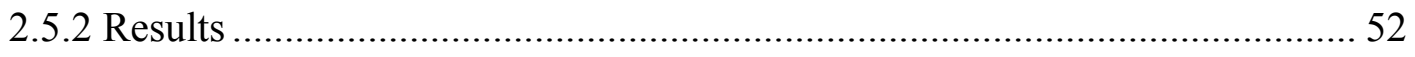

2.6 Discussion on metal-toxin complexation ............................................................ 53

2.6.1 Effects of ionic radius of metals and cavity radius of toxin molecules.......... 53

2.6.2 Effects of $d$-orbital electron configuration of metal cations............................ 54

2.6.3 Effects of structures and functional groups of algal toxin molecules ............ 56

2.6.4 Effects of redox potential of metals .............................................................. 57

2.6.5 Effects of softness-hardness of metal cations................................................. 59 


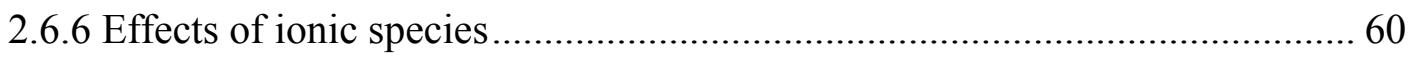

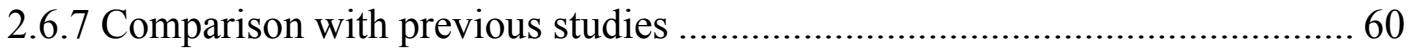

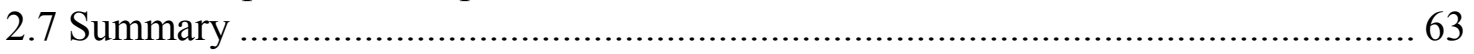

3 THE EFFECTS OF ARSENIC AND COPPER ON THE GROWTH

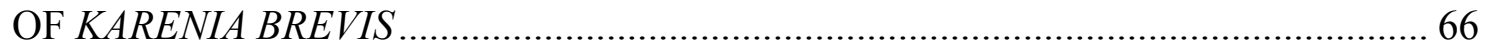

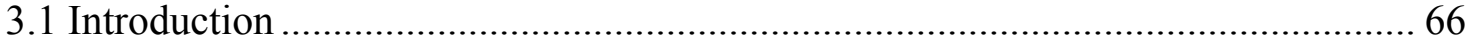

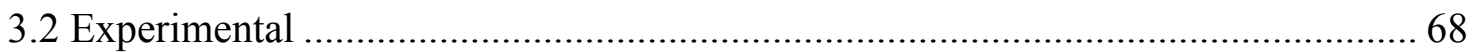

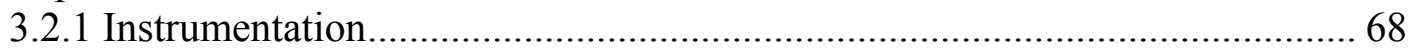

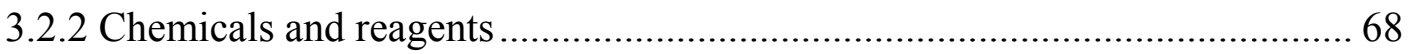

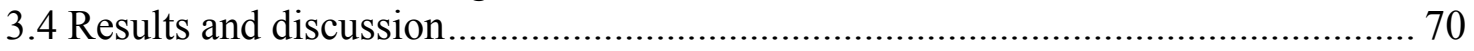

3.4.1 The effects of arsenic on the growth of Karenia brevis ................................. 70

3.4.2 The effects of copper on the growth of Karenia brevis ................................... 72

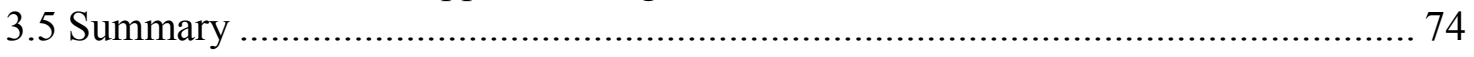

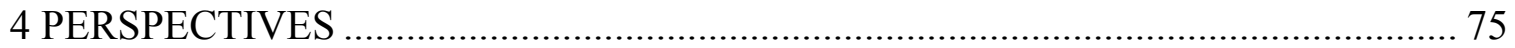

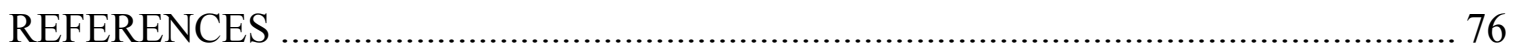




\section{LIST OF TABLES}

TABLE

PAGE

1. The stability constants of some selected toxin-metal complexes...................20

2. Optimized parameters of inductivity coupled plasma mass spectrometry used for

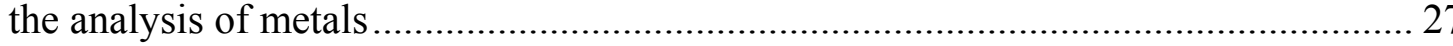

3. The detection limits of metals and the concentration ranges of calibration curves ...... 28

4. The time required to reach dialysis equilibrium and the recoveries of each metals under the experimental $\mathrm{pH}$.

5. The hydroxides of the selected metal cations and their theoretical critical $\mathrm{pH}$ value as the experimental conditions

6. The concentrations of metal ions and algal toxins used in the equilibrium dialysis experiments

7. The conditional stability constants $\left(K_{c s c}\right)$ of the metal-toxin complexes

8. The electron configuration, ionic radius, redox potential, electronegativity and strength of Lewis acid of the metal ion.

9. The recoveries of $\mathrm{Fe}^{2+}$ and distribution ratio of iron $\left(K_{d}\right)$ under the selected experimental conditions

10. Artificial seawater for RE media. 


\section{LIST OF FIGURES}

FIGURE

PAGE

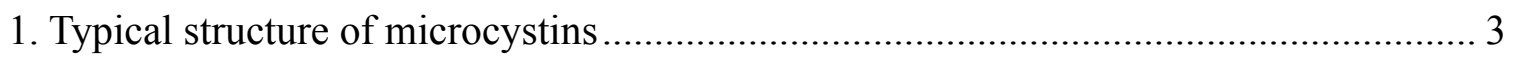

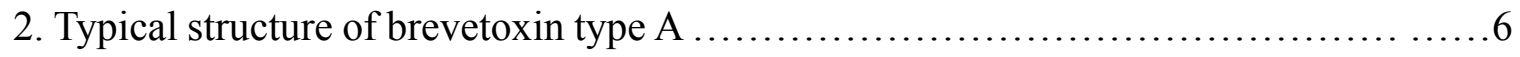

3. Typical structure of brevetoxin type B.............................................................. 7

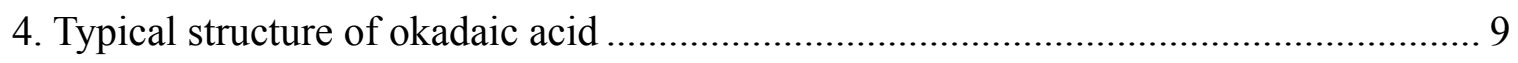

5. Typical structure of pahayokolides........................................ 10

6. Typical calibration curve of mercury analysis by using cold vapor atomic

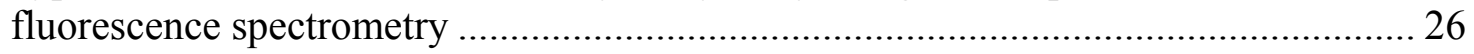

7. The relationship between the ionic radius of period 4 elements and the time requried

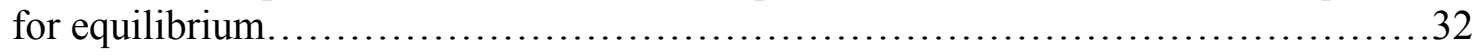

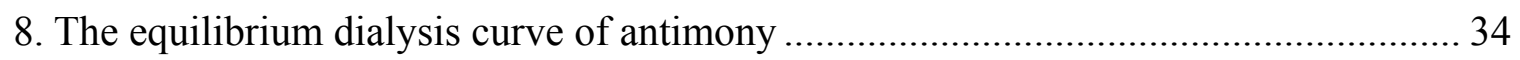

9. The equilibrium dialysis curve of arsenic..................................... 34

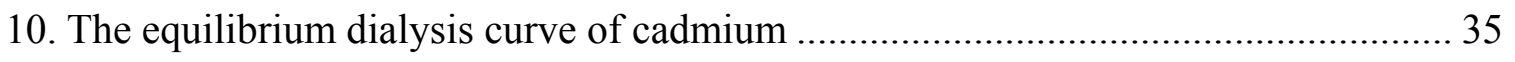

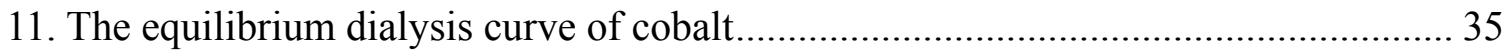

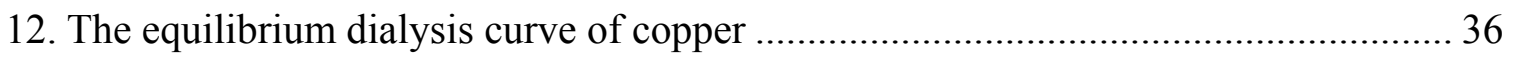

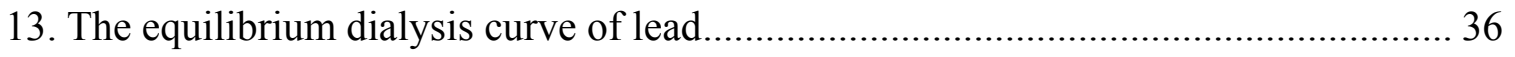

14. The equilibrium dialysis curve of manganese ….............................................. 37

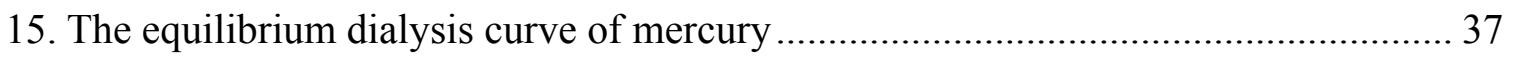

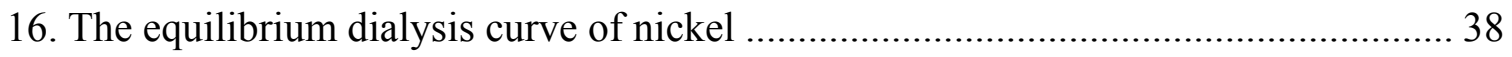

17. The equilibrium dialysis curve of silver................................... 38

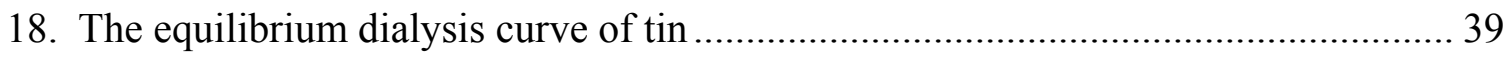

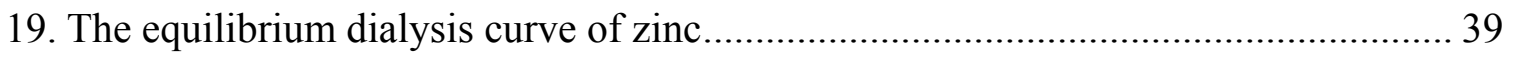

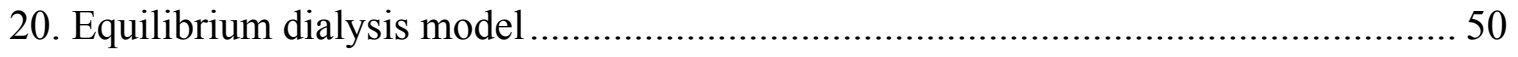


21. The effects of copper $\left(\mathrm{Cu}^{2+}\right)$ on the growth of Karenia brevis..................... 70

22. The effects of copper $\left(\mathrm{Cu}^{2+}\right)$ on the growth of Karenia brevis ............................... 73 


\section{LIST OF ABBREVIATIONS}

$\begin{array}{ll}\text { ABBREVIATION } & \text { FULLNAME } \\ \text { Adda } & \begin{array}{l}\text { (2S, 3S, 8S, 9S)-3-amino-9-methoxy-2, 6, 8- } \\ \text { trimethyl-10-phenyldeca-4, 6-dienoic acid }\end{array} \\ \text { ASP } & \text { Amnesic shellfish poisoning } \\ \text { ASV } & \text { Anodic stripping voltammetry } \\ \text { CFSE } & \text { Crystal field stabilization energy } \\ \text { CFT } & \text { Crystal field theory } \\ \text { CSI } & \text { Cryospray ionization } \\ \text { CV } & \text { Cyclic voltammetry } \\ \text { CVAFS } & \text { Cold vapor atomic fluorescence spectrometry } \\ \text { d } & \text { day(s) } \\ \text { DDI } & \text { Distilled deionized } \\ \text { DMA } & \text { Dimethylarsinic acid } \\ \text { DNA } & \text { Deoxyribonucleic acid } \\ \text { DPP } & \text { Differential pulse polarography } \\ \text { DSP } & \text { Diarrheal shellfish poisoning } \\ \text { EDTA } & \text { Ethylene diamine tetraacetic acid } \\ \text { ESI } & \text { Electrospray ionization } \\ \text { h } & \text { hour(s) } \\ \text { HABs } & \text { International Agency for Research on Cancer } \\ \text { IARC } & \\ \text { HPLC } & \end{array}$




\begin{tabular}{|c|c|}
\hline iAs & Inorganic arsenic \\
\hline ICPMS & Inductively coupled plasma mass spectrometry \\
\hline$K_{c d c}$ & Conditional distribution constant \\
\hline$K_{c s c}$ & Conditional stability constant \\
\hline$K_{s p}$ & Solubility product constant \\
\hline M & Molar \\
\hline MDha & N-methyl dehydroalanine \\
\hline MeAsp & D-erytro- $\beta$-methylaspartic acid \\
\hline $\min$ & minute(s) \\
\hline$\mu \mathrm{L}$ & Micro liter \\
\hline$\mu \mathrm{mol}$ & Micro molar \\
\hline MMA & Monomethylarsonic acid \\
\hline MWCO & Molecular weight cutoff \\
\hline $\mathrm{m} / \mathrm{z}$ & mass to charge ratio \\
\hline NMR & Nuclear magnetic resonance \\
\hline NSP & Neurotoxic shellfish poisoning \\
\hline PP1 & Protein phosphatases types 1 \\
\hline PP2A & Protein phosphatases types $2 \mathrm{~A}$ \\
\hline $\mathrm{ppb}$ & parts per billion \\
\hline ppm & parts per million \\
\hline ppt & parts per trillion \\
\hline QC & Quality control \\
\hline $\mathrm{RE}$ & Richard Eaton \\
\hline
\end{tabular}


RNA

ROS

SOD

SPM

WHO
Ribonucleic acid

Reactive oxygen species

Super oxidase dismutase

Suspended particulate matter

World Health Organization 


\section{CHAPTER 1}

\section{INTRODUCTION}

\subsection{Harmful algal blooms and algal toxins}

Harmful algal blooms (HABs) are increasing in the United States and worldwide (Hallegraeff 1993; Horner et al. 1997; Anderson et al. 2008; Carvalho et al. 2011). The depletion of dissolved oxygen, the result of the drastically increased algal individuals, creates lethal condition for local fishes and aquatic organisms (Etheridge 2010; Garcia et al. 2010). Some algal species are toxigenic and are capable of producing various toxins which threaten human health (Erdner et al. 2008; Kirkpatrick et al. 2008; Etheridge 2010; Garcia et al. 2010; James et al. 2010; Fleming et al. 2011). Eutrophication and some natural processes have been hypothesized as contributing factors in the occurrence of harmful algae bloom (Magana et al. 2003; Baden et al. 2005; Landsberg et al. 2009; Carvalho et al. 2011). River runoff, pollution, changes in the temperature of oceans, rivers, lakes and reservoir ocean circulation have been associated with blooms (Ellis 1985; Nakanishi 1985). The observed increase in harmful algae bloom events have been speculated to result from interactions of a variety of natural and anthropogenic events occurring over a broad range of temporal and spatial scales (Backer et al. 2003; Magana et al. 2003; Brand and Compton 2007; Fire et al. 2008). As secondary metabolites (defined as an organic compound which is not directly involved in the normal growth, development or a product of an organism), the ecological functions of algal toxins remain an enigma. Since the release of toxins usually occur in eutrophic water bodies, they potentially pose as a hazard to other species of organisms in aquatic environments. However, the harmful algae blooms (HABs) and algal toxins can vary substantially among sites and seasons which may be associated with 
changes in species composition of environmental factors, for instance the changes of temperature in different seasons, the input and output of nutrient elements, such as nitrate and phosphate, or other pressures from the environment (Jones and Orr 1994; Qian et al. 2010; Xiao et al. 2010). Microcystins, brevetoxins, okadaic acid and pahayokolides, were selected as representatives of algal toxins for their popularity in aquatic environment and each of them would be discussed in the following paragraphs.

\subsubsection{Microcystins}

The population of a cyanobacterium, commonly known as blue-green algae, has considerably increased over the past few decades. The cyanobacteria is a diverse group of photo-autotrophic organisms which are widespread in freshwater (Rao et al. 1998), marine (Faulkner 2002; Tett et al. 2007) and terrestrial ecosystems (Adam et al. 2011; Carvalho et al. 2011). Aquatic cyanobacteria are popularly known for highly visible blooms that can have the appearance of blue-green paint.

Microcystins, as a family of toxins produced by species of cyanobacteria, have been studied extensively worldwide (Nishiwakimatsushima et al. 1992; Mez et al. 1997; Pouria et al. 1998; Fischer and Dietrich 2000; Kurmayer et al. 2002). These toxins are a group of monocyclic heptapeptides, primarily produced by Microcystis aeruginosa (Orr and Jones 1998; Rao et al. 1998; Oh et al. 2000), but also by other Microcystis species and other genera, such as Anabaena (Fewer et al. 2008; Fewer et al. 2009; Prasanna et al. 2010; Fewer et al. 2011), Nostoc (Sivonen et al. 1990; Bajpai et al. 2009; Genuario et al. 2010; Kurmayer 2011) and Oscillatoria (Bruno et al. 1992; Luukkainen et al. 1993; Sano and Kaya 1995). The structure of microcystins (Figure 1), containing 7 amino acids, are composed of D-alanine at position 1, D-erytro- $\beta$-methylaspartic acid (MeAsp) at position 3, 
(2S, 3S, 8S, 9S) -3-amino-9-methoxy-2, 6, 8-trimethyl-10-phenyldeca-4, 6-dienoic acid (Adda) at position 5, $\gamma$-linked D-glutamic acid at position 6, N-methyl dehydroalanine (MDha) at position 7 and two variable L-amino acids at positions 2 and 4 (Kiviranta et al. 1992; Trogen et al. 1998). Scientists proposed a two-letter suffix (XY) accredited to each individual toxin to represent the two variant amino acids (Carmichael et al. 1988). Commonly, $\mathrm{X}$ is Leucine, arginine or tyrosine while $\mathrm{Y}$ is alanine, arginine or tyrosine (Luukkainen et al. 1993; Gehringer et al. 2005; Bittencourt-Oliveira et al. 2011). Currently there are over 80 variants of microcystins that have been reported (Xiao et al. 2010). Microcystin-LR, one of the most poisonous and harmful products, would appear to be the most common among them and all of these structurally related compounds differ in toxicity under different experimental conditions (Luukkainen et al. 1993; Gupta et al. 2003).

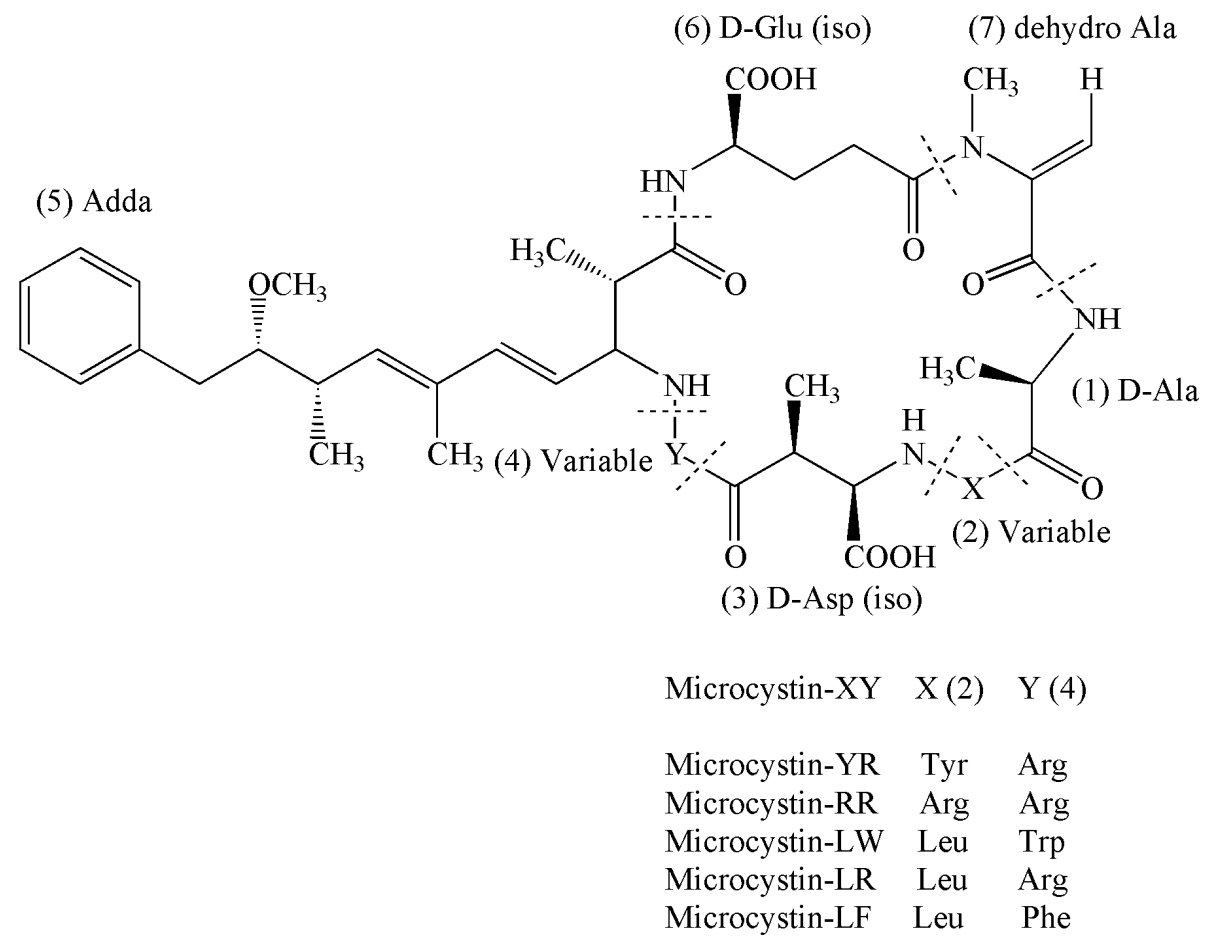

Figure 1. Typical structure of microcystins 
Microcystins usually remain contained within the cells and are only released upon lysis or if a change occurs in cell membrane permeability (Yuan et al. 2006; Daly et al. 2007; Jasionek et al. 2010). These toxins are water soluble and therefore most of them are incapable of infiltrating the lipid membranes of animal and plant cells (Campos and Vasconcelos 2010). As a result of their cyclic structure they are chemically stable and persist in the environment for extended periods of time leading to long term exposure for humans (Wang et al. 2010; Carvalho et al. 2011). The presence of microcystins in water can potentially affect human health as well as the well-being of other animals. The toxicity of microcystins has been investigated by many research groups to evaluate the potential risks and to attempt to control them in ecosystems (Garcia et al. 2010; Wang et al. 2010). The routes of exposure include direct ingestion or inhalation and through the consumption of contaminated drinking water (Zhou et al. 2002; Liu et al. 2010), fish and shellfish (Bury et al. 1995; Peng et al. 2010; Poste et al. 2011). The most famous intoxication occurred in 1996, when an acute poisoning caused 50 people to die in Brazil by the unusual exposure of microcystins through hemodialysis at a dialysis center as the result of usage of microcystins contaminated water from a nearby water reservoir without treatment (Pouria et al. 1998; Yuan et al. 2006; Bittencourt-Oliveira et al. 2011). Furthermore, increasing evidence points toward the observation that low-level but long-term exposure to microcystins may cause primary liver cancer (Nishiwakimatsushima et al. 1992; Zhou et al. 2002; Gan et al. 2010; Fujiki and Suganuma 2011).

Acute toxicity of microcystins may result in severe liver damage and injury to other organs such as kidney, lungs and the intestines (Hooser et al. 1989; Svircev et al. 2010). Microcystins are potent inhibitors of eukaryotic protein, typically at serine, threonine 
protein phosphatases types 1 (PP1) and 2A (PP2A) both in vitro and in vivo. These two major protein phosphatases have been shown to be important in tumor suppression (Jones and Orr 1994; Webster et al. 2001). Once the microcystins accumulated in the liver, they cause hepatocyte necrosis and hemorrhage (Fischer et al. 2010). Microcystin-YR was used in my experiment. This compound inhibits the synthesis of proteases and resulted in a labialization of lysosomal membranes (Campos and Vasconcelos 2010; Jasionek et al. 2010; Svircev et al. 2010).

\subsubsection{Brevetoxins}

Brevetoxins (BTX), a suite of cyclic polyether compounds, are released by a species of dinoflagellate known as Karenia brevis (K. brevis), the predominant creator of Florida red tides (Baden 1989; Backer et al. 2003; Backer et al. 2005; Bourdelais et al. 2005; Twiner et al. 2007). Harmful algal blooms (HABs) caused by K. brevis can reach extremely high concentrations with typical bloom cell densities of $10^{7}-10^{8}$ cells $\mathrm{L}^{-1}$ and has become an event of global concern as they happen worldwide (Nakanishi 1985; Truman et al. 2002; Twiner et al. 2007; Khan et al. 2010). The brevetoxins are secreted during the blooms, resulting in a variety of negative economic, environmental, and human health effects (Erdner et al. 2008; James et al. 2010; Wang et al. 2010; Fleming et al. 2011). The relationship between $K$. brevis blooms and fish kills along with respiratory illness has been known for a long time (Backer et al. 2003; Pierce et al. 2003; Backer et al. 2005; Cheng et al. 2005; Cheng et al. 2010). Florida red tide occurs annually in the Gulf of Mexico, resulting in vast economic losses for fisheries and serious public health issues. Karenia brevis blooms are responsible for respiratory illness in humans and marine mammal mortalities (Magana et al. 2003; Landsberg et al. 2009). 
There are two main types of brevetoxin, type A and type B (Figures 2 and 3). Type A consists of a flexible backbone of 10 fused polyether rings while type B, more frequently occurring in natural environment, consists of a rigid backbone of 11 polyether rings (Nakanishi 1985; Shimizu et al. 1986; Baden 1989). Almost of the naturally occurring derivatives have either type A or type B backbones and the difference amongst them is the result of the alteration of the terminal ring, or for $\mathrm{PbTx}-2$, a type $\mathrm{B}$ toxin, the derivatization at the hydroxyl at $\mathrm{C}-37$ or the epoxidation across the H-ring double bond may differ. (Baden et al. 2005; Bourdelais et al. 2005) Not all types are naturally occurring; some, such as $\mathrm{PbTx}-8$, a chloromethyl ketone derivative of $\mathrm{PbTx}-2$, is an artifact of chloroform extraction of PbTx-2 (Nakanishi 1985; Baden 1989; Ishida et al. 2004; Baden et al. 2005;

Twiner et al. 2007; Murrell and Gibson 2009).

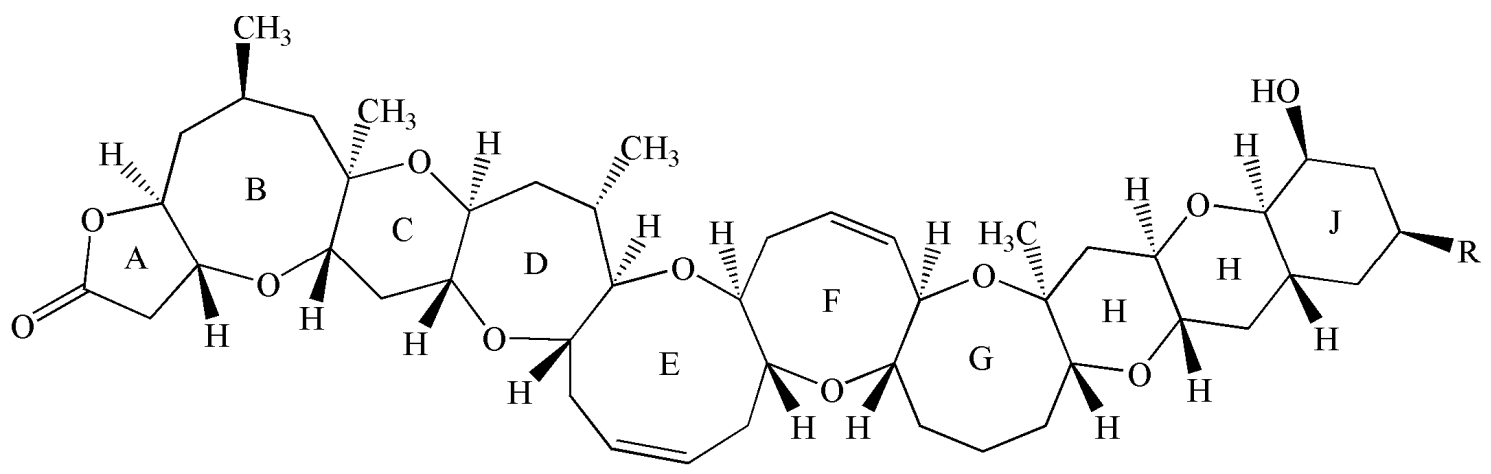

Brevetoxin type $\mathrm{A}, \mathrm{R}=$

PbTx-1, $\mathrm{CH}_{2} \mathrm{C}\left(=\mathrm{CH}_{2}\right) \mathrm{CHO}$

$\mathrm{PbTx}-7, \mathrm{CH}_{2} \mathrm{C}\left(=\mathrm{CH}_{2}\right) \mathrm{CH}_{2} \mathrm{OH}$

$\mathrm{PbTx}-10, \mathrm{CH}_{2} \mathrm{CH}\left(\mathrm{CH}_{3}\right) \mathrm{CH}_{2} \mathrm{OH}$

Figure 2. Typical structure of brevetoxin type A 


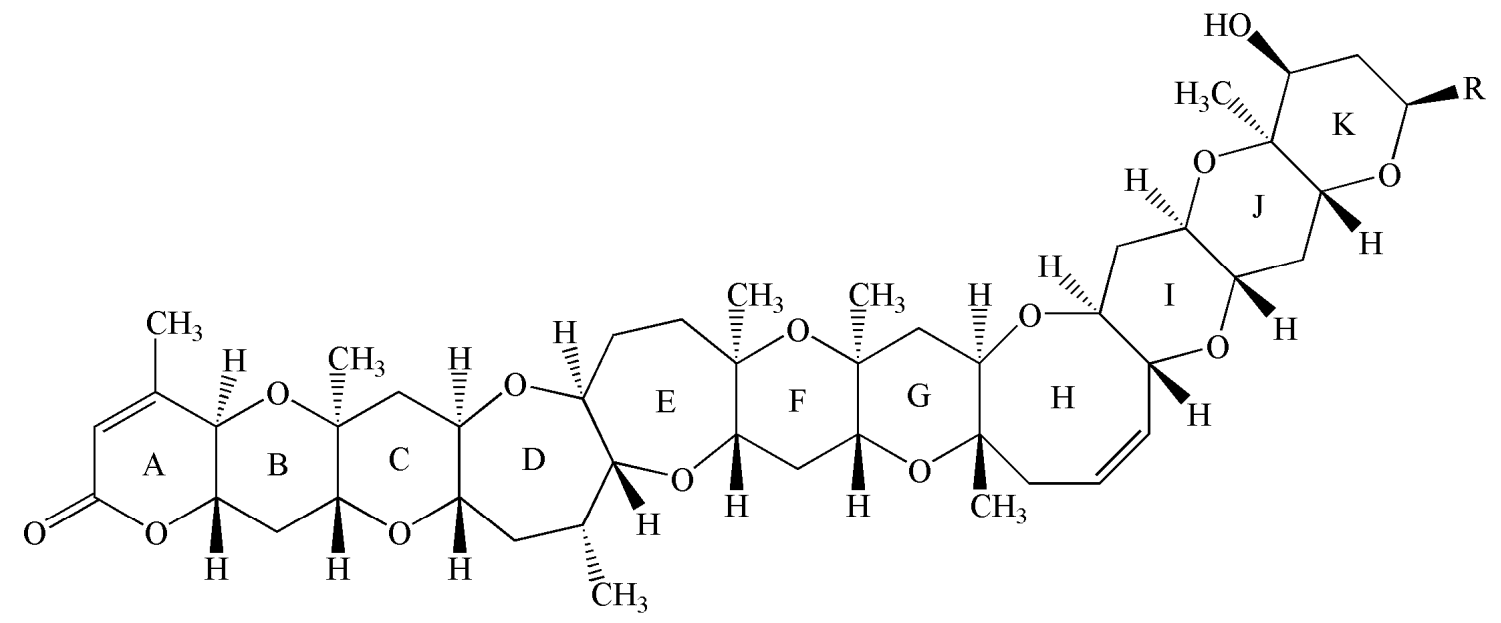

Brevetoxin type $\mathrm{B}, \mathrm{R}=$

$\mathrm{PbTx}-2, \mathrm{CH}_{2} \mathrm{C}\left(=\mathrm{CH}_{2}\right) \mathrm{CHO}$

$\mathrm{PbTx}-3, \mathrm{CH}_{2} \mathrm{C}\left(=\mathrm{CH}_{2}\right) \mathrm{CH}_{2} \mathrm{OH}$

$\mathrm{PbTx}-5,[\mathrm{PbTx}-2], \mathrm{C}-37 \mathrm{OAc}$

$\mathrm{PbTx}-6,[\mathrm{PbTx}-2]$, H-ring expoxide

$\mathrm{PbTx}-8, \mathrm{CH}_{2} \mathrm{COCH}_{2} \mathrm{Cl}$

$\mathrm{PbTx}-9, \mathrm{CH}_{2} \mathrm{CH}\left(\mathrm{CH}_{3}\right) \mathrm{CH}_{2} \mathrm{OH}$

Figure 3. Typical structure of brevetoxin type B

As the typical neurotoxins, brevetoxins have the ability to bind to site 5 of the voltagegated sodium channels (Poli et al. 1986; Trainer et al. 1990; Manger et al. 1995; Dechraoui et al. 1999). Performing as depolarizers, brevetoxins can open the voltage-gated sodium channels located in cell walls, thus altering the properties of the membrane and assisting the inward flow of sodium ions into the cells, resulting in the persistent activation of the cell leading to the eventual paralysis of the enervated cells (Poli et al. 1986; Trainer et al. 1990; Manger et al. 1995; Dechraoui et al. 1999). The consumption of brevetoxins contaminated seafood has the potential to disrupt normal neurological processes causing the illness clinically described as neurotoxic shellfish poisoning (NSP) (Truman et al. 2002; Naar et al. 2007; Twiner et al. 2007). 


\subsubsection{Okadaic acid}

Okadaic acid was originally isolated from Halichondria okadai, a black sponge. It is also found in Halichondria melanodocia collected from Florida Bay (Niwa et al. 1989; Shigemori et al. 1992; Kuramoto et al. 1996; Yamaoka et al. 2001; Sugiyama et al. 2007; Konoki et al. 2010). However, the actual producers of okadaic acid belong to the dinoflagellates, specifically the dinoflagellates of the genera Prorocentrum (Murakami et al. 1982; Torigoe et al. 1988; Faust 1991; Lafay et al. 1995) and of Dinophysis (Windust et al. 1997; Suzuki et al. 2004; MacKenzie et al. 2005). There are several tropical and subtropical benthic members of the genus Prorocentrum have been known to produce OA, for example, P. concavum Fukuyo (Dickey et al. 1990), P. maculosum Faust (Zhou and Fritz 1993), P. hoffmannianum Faust (Morton and Bomber 1994) and P. belizeanum Faust (Morton et al. 1998).

Okadaic acid belongs to a group of lipid-soluble polyether compound (Figure 4) which can accumulate in bivalves (a class of molluscs) and causes diarrheal shellfish poisoning (DSP) (Konoki et al. 2010). The syndrome of DSP was first recognized as the result of consumption of mussels and scallops harvested in Japan in 1976 (Windust et al. 1997). Okadaic acid, as a polyether of fatty acid, is able to accumulate in the hepatopancreas of mussels (Murakami et al. 1982; MacKenzie et al. 2005; Kolrep et al. 2011). The intake of okadaic acid contaminated shellfish can cause gastrointestinal disorders, such as diarrhea, nausea, vomiting and abdominal pain (Windust et al. 1997). The toxicity of okadaic acid results from the inhibition of protein phosphatases 1 and $2 \mathrm{~A}$, two of the major protein phosphatases in the cytosol of mammalian cells, in a manner similar to microcystins (Kolrep et al. 2011). Okadaic acid is also a tumor promoter, an inducer of lipid 
peroxidation and may give rise to apoptosis in cultured mammalian cells (Herschman et al. 1989).

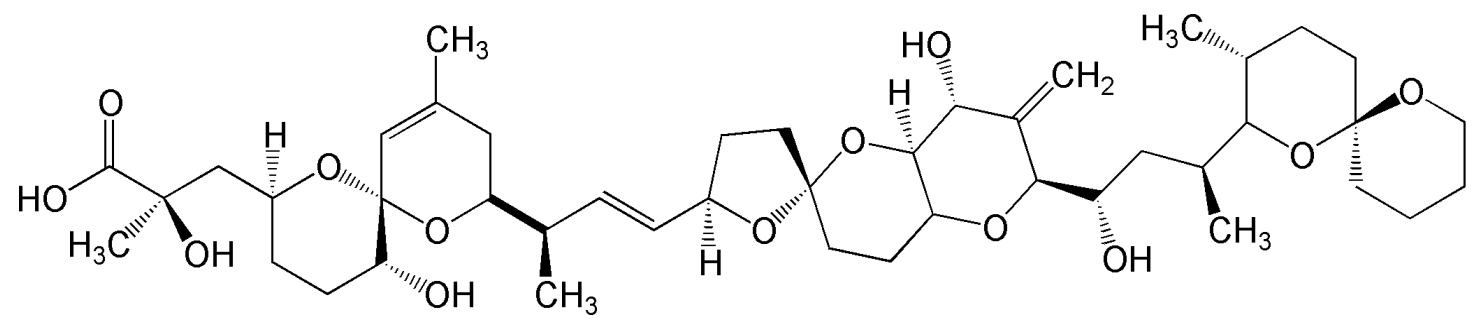

Figure 4. Typical structure of okadaic acid

\subsubsection{Pahayokolides}

Pahayokolides are cyclic undecapeptides purified from Lyngbya birgei and just recently isolated from a periphyton mat from the Florida Everglades in 2004 (An et al. 2007). As a group of growing family but newly published compounds, there is only limited reference discussing them. A published article by Liu et al discussed the pharmacology and toxicology of these compounds. They demonstrated that the pahayokolide A inhibits representative microbials and mammalian cell lines in addition to being toxic to zebrafish embryos with median lethal dose equal to $2.15 \mu \mathrm{M}$. The potential biomedical value of pahayokolide $\mathrm{A}$ as an anti-cancer agent against malignant diseases such as lung adenocarcinoma and colon cancer was also reported by the authors (Berry et al. 2004).

There are two structurally different pahayokolides called type A and B (Figure 5). Additional work has shown that the pahayokolide $\mathrm{B}$ is able to form two more configurational isomers, pahayokolide $\mathrm{C}$ and $\mathrm{D}$ under specific refined experimental conditions (An et al. 2007). Pahayokolide A, with 10 amino acids in the cyclic structure with a sequence of AThmU-Gln-Gly-Pro (2)-Phe-(Z)Dhb-Ser-(E)Dhb-Thr-homoPhe. 
Pahayokolide B differs from A in an N-acetyl-N-methyl leucine unit. These compounds could be the largest cyclic peptides isolated from any cyanobacteria and exhibit unusual structural features, including the pendent $\mathrm{N}$-acetyl-N-methyl leucine moiety and the 3-amino-2, 5, 7, 8-tetrahydroxy-10-methyl- undecanoicacid moiety (An et al. 2007).
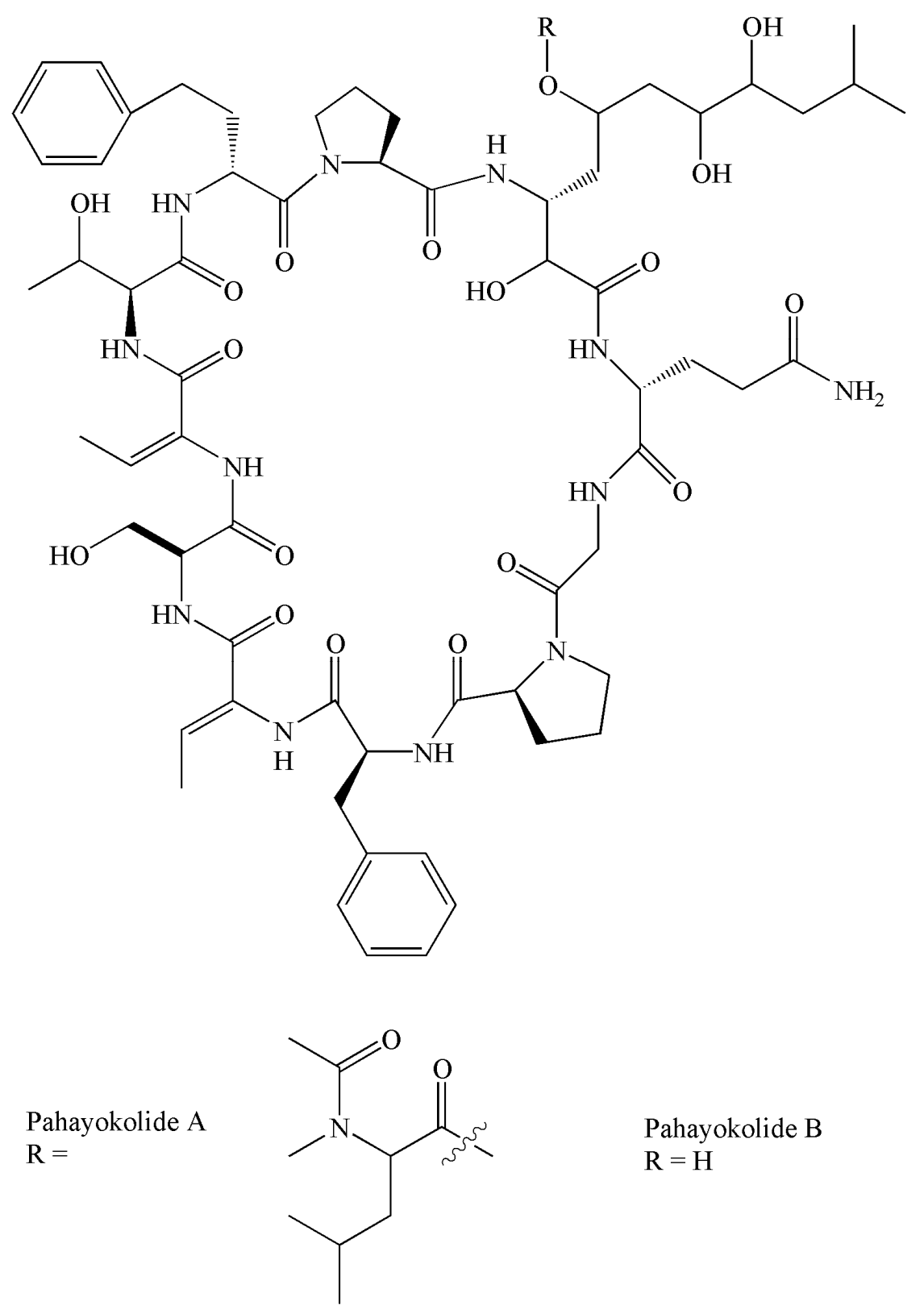

Figure 5. Typical structures of pahayokolides 


\subsection{Toxic metals in aquatic environments}

Pollution of toxic metals is another major problem in aquatic environments. Ingestion of seafood contaminated by toxic metals is unequivocally linked to some pathology, including cancer (Petsko 1995; Turkdogan et al. 2003). Arsenic, copper, cadmium, and mercury are some of the most common toxic metals present in aquatic environments.

\subsubsection{Arsenic}

Pollution of arsenic is a major global problem. Many people are now affected by elevated arsenic levels in their drinking water (Mazumder et al. 1988). Arsenic is present in many different chemical species in aquatic environments. The four major species include two inorganic species arsenite (iAs $\left.{ }^{\mathrm{III}}\right)$ and arsenate $\left(\mathrm{iAs}^{\mathrm{V}}\right)$, and two organic species, monomethylarsonic acid (MMA) and dimethylarsinic acid (DMA). The different species of arsenic could be transformed under different chemical and biological conditions in the environment. The predominant form of arsenic compound in marine and estuarine surface water is arsenate $\left(\mathrm{iAs}^{\mathrm{V}}\right)$. Arsenate could be taken up by the phosphate transport systems of phytoplankton, thanks to the similar properties of arsenate and phosphate since both of them belong to the same group in the periodic table. The algal species were probably capable of converting the inorganic arsenic species to the organic species by substituting the phosphate molecules which was the major component of their cell membrane. Besides, arsenate could be also as an alternative substrate of inorganic phosphate in some enzymatic reactions.

The toxicity of arsenic is chemical species dependent, for example, the order of toxicities of some of the arsenic species is as follows: MMA ${ }^{\prime \prime \prime} \quad \mathrm{DMA}^{\prime \prime \prime} \quad \mathrm{As}^{\mathrm{III}}=\mathrm{As}^{\mathrm{V}}$ 
$\mathrm{DMA}^{\mathrm{V}}, \mathrm{MMA}^{\mathrm{V}}$ in human Chang liver cells (Sun et al. 2002; Yehiayan et al. 2009). The toxicity of arsenic species is the result of their interaction with biomolecules such as binding to proteins and enzymes thereby disrupting their functions and/or generation of free radicals and reactive oxygen species (ROS) causing damage to cells (Vahter 2000; Meza et al. 2005). For example, the arsenic species can bind to the sulfhydryl site of glutathione, which plays a vital role in numerous metabolic (Yehiayan et al. 2009) and biochemical reactions, such as DNA synthesis and repair, protein synthesis, amino acid transport and enzyme activation (Vahter 2000; Hughes 2002). Generally, arsenic toxicity can result in various diseases, depending on the chemical form of the arsenic, the mode of exposure, the presence of other toxic co-contaminants and individual variations in metabolism (such as the result of polymorphism) (Vahter 2000; Marnell et al. 2003; Meza et al. 2005; Engstrom et al. 2007).

\subsubsection{Copper}

Copper(II) ion $\left(\mathrm{Cu}^{2+}\right)$ has been well studied for its ecological effects and toxicity. The effects of copper(II) ion, as the most toxic form of copper, on the growth of algae, especially blue-green algae species, has been widely studied. Copper(II) sulfate $\left(\mathrm{CuSO}_{4}\right)$, as an economical and effective algaecide, has been commonly used for the control of algal blooms for a long period of time. The source of copper in aquatic environment could be introduced from a number of natural ways or anthropogenic inputs, such as atmospheric cycling, minerals and biological residues. As an essential trace element involved in a number of vital biological processes, copper functions as a cofactor and it is required for structural and catalytic properties of a variety of important enzymes, such as cytochrome c oxidase and copper-zinc superoxidase dismutase (SOD) (Yim et al. 1990; Klinman et al. 
1991; White et al. 1991; Wakisaka et al. 2010). Copper can be absorbed and stored in the human body depending on its chemical forms. Ceruloplasmin, one of the main copper binding proteins contains a total of six copper atoms in both the cupric and cuprous states (Raju et al. 1982; Sato and Gitlin 1991; Mukhopadhyay et al. 1997). Metallothionein, which serves as an antioxidant, can also bind with ionic copper in order to prevent the cytotoxicity of this metal (Lerch 1980; Riordan and Richards 1980; Bremner 1987; Furst et al. 1988). The ingestion of copper contaminated water or foods is associated with the development of acute gastrointestinal symptoms such as emesis and abdominal pain possibly leading to the formation of ulcers and hemorrhage (Kaido et al. 2005; Wakisaka et al. 2010). The free copper ions participating in the formation of reactive oxygen species (ROS) and the resulting unbalanced cellular redox status is the generally accepted mechanism of copper induced cellular toxicity (Li et al. 1994).

\subsubsection{Mercury}

Mercury, a ubiquitous environmental toxic element, has been drawing more and more attention since it has become an enormous global issue as a pollutant (Fitzgerald et al. 1998; Wang et al. 2004). The source of mercury released into the aquatic environment is contributed to both natural and anthropogenic behaviors which include fossil fuel combustion, waste incineration, metal mining and refining operations (Fitzgerald et al. 1998; Braga et al. 2000; Zhang and Wong 2007). Mercury cycling, through the atmosphere, hydrosphere and geosphere is responsible for the transport, transformation and speciation conversion of mercury (Vandal et al. 1991; Zillioux et al. 1993; Fitzgerald et al. 2007).

Mercury can exist in three different forms in the environment namely as elemental

mercury $\left(\mathrm{Hg}^{0}\right)$, inorganic mercury compounds $\left(\mathrm{Hg}^{2+}\right)$ and organic mercury compounds, 
such as monomethylmercury $\left(\mathrm{CH}_{3} \mathrm{Hg}^{+}\right)$and monoethylmercury $\left(\mathrm{CH}_{3} \mathrm{CH}_{2} \mathrm{Hg}^{+}\right)$, each of which possesses different bioavailability and toxicity (Stoichev et al. 2006; Leopold et al. 2010). Amongst these three forms of mercury, the organic form is the most toxic owing to its lipid solubility resulting in direct exposure to the organism in aquatic environment (Trasande et al. 2005). Humans, being on top of the food chain, will suffer even worse effects as a consequence of bioaccumulation (Wren 1986; Downs et al. 1998; Watras et al. 1998; Braga et al. 2000). Previous research reported on acute mercury exposure. In addition, a recent review in 2005 also focused on showing adverse health effects of low doses of mercury in both adults and children or infants (Zahir et al. 2005). These adverse effects involve the nervous, motor, renal, cardiovascular, immune and reproductive systems. The strong affinity of mercury to the sulfhydryl groups of mercury is the main reason for its toxicity to organisms (Casas and Jones 1980; Hopman et al. 1986). Intracellular mercury ions attach themselves to thiol residues of proteins, particularly to glutathione and cysteine, resulting in the inactivation of sulfur and the inhibition of related enzymes, cofactors and hormones (Stankovich and Bard 1977; Taylor and Carty 1977; Refsvik 1986; Philbert et al. 1991). The other functional groups besides -SH include- $\mathrm{CONH}_{2},-\mathrm{NH}_{2},-\mathrm{COOH}$ and $-\mathrm{PO}_{4}$, for which mercury also has high affinity (Foulkes and Blanck 1992; Meyer and Nockemann 2003). Mercury blocks immune function of $\mathrm{Mn}$ and $\mathrm{Zn}$ leading to deficiency of the principal antioxidant enzymes superoxide dismutases CuZn-SOD and Mn-SOD (Rajanna et al. 1995) which have a role in various diseases including Alzheimer's disease and Parkinson's disease (Wren 1986; Zahir et al. 2005).

In addition to the metals mentioned above, cadmium (Winner 1984; Shaikh et al. 1999; 
Satarug et al. 2003), cobalt (Dave and Xiu 1991), manganese (Woolf et al. 2002) and iron (Hummert et al. 2002; Moore et al. 2002) are also elements of interest as a result of their common appearance in the aquatic environment. Some of the metal ions may play an important role in promoting the growth of the algae, while others may inhibit their growth. For example, iron is an element of particular interest because it has been used extensively in the control of algal blooms and is also used as a necessary nutrient for the growth of algae (Humble et al. 1997).

\subsection{Interactions between algal toxins and toxic metals}

Because of their co-occurrence in aquatic environments, the interactions between toxic metals and algal toxins have been extensively studied. The interactions between them could mutually affect the bioaccumulation and bioavailability of algal toxins and toxic metals. The algae species or the toxins could alter the speciation of metal, and the formation of toxin-metal complexes would change the toxicity of toxins and metals. Their interactions could occur in a variety of ways. The following paragraphs will discuss these interactions in details.

\subsubsection{The effects of toxic metals on the growth of algae species and toxin production}

Metals may alter the growth and toxin production of algae. Although the triggers of algal toxin production currently remain unclear, previous studies have shown that the production of toxin by algal species are likely to be affected by various environmental factors, including temperature, $\mathrm{pH}$, lumination (light), salinity, the amounts of nitrate, phosphate and metals present and even microgravity (Vezie et al. 2002; Gouvea et al. 2008; Qian et al. 2010; Xiao et al. 2010).

It has been reported that the production of algal toxins is affected by change in the 
environmental conditions resulted from the input of trace metals (Kenefick et al. 1993; (Lukac and Aegerter 1993). The behavior of algal species in responding to metal exposure could be explained by the acquisition of nutritional metals, the detoxification of toxic metals or as the result of responding to the environmental stress caused by metals (Kenefick et al. 1993; Utkilen and Gjolme 1995; Gong et al. 2009; Gong et al. 2009; Li et al. 2009; Zeng et al. 2009). It has been demonstrated that copper (II) sulfate could induce the loss of cell wall integrity of Microcystis aeruginosa and accelerated the release of the microcystin-LR to the medium (Kenefick et al. 1993). Lukac and Aegerter (1993) used one of the most effective toxin producer, $M$. aeruginosa PCC 7806, to study how trace metals affect the production of toxins. Zinc is required for toxin production and the growth of the organism while iron was found to affect the production of the toxin and the growth of the organism (Lukac and Aegerter 1993). Interestingly, cells grew much more slowly in the absence of or low concentrations of iron (lower than $2.5 \mu \mathrm{M}$ ) while the toxin production was increased by $20-40 \%$ (Lukac and Aegerter 1993). In contrast to these findings, Utkilen and Gjolme (1995) observed that the toxin content increased with the increase of iron concentration. The discrepancy could be attributed to the use of a different $M$. aeruginosa strain, CYA 228/1 and the difference of concentration of EDTA present. Utkilen's group proposed a working hypothesis for toxin production mechanism in M. aeruginosa. They hypothesized that the microcystins which could play a role as intra-cellular chelators were influenced by synthetase, whose activity is controlled by the presence of free iron (II) ion $\left(\mathrm{Fe}^{2+}\right)$ and its concentration (Utkilen and Gjolme 1995). The toxin-producing $M$. aeruginosa strain, unlike the non-toxin producing strain, was found to have an efficient iron uptake system. This is because the toxin can function as a chelator, and such it is 
capable of changing the amount of free $\mathrm{Fe}^{2+}$ in the cells in the organism. In the non-toxin producing strain, the iron is taken up by a less efficient uptake system due to the lack of the toxin (Utkilen and Gjolme 1995). The function of microcystins is much similar to the role of siderophores, a group of high affinity chelating compounds secreted by microorganisms, which are capable of chelating with iron. However, comparing with microcytsins, siderophores have a stronger affinity with iron and are able to form more stable complexes which could reach a stability constants as high as $10^{32}$ (Anderegg et al. 1963).

Domoic acid, produced by Pseudo-nitzschia, was thought to act as a trace metal chelator and play physiological roles in acquisition of iron and detoxification of copper by binding these metals with a conditional stability constant of $10^{8.7 \pm 0.5} \mathrm{M}^{-1}$ and $10^{9.0 \pm 0.2} \mathrm{M}^{-1}$, respectively (Rue and Bruland 2001). Maldonado et al. (2002) found that an increase in production of domoic acid isomer-C by Pseudo nitzschia australis with the addition of copper and zinc to standard growth media. Maldonado et al. (2002) found that the co-administration of selenium and magnesium elicited a $58 \%$ increase in gymnodimine production by Karenia selliformis; and the addition of copper resulted in a $100 \%$ increase in palytoxin-related compounds by Ostreopsis siamensis and a 50\% increase in okadaic acid diol esters production by Prorocentrum lima. Moreover, the addition of selenium enhanced yessotoxin production by Protoceratium reticulatum (Maldonado et al. 2002).

\subsubsection{The complexation of algal toxins with metals}

Metal ions may be complexed with algal toxins. Since some of the functional groups, such as amino, carboxyl, phenol, sulfhydryl and hydroxyl groups, are generally present in the algal toxin molecules, algal toxins have a potential to complex with metal ions, much like ethylene diamine tetraacetic acid (EDTA) interacting with metal ions. As a member of 
the polyamine carboxylic acid family of ligands in its conjugated base forms, EDTA is widely used in coordination chemistry because of its capability to bind with a metal cation through its two amines and four carboxylates. The resulting coordination complexes adopt an octahedral geometry, which is very stable and soluble in water, consequently suppressing the activity of the cations. (Baran et al. 2002; Friedly et al. 2002; Grubisic et al. 2002; Kent et al. 2002). Some algal toxins, such as microcystins and pahayokolides, are cyclic polypeptides, containing several amino acids. These toxins are capable of forming a complex with metal ions possibly by accommodating them in their cavity resulting in a stable conformation of the lowest energy state.

Humble et al. (1997) studied the complexation of copper and zinc with three cyanobacterial microcystins, MC-LR, MC-LW and MC-LF by differential pulse polarography (DPP). Similarly, Yan et al. (2000) characterized the complexation of MC-LR with many metal cations by using cyclic voltammetry (CV) and anodic stripping voltammetry (ASV). The voltammetry was used by Rue and Bruland (2001) for the determination of the complexation between domoic acid and two metal cations, iron (II) and copper (II). More recently, a modified electrospray ionization (ESI) method, namely cryospray ionization (CSI) technique has been developed for studying complexes formed by non-covalent bonding (Saito et al. 2008). The microcystin-metal complexes were observed as both singly charged and doubly charged ion peaks (Saito et al. 2008). Norte et al. (1998) carried out a study on complexation between okadaic acid and univalent and divalent metal ions utilizing nuclear magnetic resonance (NMR). A summary of previous studies on the complexation of metals and toxins is shown in Table 1.

\subsubsection{Indirect interactions between algal toxins with metal}


The coexistence of algal toxins and toxic metals in aquatic environments may mutually affect the transformation, transport and biological uptake on both of them. The environmental behavior and fate of each of these single contaminants may be influenced indirectly by the other, as one contaminant may interfere with the other's transport and transformation processes in different environmental components, such as sediments, suspended particulate matter (SPM), and biological components (Crist et al. 1981; Bocio et al. 2005; Oliveira et al. 2005; Chen et al. 2006). In addition, some algal species may play a role in the conversion of elemental species. For instance, Balogh et al. (2002) proposed that algal bloom and leaf fall events can result in elevated methylmercury (MeHg) concentrations in surface waters, potentially leading to increased $\mathrm{MeHg}$ accumulation in fish when elemental mercury is present in the water. Many published articles have shown that some algal species can facilitate the transformation of inorganic arsenic species to organic arsenic species, for example to arsenosugars, the most abundant arsenic species present in algal species (McSheehy et al. 2002; Hirata and Toshimitsu 2005). Furthermore, the coexistence of algal toxins and toxic metals could produce an additive toxicity to humans and other organisms. If these complexes can be formed and stably exist in the environment, marine life, such as fish, can uptake and accumulate the complex as a whole. The consumption of such contaminated fish would expose humans to the two classes of contaminants simultaneously. 
Table 1. The stability constants of some selected toxin-metal complexes

\begin{tabular}{|c|c|c|c|c|c|}
\hline Method & Type of toxins & $\begin{array}{l}\text { Type of } \\
\text { metals }\end{array}$ & $\mathrm{pH}$ & $\begin{array}{l}\text { Conditional stability } \\
\text { constant }\left(K_{c s c}\right)\end{array}$ & Reference \\
\hline \multirow{10}{*}{$\begin{array}{l}\text { Differential pulse } \\
\text { polarography } \\
\text { (DPP) }\end{array}$} & \multirow{6}{*}{ Microcystin-LR } & \multirow{3}{*}{$\mathrm{Cu}^{2+}$} & 5.5 & $\mathrm{~N} / \mathrm{A}$ & \multirow{10}{*}{$\begin{array}{l}\text { (Humble et al. } \\
\text { 1997) }\end{array}$} \\
\hline & & & 6.5 & $\mathrm{~N} / \mathrm{A}$ & \\
\hline & & & 7.5 & $\begin{array}{l}5.13 \pm 0.43\left(\boldsymbol{K}_{1}\right), \\
9.83 \pm 0.92\left(\boldsymbol{K}_{2}\right)\end{array}$ & \\
\hline & & \multirow{3}{*}{$\mathrm{Zn}^{2+}$} & 5.5 & $\begin{array}{c}5.39 \pm 0.42\left(\boldsymbol{K}_{1}\right), 11.33 \\
\pm 0.38\left(\boldsymbol{K}_{2}\right)\end{array}$ & \\
\hline & & & 6.5 & $\begin{array}{l}5.08 \pm 0.01\left(\boldsymbol{K}_{1}\right), \\
11.09 \pm 0.08\left(\boldsymbol{K}_{2}\right)\end{array}$ & \\
\hline & & & 7.5 & $\begin{array}{l}5.15 \pm 0.17\left(\boldsymbol{K}_{1}\right), \\
10.70 \pm 0.33\left(\boldsymbol{K}_{2}\right)\end{array}$ & \\
\hline & \multirow{2}{*}{ Microcystin-LW } & $\mathrm{Cu}^{2+}$ & 7.5 & $\begin{array}{l}4.97 \pm 0.21\left(\boldsymbol{K}_{1}\right), \\
10.93 \pm 0.39\left(\boldsymbol{K}_{2}\right)\end{array}$ & \\
\hline & & $\mathrm{Zn}^{2+}$ & 7.5 & $\begin{array}{l}5.31 \pm 0.23\left(\boldsymbol{K}_{1}\right), \\
10.76 \pm 0.43\left(\boldsymbol{K}_{2}\right)\end{array}$ & \\
\hline & \multirow{2}{*}{ Microcystin-LF } & $\mathrm{Cu}^{2+}$ & 7.5 & $\begin{array}{l}5.43 \pm 0.52\left(\boldsymbol{K}_{1}\right), \\
10.47 \pm 0.61\left(\boldsymbol{K}_{2}\right)\end{array}$ & \\
\hline & & $\mathrm{Zn}^{2+}$ & 7.5 & $\begin{array}{l}5.04 \pm 0.24\left(\boldsymbol{K}_{1}\right), \\
10.40 \pm 0.15\left(\boldsymbol{K}_{2}\right)\end{array}$ & \\
\hline \multirow{5}{*}{$\begin{array}{l}\text { Anodic stripping } \\
\text { voltammetry } \\
\text { (ASV) }\end{array}$} & \multirow{5}{*}{ Microcystin-LR } & $\mathrm{Pb}^{2+}$ & 7.0 & $9.53 \pm 0.37$ & \multirow{5}{*}{$\begin{array}{l}\text { (Yan et al. } \\
2000)\end{array}$} \\
\hline & & $\mathrm{Cd}^{2+}$ & 7.0 & $7.79 \pm 0.92$ & \\
\hline & & $\mathrm{Cu}^{2+}$ & 7.0 & $7.94 \pm 1.20$ & \\
\hline & & $\mathrm{Hg}^{2+}$ & 7.0 & $10.66 \pm 0.23$ & \\
\hline & & $\mathrm{Zn}^{2+}$ & 7.0 & $10.89 \pm 0.54$ & \\
\hline
\end{tabular}


Table 1. The stability constants of some selected toxin-metal complexes (cont'd)

\begin{tabular}{|c|c|c|c|c|}
\hline Method & Type of toxins & $\begin{array}{c}\text { Type } \\
\text { of metal }\end{array}$ & Result & Reference \\
\hline \multirow{10}{*}{$\begin{array}{l}\text { Cryospray } \\
\text { ionization-Fourier } \\
\text { transform ion cyclotron } \\
\text { resonance mass } \\
\text { spectrometry } \\
\text { (CSI-FTIC-MS) }\end{array}$} & \multirow{5}{*}{ Microcystin-RR } & $\mathrm{Cu}^{2+}$ & Detected & \multirow{10}{*}{$\begin{array}{l}\text { (Saito et al. } \\
\text { 2008) }\end{array}$} \\
\hline & & $\mathrm{Zn}^{2+}$ & Detected & \\
\hline & & $\mathrm{Mg}^{2+}$ & Detected & \\
\hline & & $\mathrm{Fe}^{2+}$ & Detected & \\
\hline & & $\mathrm{Fe}^{3+}$ & Not detected & \\
\hline & \multirow{5}{*}{ Microcystin-LR } & $\mathrm{Cu}^{2+}$ & Detected & \\
\hline & & $\mathrm{Zn}^{2+}$ & Detected & \\
\hline & & $\mathrm{Mg}^{2+}$ & Detected & \\
\hline & & $\mathrm{Fe}^{2+}$ & Detected & \\
\hline & & $\mathrm{Fe}^{3+}$ & Not detected & \\
\hline \multirow{5}{*}{$\begin{array}{l}\text { Nuclear magnetic resonance } \\
(\mathrm{NMR})\end{array}$} & \multirow{5}{*}{ Okadaic acid } & $\mathrm{Li}^{+}$ & Identified, weak & \multirow{5}{*}{$\begin{array}{l}\text { (Norte et al. } \\
\text { 1998) }\end{array}$} \\
\hline & & $\mathrm{Na}^{+}$ & Identified, weak & \\
\hline & & $\mathrm{K}^{+}$ & Identified, strong & \\
\hline & & $\mathrm{Ca}^{2+}$ & Not observed & \\
\hline & & $\mathrm{Mg}^{2+}$ & Not observed & \\
\hline
\end{tabular}

\subsection{Research objectives}

Although the occurrence and toxicity of algal toxins and toxic metals have been studied extensively, investigations on the interactions between them have been very limited. Since the coexistence of these two contaminants always happens in the aquatic system, their interaction in the aquatic environment needs to be addressed. Such information is useful for us in order to evaluate the toxicity of these potentially harmful metals and algal toxins in their co-occurrence, whether it is synergetic or antagonistic, and the results of such study will be very helpful in assessing the potential risk of seafood consumption to human and other organisms.

The objectives of this study were 1) to determine the stability constants of selected 
toxin-metal complexes and 2) to determine the effects of arsenic and copper on the growth of Karenia brevis. Microcystin-YR, pahayokolide A, okadaic acid and brevetoxin (PbTx-2) were selected as representatives of algal toxins because of their common occurrence in freshwater and marine environments, while arsenic, copper, cadmium, cobalt, manganese, iron and mercury were selected as representatives of toxic metals because these metals are ubiquitous in aquatic environment.

To achieve these aims, the classical technique of using dialysis membrane along with ultrafiltration device was employed to characterize the interactions of algal toxins with toxic metals. The conditional stability constants were determined by using the data obtained from inductively coupled plasma mass spectrometry (ICP-MS) or cold vapor atomic fluorescence spectrometry (CVAFS). A direct exposure of Karenia brevis to arsenic and copper was carried out to determine the effects of these metals on the growth of the algal cell. 


\section{CHAPTER 2}

\section{DETERMINATION OF CONDITIONAL STABILITY CONSTANTS \\ OF THE METAL-TOXIN COMPLEXES}

\subsection{Introduction}

Toxic metals have the potential to form complexes with algal toxin molecules, because the functional groups present within the algal toxin molecules, such as amino, carboxyl, phenol, sulfhydryl and hydroxyl groups, may have high affinity for metal binding. Although the conundrum of toxin release by numerous specific algal species has yet to be solved, a hypothesis for toxin production mechanism of $M$. aeruginosa has been proposed by Utkilen and Gjolme (1995). They proposed that the microcystin-producing ability of algae is influenced by synthetase whose activity is controlled by the presence of free iron(II) ion $\left(\mathrm{Fe}^{2+}\right)$ and its concentration. In addition, the behavior of the algae to produce toxin, which serves as an intra-cellular chelator, could help to address the stress caused by the high concentration of the free $\mathrm{Fe}^{2+}$ in the aquatic environment (Utkilen and Gjolme 1995). Besides the above limited study, only a few other papers discussed these algal toxin-metal ion complexes that could be potentially formed in the coexistence of metals and algal toxins (Humble et al. 1997; Norte et al. 1998; Yan et al. 2000; Rue and Bruland 2001; Saito et al. 2008).

The complexation between algal toxins and toxic metals would significantly affect their transformation, transport and bioaccumulation, and therefore critically affect the toxicity of both the toxin and the metal ion involved. In spite of the aforementioned efforts in studying the algal toxin-metal interactions which only involved a few toxin species and metals, a comprehensive investigation of this complexation is lacking. The stabilities of 
these complexes were affected by many factors, for example, the chelate ring size of the algal toxin molecules, the functional groups present in the toxin structure, the ionic radius of the metals and their redox potential as well as the Lewis acid strengths of these metal cations. Therefore, a systematic study on the toxin-metal interactions using various algal toxins and metals would not only create a global database on the stability constants of a variety of metal-toxin complexes, but also help understand how the structures and properties of toxins and metals influence the complexation stability.

The object of this study was to determine the stability constants of a variety of toxin-metal complex compounds which could be formed by mixing algal toxins (including microcystin-YR, PbTx-2, okadaic acid and pahayokolide A) and metals (including arsenic, cadmium, cobalt, copper, iron, manganese and mercury). Equilibrium dialysis technique was used here for separating the formed metal-toxin complexes for all metals, except for $\mathrm{Fe}$ in which case a centrifugal ultrafiltration method was employed to avoid the formation and precipitation of Fe colloids. Compared to the previous studies, such as DPP, NMR and CSI-MS, the dialysis membrane method needs relatively larger amounts of the substances, somewhat lower cost of operation and it is easier to perform because the simple experimental setup and sample preparation.

\subsection{Experimental}

\subsubsection{Instrumentation}

Cold vapor atomic fluorescence spectrometry (CVAFS) system (Merlin 10.035, PS Analytical, UK) was used for mercury analysis with software (Millennium version 2.10) for data acquisition. Inductively coupled plasma mass spectrometry (ICP-MS) system (Perkin Elmer Elan DRC-e, USA) was employed for total metal analysis, including antimony, 
arsenic, cadmium, cobalt, copper, iron, lead, manganese, nickel, silver, tin and zinc. The ICP-MS software (Elan 3.4, Perkin Elmer Sciex, Waltham, MA) was utilized for automated data collecting. Arsenic speciation analysis was performed by using high performance liquid chromatography (HPLC) coupled with ICP-MS.

\subsubsection{Chemicals and reagents}

All chemicals used were of analytical or trace metal grade. Standards for metal analysis were of ICP-MS grade $\left(1000 \mathrm{mg} / \mathrm{L}\right.$ in $5 \% \mathrm{HNO}_{3}$, GFS Chemicals, Columbus, $\mathrm{OH}$, USA). Sodium chloride $(\mathrm{NaCl})$, sodium azide $\left(\mathrm{NaN}_{3}\right)$, nitric acid $\left(\mathrm{HNO}_{3}\right)$ and hydrochloride acid $(\mathrm{HCl})$ were purchased from Fisher Scientific (Fairlawn, NJ, USA). Sodium metaarsenite, $98 \%\left(\mathrm{As}^{\mathrm{III}}\right)$ and sodium arsenate dibasic, $99 \%\left(\mathrm{As}^{\mathrm{V}}\right)$ were purchased from Sigma-Aldrich, USA. All the algal toxins, including brevetoxin (PbTx-2), microcystin-YR, pahayokolide A and okadaic acid, were obtained from Dr. Kathleen

Rein's research laboratory (Department of Chemistry and Biochemistry, Florida International University, FL). All glassware were soaked in $10 \% \mathrm{HNO}_{3}$ overnight and then thoroughly rinsed with distilled deionized (DDI) water $(18.2$ mega-ohm·cm, Barnstead Nanopure Diamond Lab Water System).

\subsubsection{Mercury analysis}

All the samples and standards were prepared with diluted $\mathrm{HCl}(1 \%, \mathrm{v} / \mathrm{v})$. The reductant $\left(\mathrm{SnCl}_{2}, 2 \% \mathrm{w} / \mathrm{v}\right)$ and blank $(1 \% \mathrm{HCl})$ solutions used in mercury analysis were freshly prepared daily. The reductant solution was made by adding $40 \mathrm{~g}$ of stannous chloride into $2 \mathrm{~L}$ of DDI water containing $50 \mathrm{~mL}$ of concentrated hydrochloric acid (ca. 12 M). Before the start of mercury analysis, the reductant solution was purged with argon gas for 20 minutes as a minimum in order to eliminate the potential mercury contaminant in the 
solid stannous chloride which could have resulted in the inaccuracy of the data and even had the potential to ruin the whole experiment caused by the high sensitivity of the instrument and the low concentration of mercury in the samples.

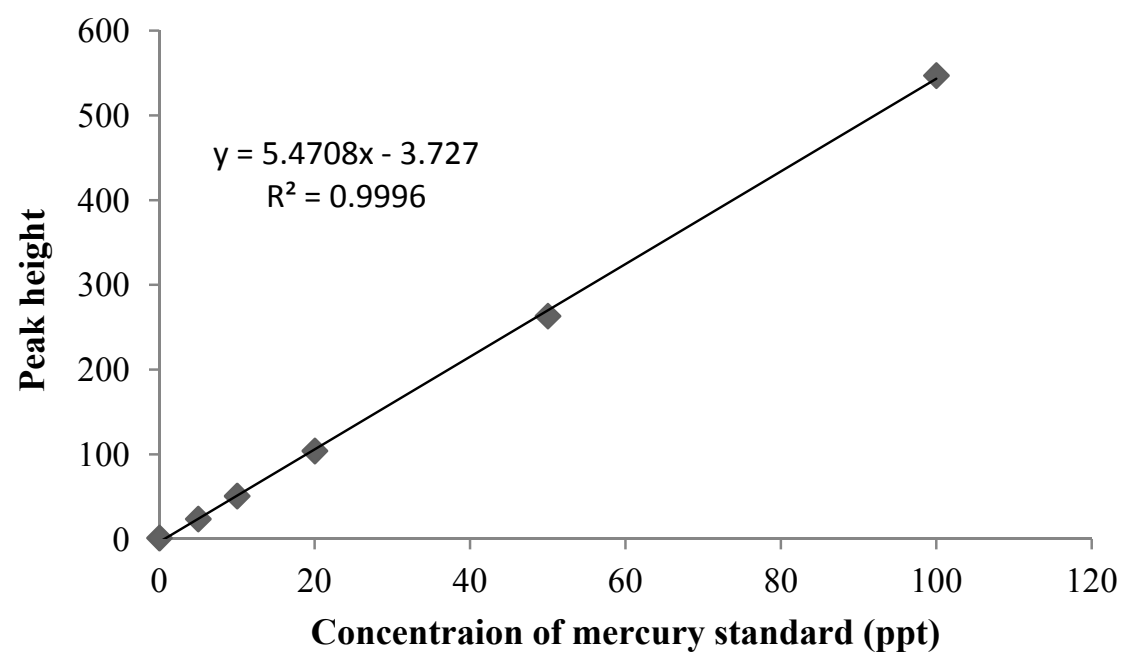

Figure 6. Typical calibration curve of mercury analysis by using cold vapor atomic fluorescence spectrometry

The mercury concentrations were determined by external standard method. The calibration curve was obtained by the signal response (converted to the peak height) of mercury standard solutions in the range of $0,5,10,20,50$ and 100 ppt. A second source of mercury standard solution used as the quality control (QC) was injected immediately after the calibration. All the results for data analysis were obtained by averaging the duplicate runs of standards or samples. In addition, a 50 ppt check solution was run during the instrumental analysis in order to check the performance of the instrument. The mercury waste was collected and stored in a special hazardous container for later disposal. For the typical calibration curve, in the range of 5 to $100 \mathrm{ppt}$ for the mercury standards, there was a linear relationship between peak height and concentration of the analyte. A typical calibration curve 
of mercury analysis was shown on Figure 6.

\subsubsection{Total metal analysis (except for mercury)}

The ICP-MS (Perkin Elmer Elan DRC-e) equipped with a cyclonic spray chamber and a Meinhard nebulizer was used in non-DRC mode for the determination of the concentration of metal ions. The daily performance check of the ICP-MS instrument was performed before each run. If necessary, the instrumental parameters were optimized against a tuning solution until the instrument performed with the maximum sensitivity and met all the performance requirements. The optimized parameters of ICP-MS were shown in Table 2 and the detection limits of metals as well their concentration of the calibration ranges were shown in Table 3.

Table 2. Optimized parameters of inductivity coupled plasma mass spectrometry used for the analysis of metals

Optimized parameters of ICP-MS

\begin{tabular}{ll}
\hline Rf power (W) & 1350 \\
\hline Plasma gas flow rate (L/min) & 15.00 \\
\hline Auxiliary gas flow rate (L/min.) & 1.20 \\
\hline Nebulizer gas flow rate (L/min.) & $0.96-1.04$ \\
\hline Dwell time (ms) & 600 \\
\hline Lens voltage (V) & $7-8$ \\
\hline${ }^{24} \mathrm{Mg}$ intensity & $>500000$ \\
\hline${ }^{115}$ In intensity & $>250000$ \\
\hline${ }^{238} \mathrm{U}$ intensity & $>20000$ \\
\hline CeO/Ce $\%$ & $<3$ \\
\hline Ba ${ }^{++}$Ba $\%$ & $<3$ \\
\hline Background (220amu) & $<2$ \\
\hline Background (8.5amu): & $<3$ \\
\hline
\end{tabular}


Internal standard stock solution $(10 \mathrm{mg} / \mathrm{L})$ was prepared by adding $200 \mu \mathrm{L}$ yttrium $(89$ Y) primary standard (1000 mg/L) to $19,800 \mu \mathrm{L} 2 \% \mathrm{HNO}_{3}$ in a FEP fluorocarbon bottle. The stock solution was bi-weekly prepared and further diluted to $1 \mathrm{mg} / \mathrm{L}$ to be used as working solution by pipetting $2000 \mu \mathrm{L}$ of the stock solution into $18,000 \mu \mathrm{L}$ of $2 \% \mathrm{HNO}_{3}$. The working solution was daily prepared before use.

\begin{tabular}{lcc}
\hline \multicolumn{2}{l}{ Table 3. The detection limits of metals and the concentration ranges of calibration curves } \\
\hline Elements & Detection limits $(\mu \mathrm{g} / \mathrm{L})$ & Calibration range $(\mu \mathrm{g} / \mathrm{L})$ \\
\hline Antimony $(121 \mathrm{Sb})$ & 0.030 & $0,0.5,1,2,5,10,25$ \\
\hline Arsenic $(75 \mathrm{As})$ & 0.100 & $0,0.5,1,2,5,10,25$ \\
\hline Cadmium $(111 \mathrm{Cd})$ & 0.010 & $0,0.5,1,2,5,10,25$ \\
\hline Cobalt $(59 \mathrm{Co})$ & 0.004 & $0,0.5,1,2,5,10,25$ \\
\hline Copper $(63 \mathrm{Cu})$ & 0.200 & $0,0.5,1,2,5,10,25$ \\
\hline Iron $(57 \mathrm{Fe})$ & 5.000 & $0,5,10,25,50,75,100$ \\
\hline Lead $(208 \mathrm{~Pb})$ & 0.010 & $0,0.5,1,2,5,10,25$ \\
\hline Manganese $(55 \mathrm{Mn})$ & 0.700 & $0,0.5,1,2,5,10,25$ \\
\hline Nickel $(60 \mathrm{Ni})$ & 0.100 & $0,0.5,1,2,5,10,25$ \\
\hline Silver $(107 \mathrm{Ag})$ & 0.010 & $0,0.5,1,2,5,10,25$ \\
\hline Tin $(120 \mathrm{Sn})$ & 0.020 & $0,0.5,1,2,5,10,25$ \\
\hline Zinc $(66 \mathrm{Zn})$ & 0.200 & $0,0.5,1,2,5,10,25$ \\
\hline
\end{tabular}

\subsubsection{Arsenic speciation analysis}

The HPLC-ICP-MS in the non-DRC mode was used for arsenic speciation analysis. Two post-column 6 port valves were employed, a nebulizer feed valve to direct the flow from the HPLC into the ICP-MS and an internal standard valve for post-column injection of an internal standard. The $\mathrm{m} / \mathrm{z}$ signal of 75 was monitored for As. Data were collected and processed with the Chromera software (Perkin Elmer, USA). As ${ }^{\mathrm{V}}(20 \mathrm{ppb})$ was used as an internal standard to correct for the instrumental drifts occurring during the process of 
analysis by post column injection. The primary arsenic species standards (1000 ppm) were prepared by dissolving solid sodium metaarsenite $\left(98 \%, \mathrm{As}^{\mathrm{III}}\right)$ and sodium arsenate dibasic $\left(99 \%, \mathrm{As}^{\mathrm{V}}\right)$ in DDI water, separately. Mix standards of $\mathrm{As}^{\mathrm{III}}$ and $\mathrm{As}^{\mathrm{V}}$ to be used as working standards were prepared by a series of dilutions at the following concentrations of $0,5,10$, $25,50,75$ and $100 \mathrm{ppb}$.

\subsection{Determination of time required for equilibrium dialysis}

\subsubsection{Procedure}

Before the equilibrium dialysis experiment of metal-toxin mixtures, preliminary work was performed to determine the time required for reaching the dialysis equilibrium. The concentrations of metal ions, both inside and outside of the dialysis bag were required to be monitored. The experimental medium $(245 \mathrm{~mL})$ used was prepared by adding $\mathrm{NaN}_{3}(0.2 \%$ $\mathrm{w} / \mathrm{w}$ ) (used to inhibit the growth of microorganisms) and $\mathrm{NaCl}(2 \mathrm{mM})$ (added to adjust the ion strength) to DDI water. The metal ions, including copper, nickel, cobalt, zinc, arsenic, antimony, manganese, cadmium, lead, tin and silver, with an initial concentration of 500 ppb and mercury with an initial concentration of $100 \mathrm{ppb}$ were individually spiked into the experimental medium. The dialysis bag (MWCO 500 Delton) filled with $5 \mathrm{~mL}$ buffer solution was then submerged in these metal ion containing solutions. The volume ratio of the outside/inside solutions was set to $49: 1$. The solutions were continuously stirred by using a magnetic stir bar at room temperature $\left(20^{\circ} \mathrm{C}\right)$ and the beaker was sealed with parafilm in order to prevent evaporation of water and the contamination of the solutions during the course of the experiments. All experiments were performed in triplicate. A small amount $(50 \mu \mathrm{L})$ of solution was sampled at regular time intervals from both inside and outside compartments and transferred into $10 \mathrm{~mL}$ tubes. The dialysis bags and the beakers 
were then resealed. Inductively coupled plasma mass spectrometry was used to determine the concentrations of copper, nickel, cobalt, zinc, arsenic, antimony, manganese, cadmium, lead, tin and silver, while AFS was employed for the analysis of mercury. For ICP-MS analysis, sample $(50 \mu \mathrm{L})$ was spiked with the yttrium solution $(125 \mu \mathrm{L}, 1 \mathrm{ppm}$, used as the internal standard) and then diluted with nitric acid $(4825 \mu \mathrm{L}, 2 \%)$. For the mercury, sample solutions $(50 \mu \mathrm{L})$ were diluted to $2 \mathrm{~mL}$, and then $1 \mathrm{~mL}$ was taken in order to further dilute to $40 \mathrm{~mL}$. All the samples were well mixed by hand shaking.

\subsubsection{Results and Discussion}

Equilibrium time. The results indicated that the time required to reach the equilibrium and the variance of recovery were metal ion dependent. The time required to reach the equilibrium during dialysis under the selected $\mathrm{pH}$ are summarized in Table 4. Dialysis of copper(II) ion $\left(\mathrm{Cu}^{2+}\right)$, being the quickest, required $30 \mathrm{~h}$ to reach the equilibrium dialysis, while arsenic $\left(\mathrm{AsO}_{4}{ }^{3-}\right)$ was the lowest among all metal ion tested, requiring $860 \mathrm{~h}$ (Table 4). The time required to reach the equilibrium dialysis for the following ions, iron(II) ion $\left(\mathrm{Fe}^{2+}\right)$, iron(III) ion $\left(\mathrm{Fe}^{3+}\right)$, lead(II) ion $\left(\mathrm{Pb}^{2+}\right)$, silver(I) ion $\left(\mathrm{Ag}^{+}\right)$and tin(II) ion $\left(\mathrm{Sn}^{2+}\right)$ were not obtained because of their low recoveries probably caused by the high $\mathrm{pH}$ in experimental system or other reasons (see below for discussion on recoveries of metals) in this experiment and N/A was placed in Table 4 for the recovery of these ions. The equilibrium dialysis curves of these metals were shown in Figures 7-18. The recoveries were calculated by sum up the mass of metals being sampled for analysis and remained in medium divided by their initial mass spiked into the medium.

For a given dialysis membrane, the dialysis equilibrium time (and also the recovery) of the metals were possibly affected by a number of factors, including the site (radius) of ions, 
$\mathrm{pH}$ value of the solution and ionic strength (Table 5). Figure 7 showes that the time required for equilibrium dialysis was related to the radius of the metal ion. Copper(II) ion $\left(\mathrm{Cu}^{2+}\right)$, the smallest metal ion used in this experiment, could reach the equilibrium within $30 \mathrm{~h}$. On the contrary, the only selected anion in the dialysis study, arsenate $\left(\mathrm{HAsO}_{4}{ }^{2-}\right)$, which has a large ionic radius, needed 860h to reach equilibrium. As shown in Figure 19, the time required to reach the equilibrium for $\mathrm{Cu}^{2+}, \mathrm{Co}^{2+}, \mathrm{Ni}^{2+}$ and $\mathrm{Mn}^{2+}$ ions increases with an increase of the radius. As the pore size of the dialysis membrane bags was constant (MWCO 500 Delton), the larger the radius of an ion, the longer it took for the ion to move between the inside and the outside of the membrane. However, reaching the dialysis equilibrium of zinc(II) $\left(\mathrm{Zn}^{2+}\right)$ and cadmium(II) ions $\left(\mathrm{Cd}^{2+}\right)$ required less time than that needed for cobalt(II) $\left(\mathrm{Co}^{2+}\right)$ and nickel(II) ions $\left(\mathrm{Ni}^{2+}\right)$ despite of the fact that $\mathrm{Zn}^{2+}$ and $\mathrm{Cd}^{2+}$ have a larger ionic radii than $\mathrm{Co}^{2+}$ and $\mathrm{Ni}^{2+}$. The radius of metal ion would be changed by the ligands present in the aqueous phase. For example, hydrated metal ions can form as the result of the binding of metal ions with water molecules. Previous results showed that these metal ions possibly exist in the hydrated form in aqueous systems with varying coordination number depending on their ionic radius and charges (Lundqvist et al. 1981; Fourest et al. 1982; Tansel et al. 2006; Heyrovska 2007). The ionic radius depends on the orbitals of the ionic valence-shell, the configuration of valence-shell electrons and the size of the nucleus. However, the radii of the hydrated ions depend on more factors, such as the temperature, $\mathrm{pH}$, central atom and its charges, complexing agents (ligands) and their concentraion, as well as the influences of other electrolytes in the aqueous system. Besides, the favorable coodination numbers and the stabilily of the complex with the specific metal cations would differ depending on the experimental conditions. 


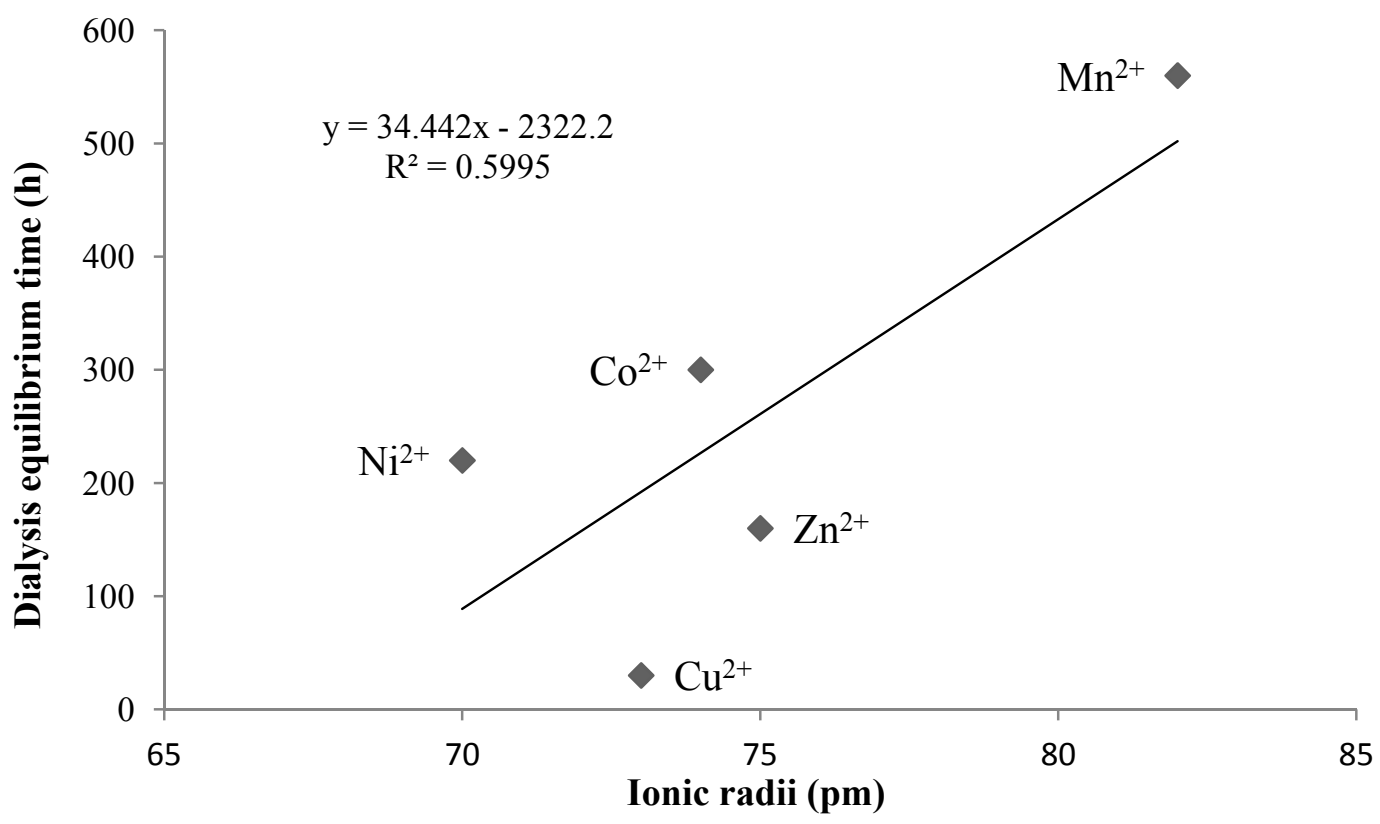

Figure 7. The relationship between the ionic radius of period 4 elements and the time required for equilibrium

Moreover, the charges of the ions would also affect the time required for reaching the equilibrium. For example, the antimony(III) ion $\left(\mathrm{Sb}^{3+}\right)$ and arsenate anion $\left(\mathrm{AsO}_{4}{ }^{3-} / \mathrm{HAsO}_{4}{ }^{2-}\right)$, which were highly charged, required longer time to reach the dialysis equilibrium than the divalent ions.

An interesting result was revealed for the dialysis of zinc(II) ion $\left(\mathrm{Zn}^{2+}\right)$, cadmium(II) ion $\left(\mathrm{Cd}^{2+}\right)$ and mercury(II) ion $\left(\mathrm{Hg}^{2+}\right)$. Although the radii of these ions varied greatly, the differnces in the time required to reach the equilibrium among them were very little. This phenomenon could be attributed to their electronic confiuguration of [ ] $\mathrm{d}^{10} \mathrm{~s}^{2}$, which has no incomplete $d$ sub-shell. In spite of the position of these elements in the periodic table belonging to the transition elements, they were sometimes not classified as that. As a result 
of their fully occupied $d$-orbitals, their solvation would be weaker and therefore enhance their mobility in aqueous phase (Jensen 2003).

Table 4.The time required to reach dialysis equilibrium and the recoveries of metals under the experimental $\mathrm{pH}$

\begin{tabular}{lccc}
\hline Elements & $\mathrm{pH}$ & Equilibrium dialysis time (h) & Recovery (\%) \\
\hline Antimony(III) & 5.73 & 780 & 98 \\
\hline Arsenic(V) & 5.68 & 860 & 97 \\
\hline Cadmium(II) & 5.75 & 180 & 98 \\
\hline Cobalt(II) & 5.72 & 300 & 110 \\
\hline Copper(II) & 5.80 & 30 & 93 \\
\hline Iron(III) & 5.65 & N/A & $<5$ \\
\hline Iron(II) & 5.98 & N/A & $<10$ \\
\hline Lead(II) & 5.91 & N/A & 34 \\
\hline Manganese(II) & 5.90 & 560 & 116 \\
\hline Mercury(II) & 5.77 & 100 & 93 \\
\hline Nickel(II) & 5.79 & 220 & 108 \\
\hline Silver(II) & 5.82 & N/A & 57 \\
\hline Tin(II) & 5.86 & N/A & 58 \\
\hline Zinc(II) & 5.79 & 160 & 85 \\
\hline
\end{tabular}




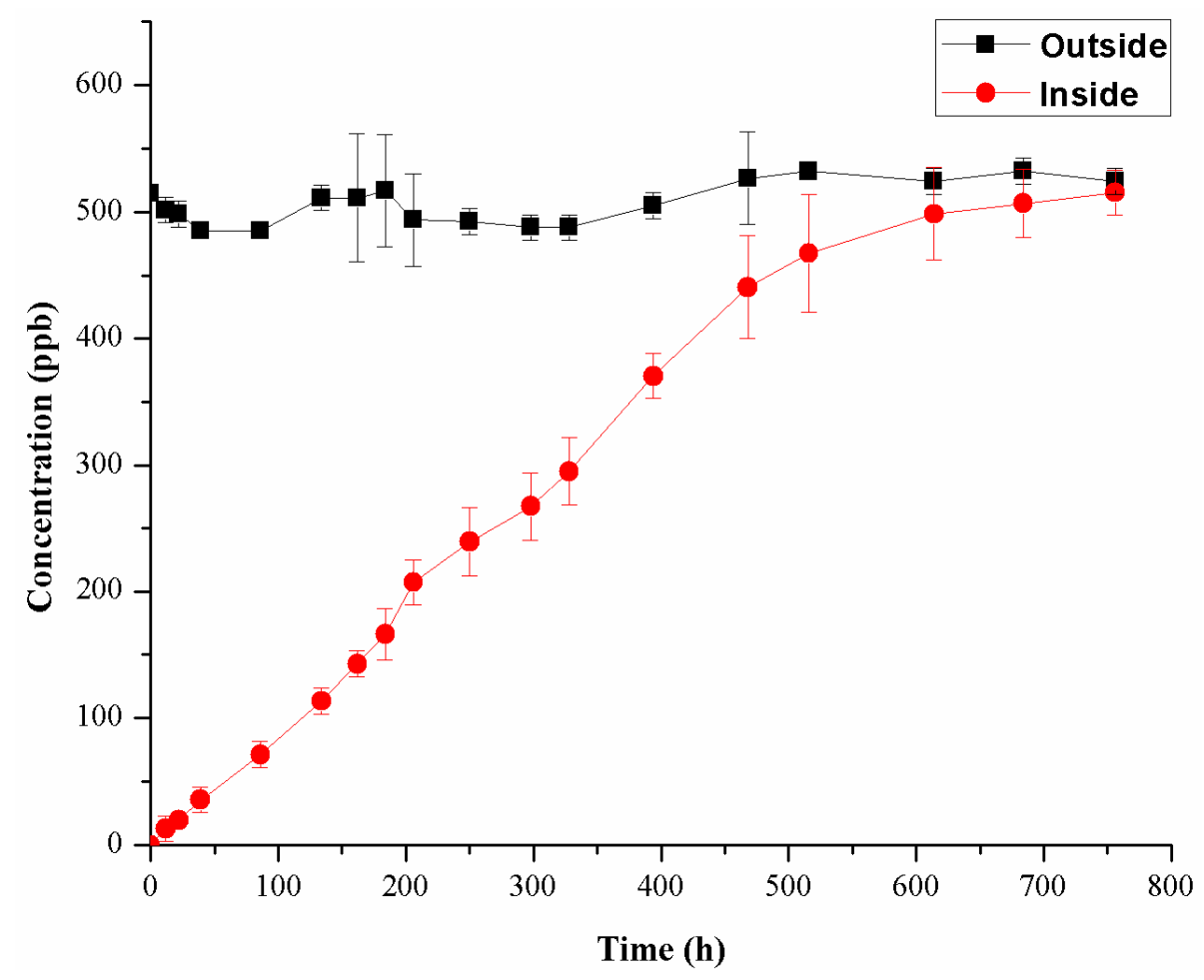

Figure 8 . The equilibrium dialysis curve of antimony

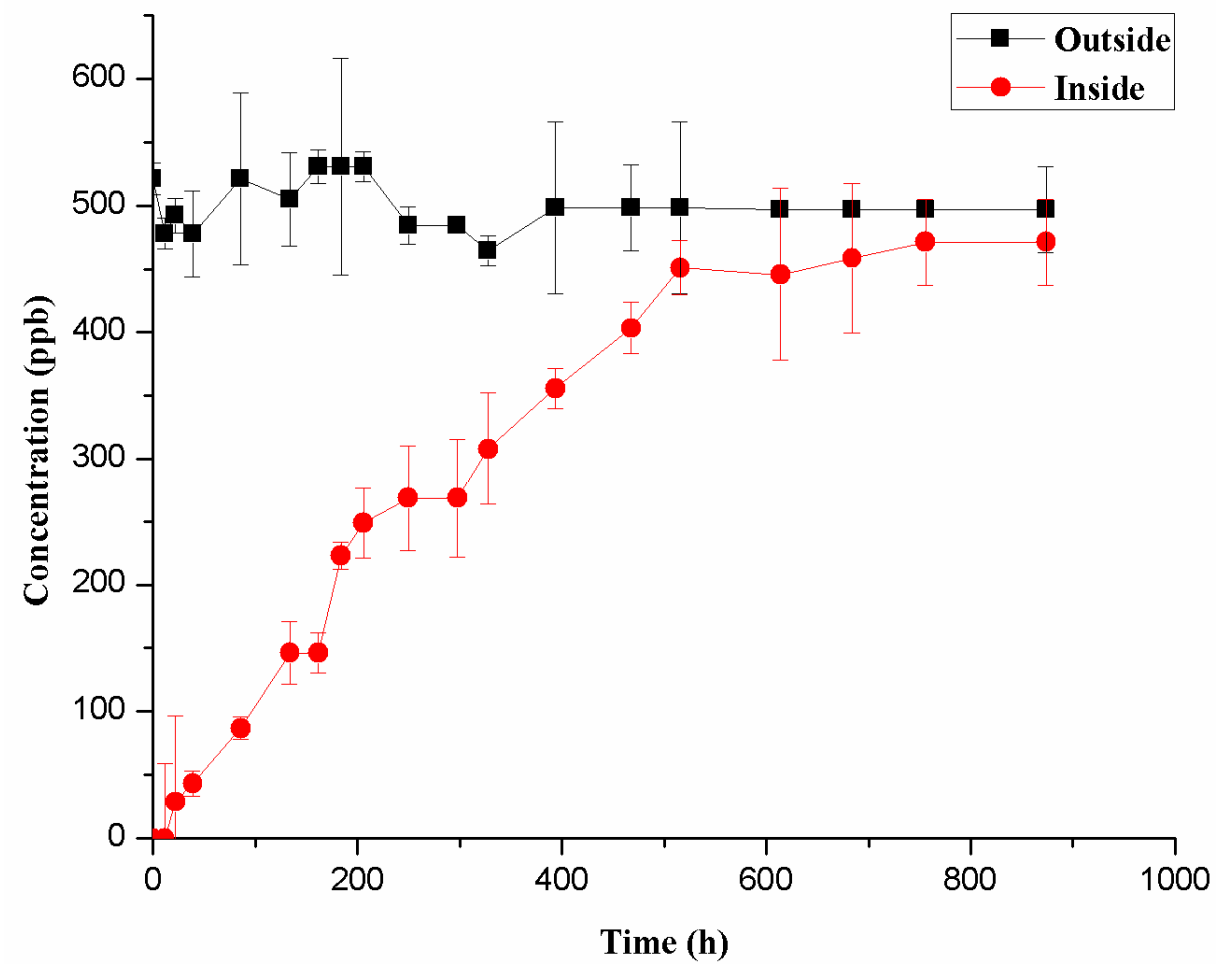

Figure 9. The equilibrium dialysis curve of arsenic 


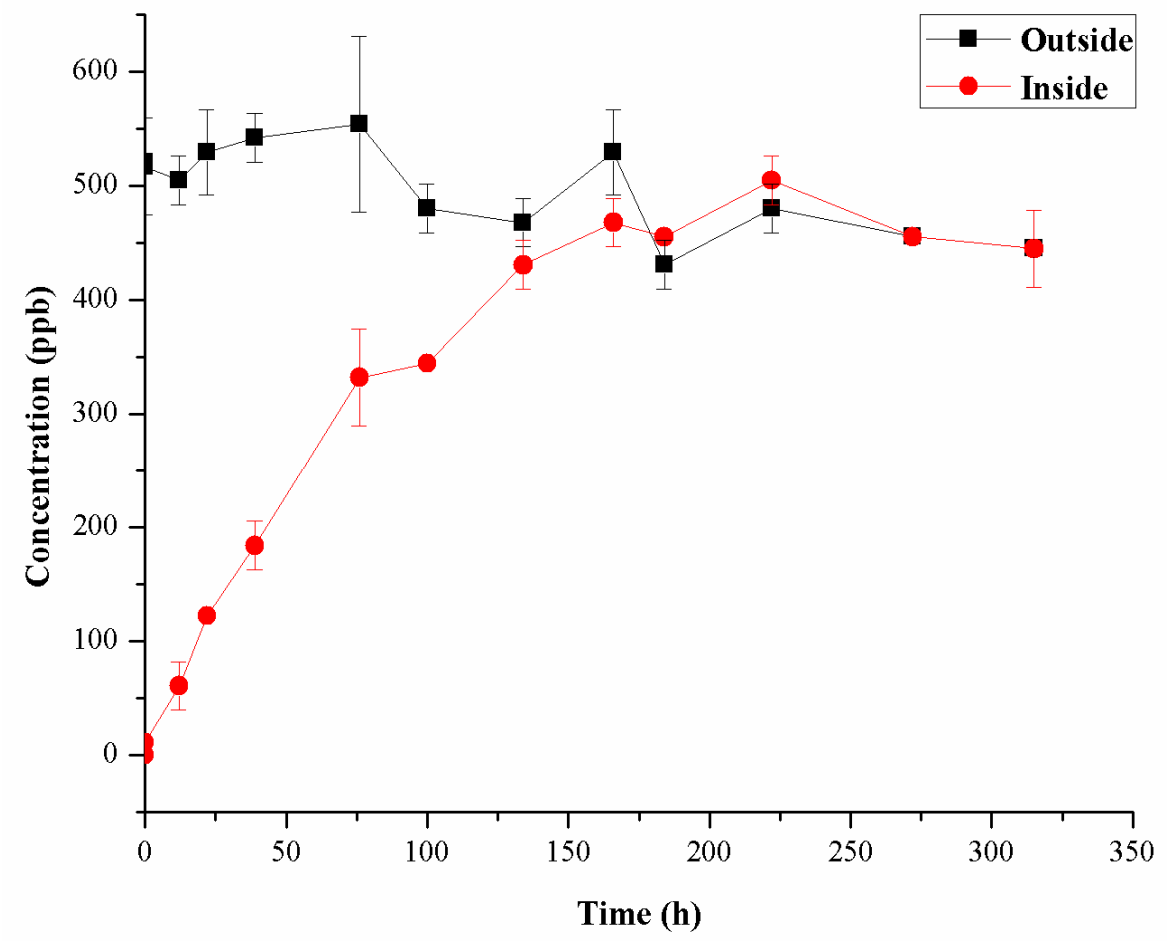

Figure 10. The equilibrium dialysis curve of cadmium

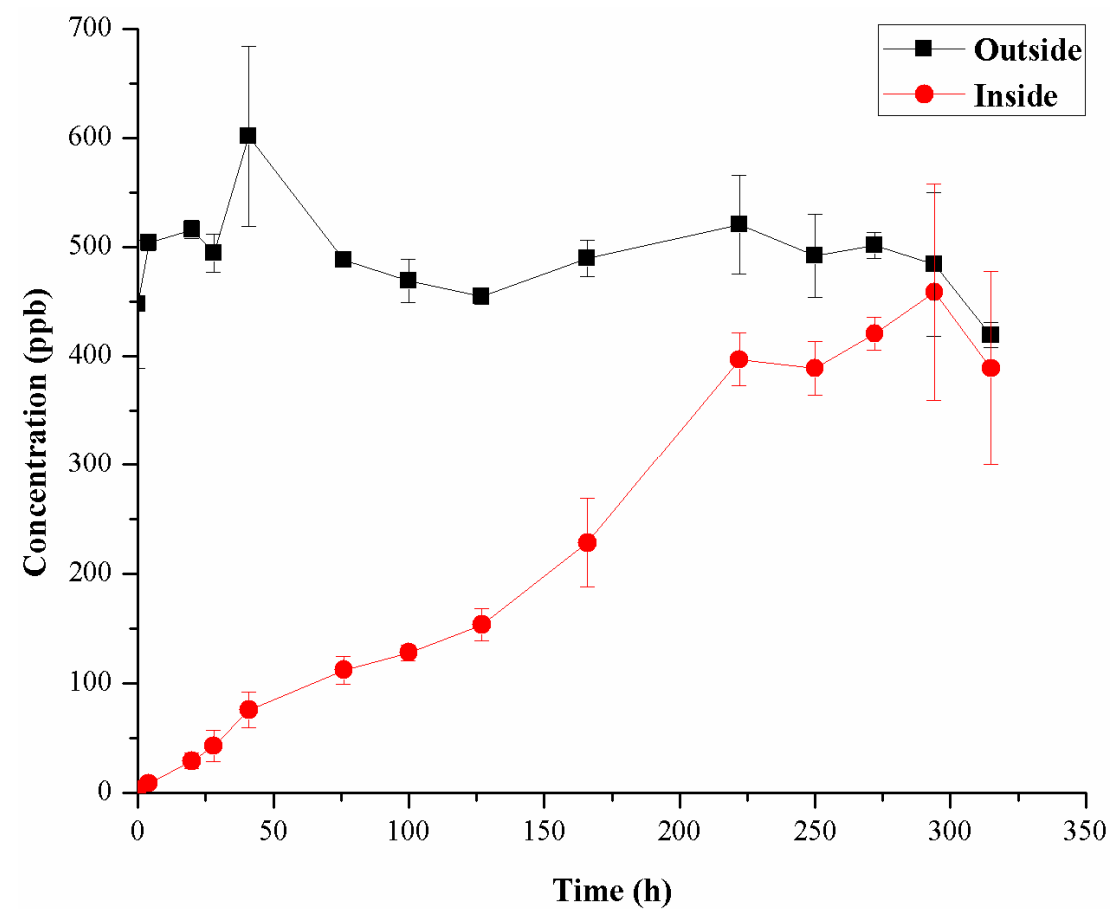

Figure 11. The equilibrium dialysis curve of cobalt 


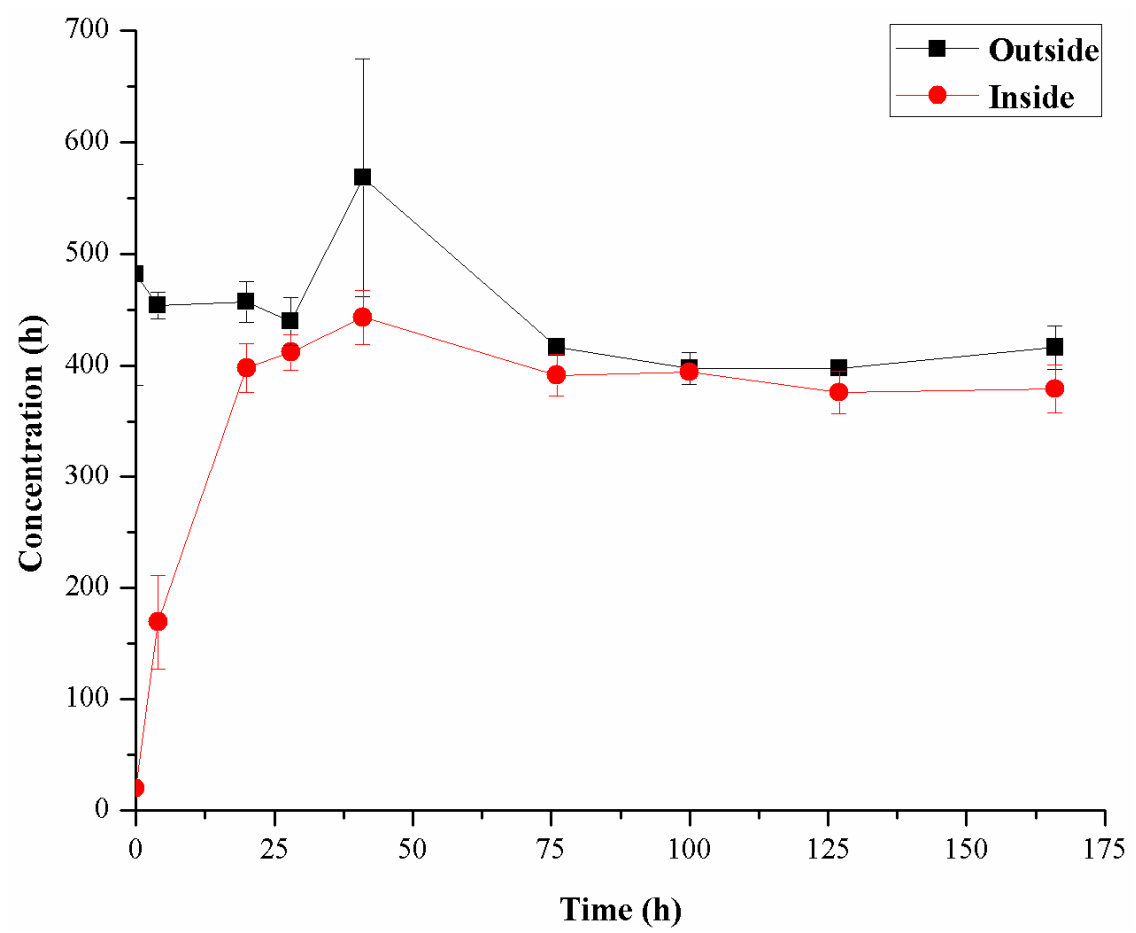

Figure 12. The equilibrium dialysis curve of copper

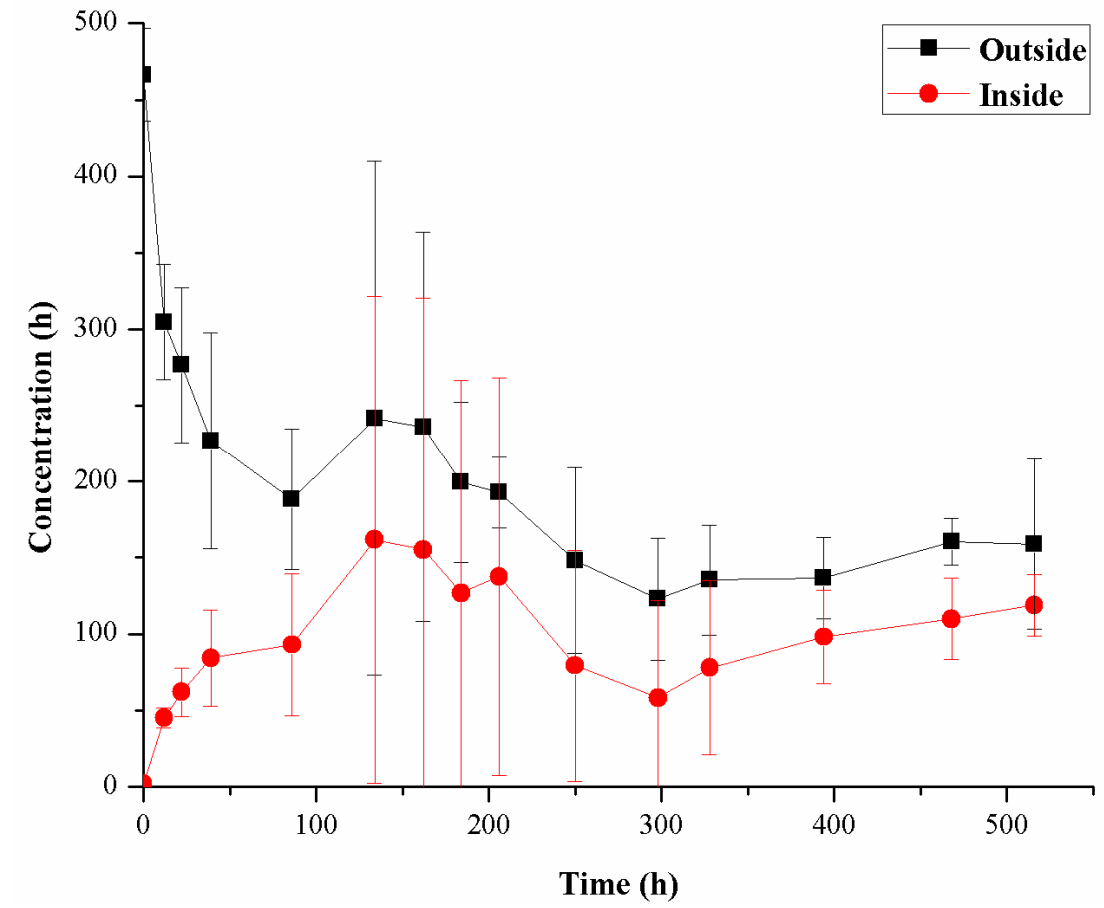

Figure 13. The equilibrium dialysis curve of lead 


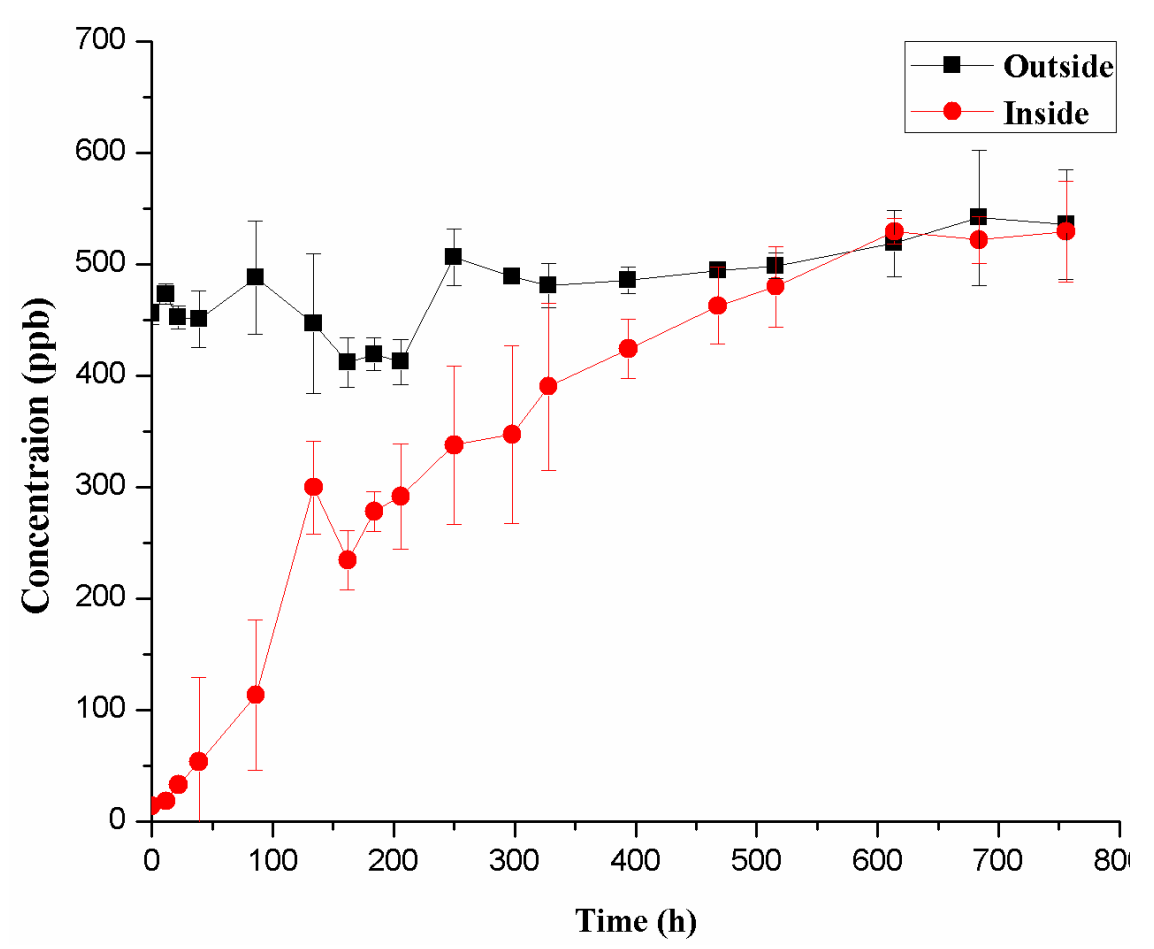

Figure 14. The equilibrium dialysis curve of manganese

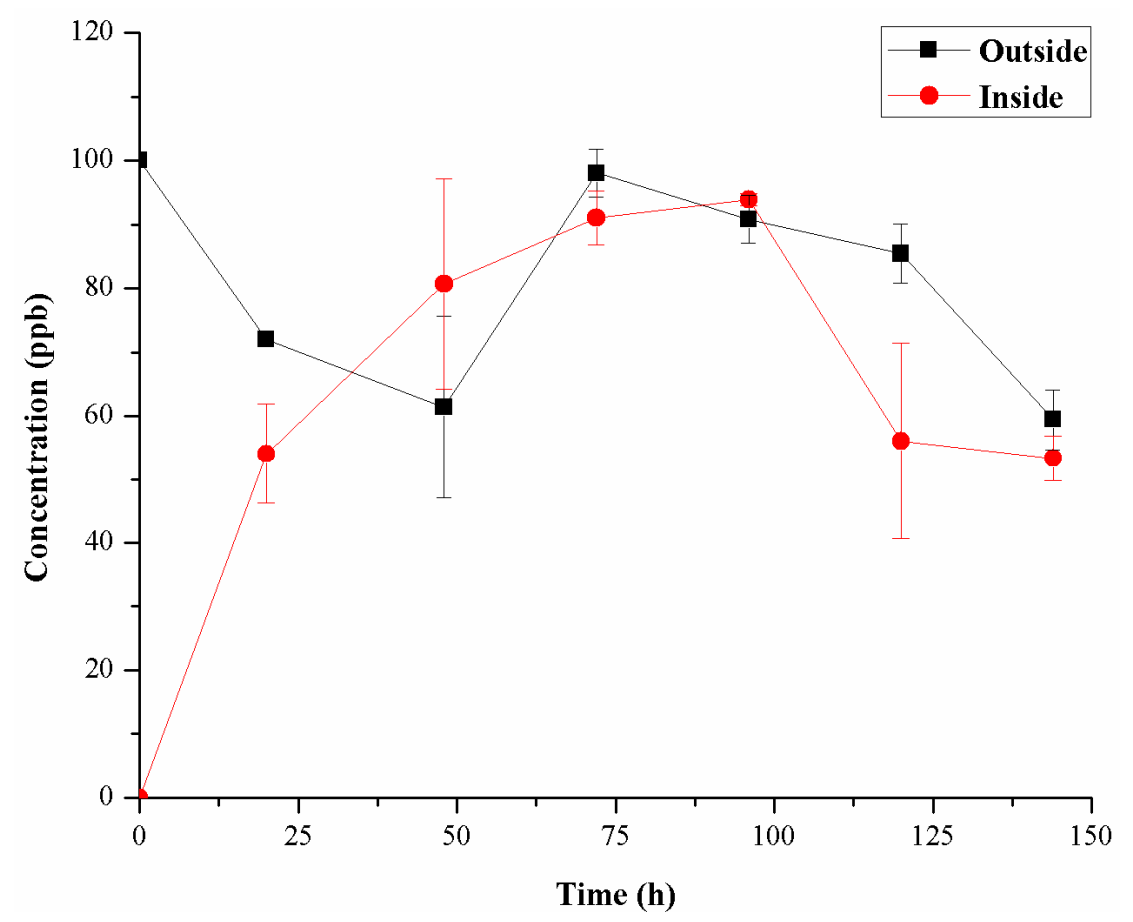

Figure 15. The equilibrium dialysis curve of mercury 


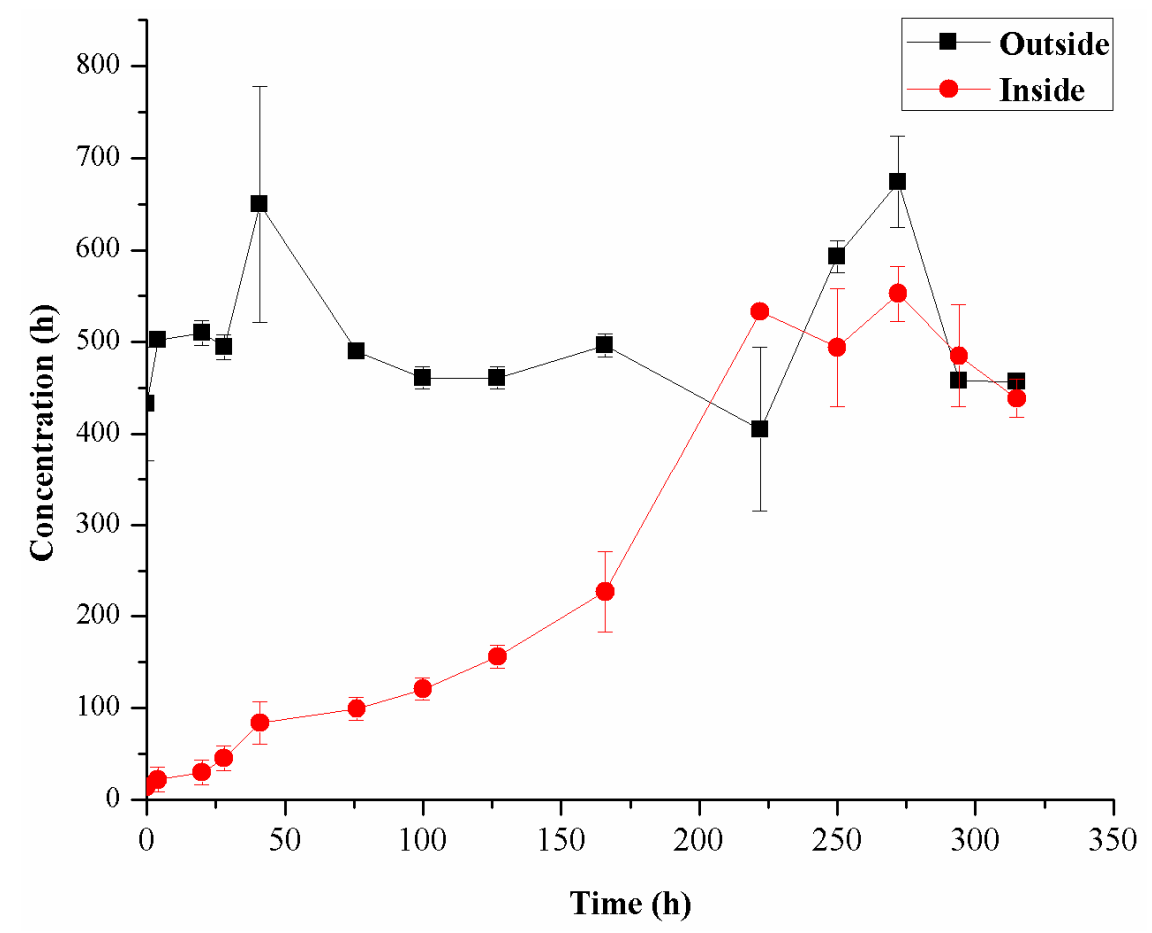

Figure 16. The equilibrium dialysis curve of nickel

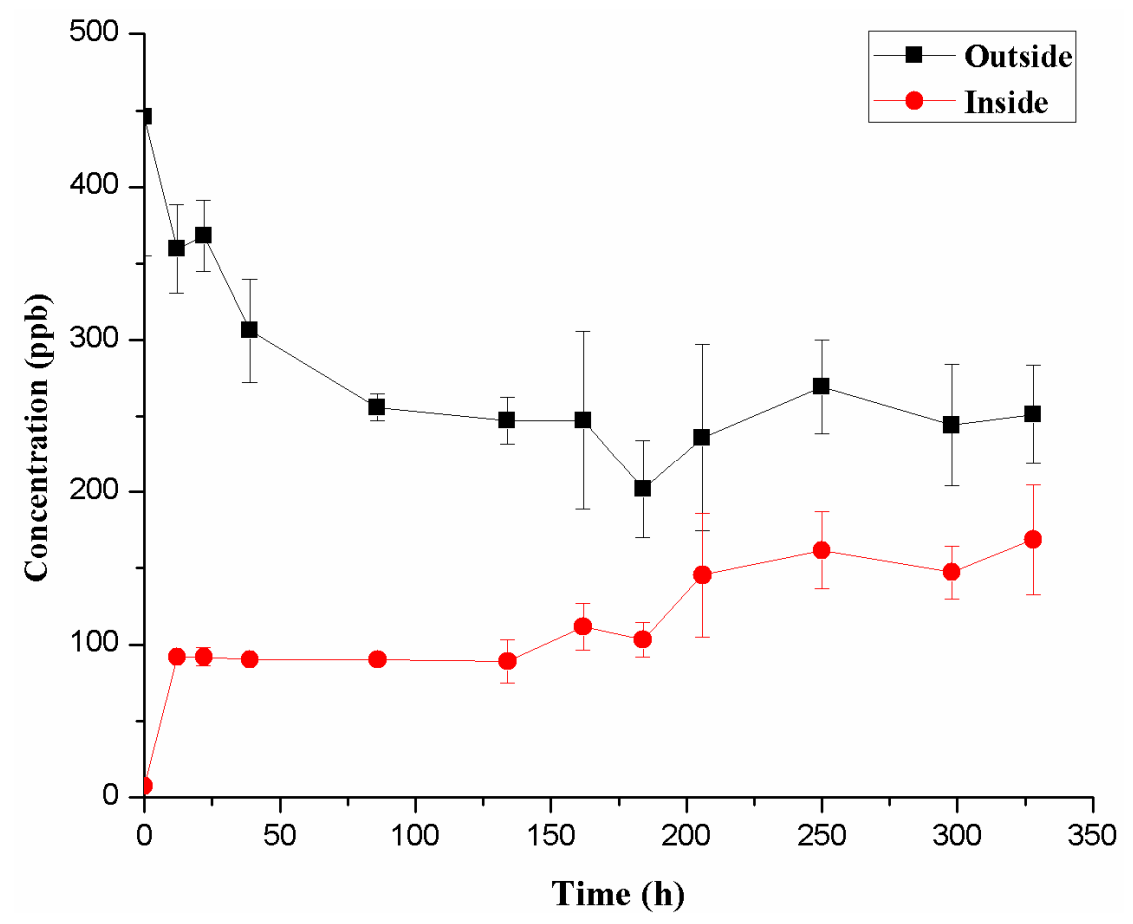

Figure 17. The equilibrium dialysis curve of silver 


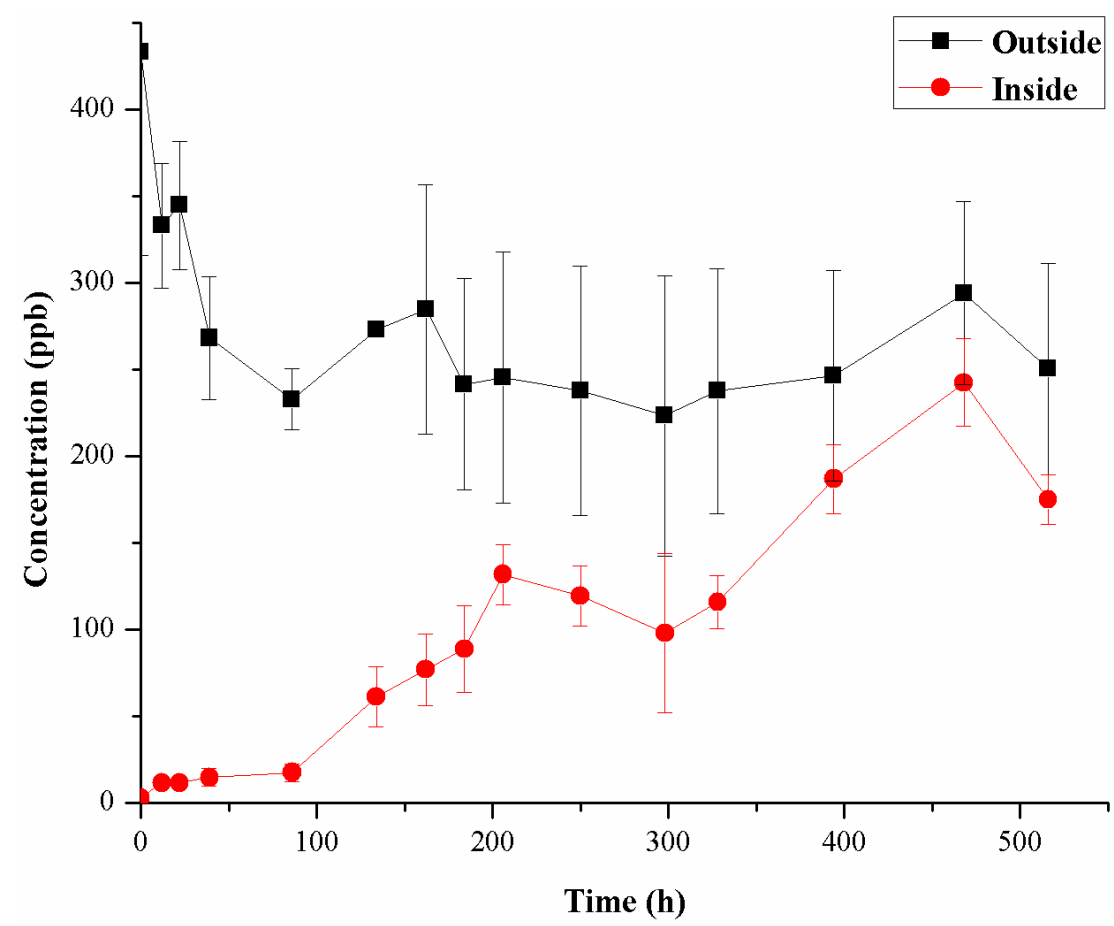

Figure 18. The equilibrium dialysis curve of tin

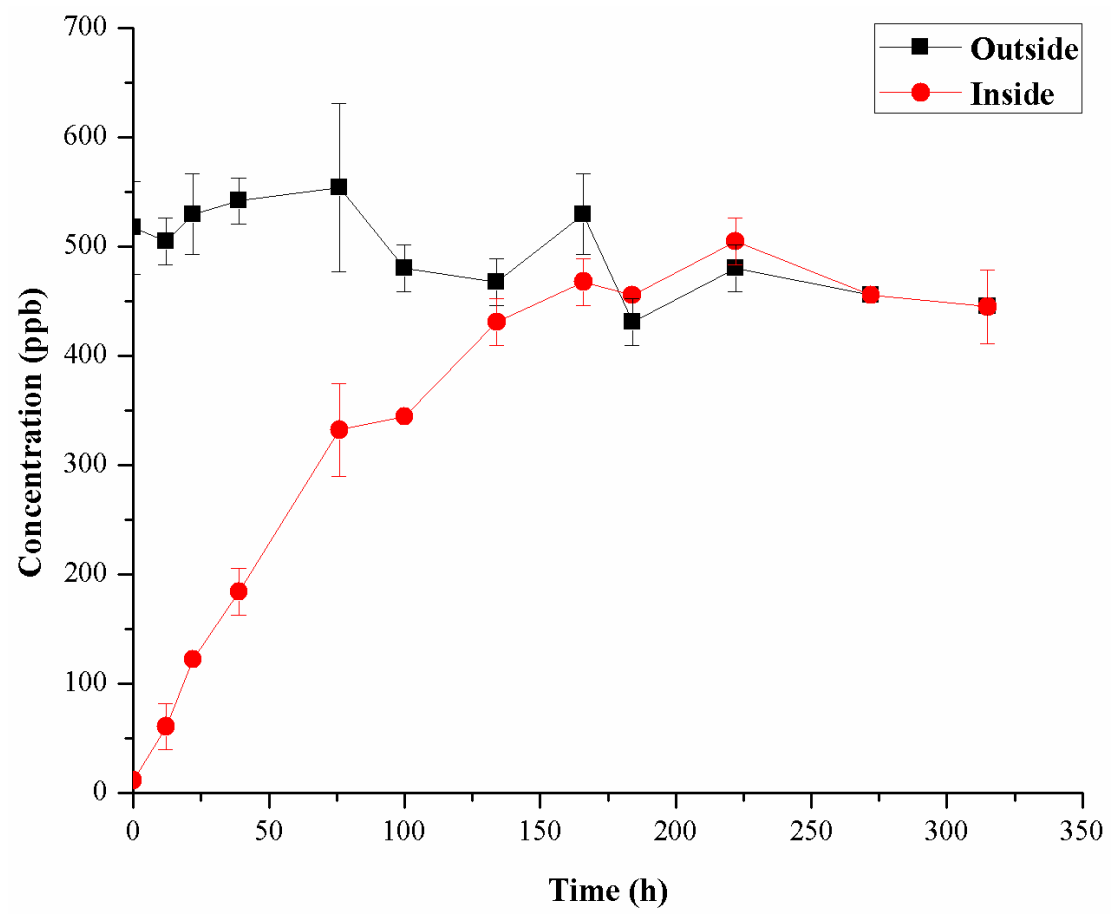

Figure 19. The equilibrium dialysis curve of zinc 
Mass balance of metals. During the dialysis experiments, it was observed that some of the spiked metals could not be recovered, indicating loss (e.g., through precipitation or adsorption onto the beaker wall) of metals during the course of dialysis. In order to evaluate the behavior of the metals during the dialysis, the recovery of metals was calculated by the following equation:

$$
\text { Recovery } \%=\frac{C_{e o s}\left(V_{o s}-V_{S} N\right)+C_{e i s}\left(V_{i s}-V_{S} N\right)+\sum_{n=1}^{N}\left(C_{n o s} V_{S}+C_{n i s} V_{S}\right)}{C_{0} V_{0}} * 100 \%
$$

Where $C_{e o s}$ and $C_{e i s}$ were the concentration of metals in the outside and inside of the dialysis membrane bag while reaching the equilibrium, respectively; $V_{o s}$ and $V_{i s}$ were the initial volume in the outside and inside of the bag, respectively; $C_{n o s}$ and $C_{n i s}$ were the concentration of metals in the outside and inside of the dialysis membrane bag before reaching the equilibrium; $V_{s}$ was the sampled volume $(50 \mu \mathrm{L})(20 \mu \mathrm{L}$ for mercury); $\mathrm{N}$ was the time points for sampling; $C_{0}$ and $V_{0}$ were the initial total concentration of metal and initial total volume of solution $(250 \mathrm{~mL})$ respectively. 
Table 5. The hydroxides of the selected metal cations and their theoretical critical $\mathrm{pH}$ value as the experimental conditions

\begin{tabular}{lcccc}
\hline $\begin{array}{l}\text { Metal } \\
\text { hydroxide }\end{array}$ & $\begin{array}{c}K_{s p}(\text { Dean } \\
1972)\end{array}$ & $\begin{array}{c}\text { Initial concentration } \\
\text { of element }(\mathrm{ppb})\end{array}$ & $\begin{array}{c}\text { Initial concentration } \\
\text { of element }(\mathrm{mol} / \mathrm{L})\end{array}$ & $\begin{array}{c}\text { The theoretical critical } \\
\mathrm{pH} \text { value }(\mathrm{I}=0)\end{array}$ \\
\hline $\mathrm{AgOH}$ & $2.0 \times 10^{-8}$ & 500 & $4.64 \times 10^{-6}$ & 11.6 \\
\hline $\mathrm{Cd}(\mathrm{OH})_{2}$ & $7.2 \times 10^{-15}$ & 500 & $4.45 \times 10^{-6}$ & 9.6 \\
\hline $\mathrm{Co}(\mathrm{OH})_{2}$ & $5.92 \times 10^{-15}$ & 500 & $8.48 \times 10^{-6}$ & 9.4 \\
\hline $\mathrm{Cu}(\mathrm{OH})_{2}$ & $2.2 \times 10^{-20}$ & 500 & $7.87 \times 10^{-6}$ & 6.7 \\
\hline $\mathrm{Fe}(\mathrm{OH})_{3}$ & $2.79 \times 10^{-39}$ & 500 & $8.95 \times 10^{-6}$ & 2.8 \\
\hline $\mathrm{Fe}(\mathrm{OH})_{2}$ & $4.87 \times 10^{-17}$ & 500 & $8.95 \times 10^{-6}$ & 8.4 \\
\hline $\mathrm{Hg}(\mathrm{OH})_{2}$ & $3.2 \times 10^{-26}$ & 100 & $4.99 \times 10^{-7}$ & 4.4 \\
\hline $\mathrm{Mn}(\mathrm{OH})_{2}$ & $1.9 \times 10^{-13}$ & 500 & $9.10 \times 10^{-6}$ & 10.2 \\
\hline $\mathrm{Pb}(\mathrm{OH})_{2}$ & $1.43 \times 10^{-15}$ & 500 & $4.66 \times 10^{-6}$ & 6.7 \\
\hline $\mathrm{Ni}(\mathrm{OH})_{2}$ & $5.48 \times 10^{-16}$ & 500 & $8.52 \times 10^{-6}$ & 8.9 \\
\hline $\mathrm{Sn}(\mathrm{OH})_{2}$ & $5.45 \times 10^{-28}$ & 500 & $4.21 \times 10^{-6}$ & 3.1 \\
\hline $\mathrm{Zn}(\mathrm{OH})_{2}$ & $3 \times 10^{-17}$ & 500 & $7.65 \times 10^{-6}$ & 8.3 \\
\hline
\end{tabular}

Low recoveries for silver, tin, lead and iron (Table 4) could possibly be explained by the $\mathrm{pH}$ value of the solutions. Silver(I) ion $\left(\mathrm{Ag}^{+}\right)$can co-precipitate with both hydroxide ion $\left(\mathrm{OH}^{-}\right)$and chloride $\left(\mathrm{Cl}^{-}\right)$under the experimental conditions, and the solubility product constants $\left(K_{s p}\right)$ are $2.0 \times 10^{-8}$ for $\mathrm{AgOH}$ and $1.77 \times 10^{-10}$ for $\mathrm{AgCl}$ (Dean 1972), respectively. It is plausible that the effect of $\mathrm{Cl}^{-}$(present in the experimental medium) was greater than that of $\mathrm{OH}^{-}$because of the value of $K_{s p(\mathrm{AgOH})}$ is 100 times greater than $K_{s p(\mathrm{AgCl})}$ resulting in $\mathrm{AgCl}$ as the main precipitate. However, once $\mathrm{AgOH}$ is formed, it would decompose quickly to form silver(I) oxide $\left(\mathrm{Ag}_{2} \mathrm{O}\right)$ because of its thermal instability. Furthermore, the photochemical decomposition of $\mathrm{Ag}_{2} \mathrm{O}$ would result in the formation of elemental silver $\left(\mathrm{Ag}^{0}\right)$. Although the thermodynamic effects favored the formation of $\mathrm{AgCl}$, the dynamic effects would play a decisive role in the formation of the ultimate product. In other words, 
the concentration of $\mathrm{OH}^{-}$, which was directly related to $\mathrm{pH}$, could explain the low recovery of $\mathrm{Ag}^{+}$.

$$
\begin{gathered}
\mathrm{Ag}^{+}+\mathrm{Cl}^{-}=\mathrm{AgCl} \\
\mathrm{Ag}^{+}+\mathrm{OH}^{-}=\mathrm{AgOH} \\
2 \mathrm{AgOH}=\mathrm{Ag}_{2} \mathrm{O}+\mathrm{H}_{2} \mathrm{O} \\
\mathrm{Ag}_{2} \mathrm{O}=\mathrm{Ag}+\mathrm{O}_{2}
\end{gathered}
$$

Moreover, a very low recovery of tin(II) ion $\left(\mathrm{Sn}^{2+}\right)$ was observed caused probably by the formation of tin(II) hydroxide $\left(\mathrm{Sn}(\mathrm{OH})_{2}\right)$ precipitate. The $K_{s p}$ of $\mathrm{Sn}(\mathrm{OH})_{2}$ is $5.45 \times 10^{-28}$ at room temperature $\left(20^{\circ} \mathrm{C}\right)$ (see Table 5), and the initial concentration of $\mathrm{Sn}^{2+}$ was $500 \mathrm{ppb}$ and therefore the theoretical critical $\mathrm{pH}$ value could be calculated. The theoretical calculated critical $\mathrm{pH}$ (which is calculated by using $K_{s p}$ of metal hydroxides to predict the $\mathrm{pH}$ of metal ions start forming the precipitate) of the base $\mathrm{M}(\mathrm{OH})_{\mathrm{n}}$, was obtained from the following equation:

$$
K_{s p}=\left[\mathrm{M}^{\mathrm{n}+}\right]\left[\mathrm{OH}^{-}\right]^{\mathrm{n}}
$$

Where $\mathrm{M}^{\mathrm{n}+}$ is the concentration $(\mathrm{mol} / \mathrm{L})$ of metal cation, $\left[\mathrm{OH}^{-}\right]$is the concentration $(\mathrm{mol} / \mathrm{L})$ of hydroxide ion and $\mathrm{n}$ is the charge number of the metal cation. Given the $K_{s p}$, the critical $\mathrm{pH}$ value could be calculated by using the modified equation below:

$$
\mathrm{pH}=-\log \left(10^{-14} /\left(K_{s p} /\left[\mathrm{M}^{\mathrm{n}+}\right]\right)^{1 / \mathrm{n}}\right)
$$

In this experiment, using the equation above, the $\mathrm{pH}$ value of 3.1 was calculated. If the $\mathrm{pH}$ value was greater than that, $\mathrm{Sn}(\mathrm{OH})_{2}$ would start to precipitate from the solution. In other words, in order to avoid the formation of $\mathrm{Sn}(\mathrm{OH})_{2}$, the highest $\mathrm{pH}$ applied in the experiment should be lower than 3.1. Since the $\mathrm{pH} 5.86$ was used in the experiment, the formation of $\mathrm{Sn}(\mathrm{OH})_{2}$ precipitate would lead to a low recovery of $\mathrm{Sn}^{2+}$. Moreover, these 
two following chemical reactions could also have occurred under the above experimental conditions:

$$
\begin{aligned}
2 \mathrm{Sn}^{2+}+\mathrm{O}_{2}+4 \mathrm{H}^{+} & =2 \mathrm{Sn}^{4+}+2 \mathrm{H}_{2} \mathrm{O} \\
\mathrm{Sn}^{4+}+4 \mathrm{OH}^{-} & =\mathrm{Sn}(\mathrm{OH})_{4}
\end{aligned}
$$

Once $\mathrm{Sn}^{2+}$ converted to tin(IV) ion $\left(\mathrm{Sn}^{4+}\right)$ and $\operatorname{tin}(\mathrm{IV})$ hydroxide $\left(\mathrm{Sn}(\mathrm{OH})_{4}\right)$ formed, the number of free tin ions significantly decreased due to the fact that $\mathrm{Sn}(\mathrm{OH})_{4}$ has a $K_{s p}$ of about $1.0 \times 10^{-56}$, which is much lower than the $K_{s p}$ of $\operatorname{Sn}(\mathrm{OH})_{2}$.

Very low recoveries were also observed for both iron(II) and iron(III) in the experiment. At experimental $\mathrm{pH}$, the free iron(III) ion $\left(\mathrm{Fe}^{3+}\right)$ solution could not be prepared because of the formation of $\mathrm{Fe}(\mathrm{OH})_{3}$, which is a lyophobic colloid and readily precipitated by vibration or addition of small quantities of electrolytes. It has been observed that the formation of $\mathrm{Fe}(\mathrm{OH})_{3}$ colloid happened within 30 min and colloids precipitated onto the wall of the beaker, as the experimental $\mathrm{pH}$ was higher than 2.8 . The recovery of iron(III) ion after 4 hours of experiment was less than $5 \%$, indicating that the equilibrium dialysis method could not be used to determine the interactions between iron(III) ion and algal toxins.

As for $\mathrm{Fe}^{2+}$, although it was not expected to precipitate under the experimental $\mathrm{pH}$ according to the $K_{s p}$ of $\mathrm{Fe}(\mathrm{OH})_{2}$, the precipitation did occur. The $24 \mathrm{~h}$ recovery of $\mathrm{Fe}^{2+}$ ion was less than $10 \%$, caused possibly by the oxidation of $\mathrm{Fe}^{2+}$ to $\mathrm{Fe}^{3+}$ and followed by the formation of $\mathrm{Fe}(\mathrm{OH})_{3}$. The following chemical reactions show the formation of $\mathrm{Fe}(\mathrm{OH})_{3}$ precipitate from $\mathrm{Fe}^{2+}$ in a two-step reaction:

$$
\begin{gathered}
4 \mathrm{Fe}^{2+}+\mathrm{O}_{2}+4 \mathrm{H}^{+}=4 \mathrm{Fe}^{3+}+2 \mathrm{H}_{2} \mathrm{O} \\
\mathrm{Fe}^{3+}+3 \mathrm{OH}^{-}=\mathrm{Fe}(\mathrm{OH})_{3}
\end{gathered}
$$


Alternatively, $\mathrm{Fe}(\mathrm{OH})_{3}$ may also be formed through the following reactions:

$$
\begin{gathered}
\mathrm{Fe}^{2+}+2 \mathrm{OH}^{-}=\mathrm{Fe}(\mathrm{OH})_{2} \\
4 \mathrm{Fe}(\mathrm{OH})_{2}+\mathrm{O}_{2}+2 \mathrm{H}_{2} \mathrm{O}=4 \mathrm{Fe}(\mathrm{OH})_{3}
\end{gathered}
$$

Mercury in the form of $\mathrm{Hg}^{2+}$ should have completely precipitated in the form of mercury hydroxide $\left(\mathrm{Hg}(\mathrm{OH})_{2}\right)$ from the solution under the experimental $\mathrm{pH}$. However, precipitation did not occur possibly because of the existence of high concentration of chloride $\left(\mathrm{Cl}^{-}\right)$in the buffer which was capable of forming soluble mercury species $\left[\mathrm{HgCl}_{\mathrm{n}}\right]^{(\mathrm{n}-2)-}($ Bienvenue et al. 1984; Persson et al. 1987; Barrow and Cox 1992; Barrow and Cox 1992; Delnomdedieu et al. 1992). A similar phenomenon was also found in case of the antimony(III) ion $\left(\mathrm{Sb}^{3+}\right)$ which was capable of complexing with chloride $\left(\mathrm{Cl}^{-}\right)$to form $\left[\mathrm{SbCl}_{4}\right]^{-}$and $\left[\mathrm{Sb}_{2} \mathrm{Cl}_{9}\right]^{3-}$ in aquatic media (Owen and Msayib 1985; Nikol and Vogler 1991; Oelkers et al. 1998; Dehghani and Sardrood 2007).

The metals with high recoveries (80-120\%), including arsenic, mercury, copper, cobalt, cadmium and manganese were selected to study their interaction with algal toxin molecules. The required equilibrium time obtained from these experiments was used for determining the stability constants of the toxin-metal complexes. The selected metals are among the most toxic metals/metalloids occurring in the aquatic environments.

\subsection{Determination of conditional stability constants $\left(K_{c s c}\right)$}

\subsubsection{Procedures}

Dialysis membrane bags (Spectrum Laboratories, Inc., Rancho Dominguez, CA) with a molecular weight cutoff (MWCO) of $500 \mathrm{Da}$ were used for the equilibrium dialysis. Before experimentation, the bags were soaked in DDI water for $1 \mathrm{~h}$, and then rinsed thoroughly with DDI water for 5 min in order to wash away sodium azide which was used 
as membrane preservative. Pyrex glass beakers $(600 \mathrm{~mL})$ were used as dialysis containers. The containers were filled with $245 \mathrm{ml}$ of metal ion solutions with the concentrations listed in Table 6, referred to hereafter as outside solution. A dialysis bag filled with $5 \mathrm{~mL}$ of algal toxin solutions, referred to hereafter as the inside solution, was immersed in the outside solution. The volume ratio of the outside/inside solutions was set to 49:1. The solution was continuously stirred at room temperature $\left(20^{\circ} \mathrm{C}\right)$ using a magnetic stirring bar and the beaker was sealed with parafilm in order to avoid the evaporation of water and prevent the potential contamination during the course of the experiments. All experiments were conducted in duplicate. The initial concentrations of the selected algal toxins in the inside solution and the initial concentrations of the selected metals in the outside solution were listed in Table 6.

Table 6. The concentrations of metal ions and algal toxin used in the equilibrium dialysis experiments

\begin{tabular}{lccc}
\hline Element & $\begin{array}{c}\text { Concentration of } \\
\text { metal ions }(\mathrm{ppb})\end{array}$ & $\begin{array}{c}\text { Concentration of } \\
\text { metal ions }(\mu \mathrm{mol} / \mathrm{L})\end{array}$ & $\begin{array}{c}\text { Concentration of } \\
\text { toxin }(\mu \mathrm{mol} / \mathrm{L})\end{array}$ \\
\hline Arsenic & 100 & 1.33 & 6.68 \\
\hline Cadmium & 100 & 0.89 & 4.45 \\
\hline Cobalt & 100 & 1.70 & 8.49 \\
\hline Copper & 100 & 1.57 & 7.87 \\
\hline Manganese & 100 & 1.82 & 9.10 \\
\hline Mercury & 100 & 0.50 & 2.50 \\
\hline
\end{tabular}

The selection of $500 \mathrm{Da}$ MWCO as the pore size of dialysis membrane would allow the exchange of only the free (not bound by algal toxins) metal ions between the outside and inside solution and keep the algal toxin molecules inside the dialysis bag. After the 
metal-toxin complex formed, it would also remain inside of the bag. In the meantime, the free metal ions could freely transfer between the inside and outside of the bag and reached equilibrium after a certain period of time. The addition of metal ions into the outside solution could reduce the possibility of disturbing the metal-toxin association equilibrium inside the dialysis bag. As the metal ion concentration in the outside solution was almost constant during the whole process of equilibrium dialysis, the association of the algal toxins with the metal ions inside the dialysis bag would not be influenced by the outside solution, making the data more accurate. Furthermore, the obvious variation of metal ion concentration in outside solution would not occur at the beginning of equilibrium dialysis as a large volume ratio (outside to inside solutions) (49:1) was selected. In other words, if the metal ions were spiked inside the dialysis bag, the decrease in free metal ion concentrations would change drastically inside the dialysis bag at the very beginning of the equilibrium dialysis. The concentration of metal ions would be highly diluted outside the dialysis bag, making measurement difficult.

Inductively coupled plasma mass spectrometry (ICP-MS) was used to determine the concentration of all metals (except mercury), while AFS was employed for the analysis of mercury. All metal samples $(50 \mu \mathrm{L})$ except mercury, were sampled from both inside and outside solutions and placed in $10 \mathrm{~mL}$ tubes and then spiked with the yttrium solution (125 $\mu \mathrm{L}, 1 \mathrm{ppm})$ as the internal standard followed by the addition of nitric acid (4825 $\mu \mathrm{L}, 2 \%)$. For mercury, sample solutions $(50 \mu \mathrm{L})$ were diluted to $2 \mathrm{~mL}$, and then $1 \mathrm{~mL}$ was taken and further diluted to $40 \mathrm{~mL}$ in tubes. All the samples were well mixed by hand shaking and covered with parafilm before analysis. 


\subsubsection{Results}

The conditional stability constants $\left(K_{c s c}\right)$ of the metal-toxin complexes were list in Table 7. The results indicate that PbTx-2 was incapable of forming complexes with all the selected metal ions. Microcytin-YR could form complexes with $\mathrm{Cd}^{2+}, \mathrm{Cu}^{2+}$ and $\mathrm{Hg}^{2+}$; pahayokilde A could form complexes with $\mathrm{Cd}^{2+}, \mathrm{Co}^{2+}, \mathrm{Cu}^{2+}$ and $\mathrm{Hg}^{2+}$, okadaic acid could form complexes with $\mathrm{Cd}^{2+}$ and $\mathrm{Cu}^{2+}$. An equilibrium dialysis model is shown in Figure 20.

\begin{tabular}{llllll}
\multicolumn{2}{l}{ Table 7. The conditional stability constants $\left(\boldsymbol{K}_{c s c}\right)$ of the metal-toxin complexes } \\
\hline \multirow{2}{*}{ Element } & $\mathrm{pH}$ & \multicolumn{4}{c}{ Conditional stability constants $\left(K_{c s c}\right)$} \\
\cline { 3 - 6 } & & $\mathrm{PbTx}-2$ & Microcystin-YR & Pahayokolide A & Okadaic acid \\
\hline Arsenic & 5.68 & $\mathrm{~N} / \mathrm{A}$ & $\mathrm{N} / \mathrm{A}$ & $\mathrm{N} / \mathrm{A}$ & $\mathrm{N} / \mathrm{A}$ \\
\hline Cadmium & 5.72 & $\mathrm{~N} / \mathrm{A}$ & $8.44 \times 10^{3}$ & $9.29 \times 10^{3}$ & $1.06 \times 10^{4}$ \\
\hline Cobalt & 5.74 & $\mathrm{~N} / \mathrm{A}$ & $\mathrm{N} / \mathrm{A}$ & $5.24 \times 10^{3}$ & $\mathrm{~N} / \mathrm{A}$ \\
\hline Copper & 5.74 & $\mathrm{~N} / \mathrm{A}$ & $2.29 \times 10^{4}$ & $5.31 \times 10^{3}$ & $6.28 \times 10^{3}$ \\
\hline Manganese & 5.71 & N/A & N/A & N/A & N/A \\
\hline Mercury & 5.76 & N/A & $6.92 \times 10^{4}$ & $4.70 \times 10^{4}$ & N/A \\
\hline
\end{tabular}

The conditional stability constants $\left(K_{c s c}\right)$ of toxin-metal complexes varied depending on the algal toxins and the metal ions. Generally, the $K_{c s c}$ could be expressed by the equation below:

$$
K_{c s c}=[\text { toxin-metal }] /[\text { toxin }][\text { metal }]
$$

where the [toxin], [metal] and [toxin-metal] were the concentrations of algal toxin, free metal ion and their complex respectively under the equilibrium conditions. The concentrations of algal toxin, free metal ion and their complex could be calculated using the following equations: 


$$
\begin{gathered}
{[\text { metal }]=\left[\frac{C_{o s}}{\mathrm{M}}\right] * 10^{-6}(\mathrm{~mol} / \mathrm{L})} \\
{[\text { toxin-metal }]=\left[\frac{C_{i s}-C_{o s}}{\mathrm{M}}\right] * 10^{-6}(\mathrm{~mol} / \mathrm{L})} \\
{[\text { toxin }]=\left[C_{T}-\frac{C_{i s}-C_{o s}}{\mathrm{M}}\right] * 10^{-6}(\mathrm{~mol} / \mathrm{L})}
\end{gathered}
$$

where $\mathrm{M}(\mathrm{g} / \mathrm{mol})$ is the atomic weight of the metal, $\mathrm{C}_{\mathrm{T}}(\mu \mathrm{mol} / \mathrm{L})$ is the total concentration of algal toxin, $\mathrm{C}_{\mathrm{is}}(\mu \mathrm{g} / \mathrm{L})$ and $\mathrm{C}_{\mathrm{os}}(\mu \mathrm{g} / \mathrm{L})$ are the concentrations of metal inside and outside the dialysis bag measured by using ICP-MS. Thus, the $K_{c s c}$ could be calculated using the following equation:

$$
K_{c s c}=\frac{C_{i s}-C_{o s}}{C_{o s}\left[C_{T}-\frac{C_{i s}-C_{o S}}{\mathrm{M}}\right] * 10^{-6}}(\mathrm{~L} / \mathrm{mol})
$$

The conditional stability constants of the algal toxin-metal ion complexes were calculated and listed in Table 7. N/A was placed in Table 7 if the toxin-metal complex was not formed. 
Table 8. The electron configuration, ionic radius, redox potential, electronegativity and strength of Lewis acid of the metal ion.

H: High spin; L: Low spin

\begin{tabular}{llllll}
\hline $\begin{array}{l}\text { Initial ion } \\
\text { speciation }\end{array}$ & $\begin{array}{l}\text { Electron } \\
\text { Configuration }\end{array}$ & $\begin{array}{l}\text { Ionic radius (pm) } \\
(\text { Wang and Feng 2004) }\end{array}$ & $\begin{array}{l}\text { Redox potential } \\
\left(E_{M}^{o}{ }^{2+}{ }_{M}\right)(\mathrm{V})(\text { Dean 1972) }\end{array}$ & $\begin{array}{l}\text { Electronegativity } \\
\text { of ion (Zhang 1982) }\end{array}$ & $\begin{array}{l}\text { Strengths of Lewis acid } \\
\text { (Zhang 1982) }\end{array}$ \\
\hline $\mathrm{HAsO}_{4}{ }^{2-}$ & - & - & - & 2.159 & - \\
\hline $\mathrm{Cd}^{2+}$ & {$[\mathrm{Kr}] 5 \mathrm{~s}^{0} 4 \mathrm{~d}^{10} 5 \mathrm{p}^{0}$} & 97 & -0.40 & 1.276 & -0.108 \\
\hline $\mathrm{Co}^{2+}$ & {$[\mathrm{Ar}] 4 \mathrm{~s}^{2} 3 \mathrm{~d}^{5} 4 \mathrm{p}^{0}$} & $65(\mathrm{~L}) 74(\mathrm{H})$ & -0.28 & 1.377 & 0.356 \\
\hline $\mathrm{Cu}^{2+}$ & {$[\mathrm{Ar}] 4 \mathrm{~s}^{0} 3 \mathrm{~d}^{9} 4 \mathrm{p}^{0}$} & 73 & +0.34 & 1.372 & 0.177 \\
\hline $\mathrm{Fe}^{3+}$ & {$[\mathrm{Ar}] 4 \mathrm{~s}^{0} 3 \mathrm{~d}^{5} 4 \mathrm{p}^{0}$} & $58(\mathrm{~L}) 65(\mathrm{H})$ & - & 1.390 & 1.311 \\
\hline $\mathrm{Fe}^{2+}$ & {$[\mathrm{Ar}] 4 \mathrm{~s}^{0} 3 \mathrm{~d}^{6} 4 \mathrm{p}^{0}$} & $61(\mathrm{~L}) 71(\mathrm{H})$ & -0.44 & 1.326 & -1.063 \\
\hline $\mathrm{Hg}^{2+}$ & {$[\mathrm{Xe}] 6 \mathrm{~s}^{0} 4 \mathrm{f}^{14} 5 \mathrm{~d}^{10} 6 \mathrm{p}^{0}$} & 110 & +0.796 & 1.343 & 0.307 \\
\hline $\mathrm{Mn}^{2+}$ & {$[\mathrm{Ar}] 4 \mathrm{~s}^{0} 3 \mathrm{~d}^{5} 4 \mathrm{p}^{0}$} & $67(\mathrm{~L}) 82(\mathrm{H})$ & -1.18 & 1.367 & 0.293 \\
\hline $\mathrm{Ni}^{2+}$ & {$[\mathrm{Ar}] 4 \mathrm{~s}^{0} 3 \mathrm{~d}^{8} 4 \mathrm{p}^{0}$} & 70 & -0.23 & 1.476 & 0.624 \\
\hline $\mathrm{Sb}^{3+}$ & {$[\mathrm{Kr}] 5 \mathrm{~s}^{2} 4 \mathrm{~d}^{10} 5 \mathrm{p}^{0}$} & 76 & - & 1.336 & 0.656 \\
\hline $\mathrm{Zn}^{2+}$ & {$[\mathrm{Ar}] 4 \mathrm{~s}^{0} 3 \mathrm{~d}^{10} 4 \mathrm{p}^{0}$} & 75 & -0.76 & & \\
\hline
\end{tabular}




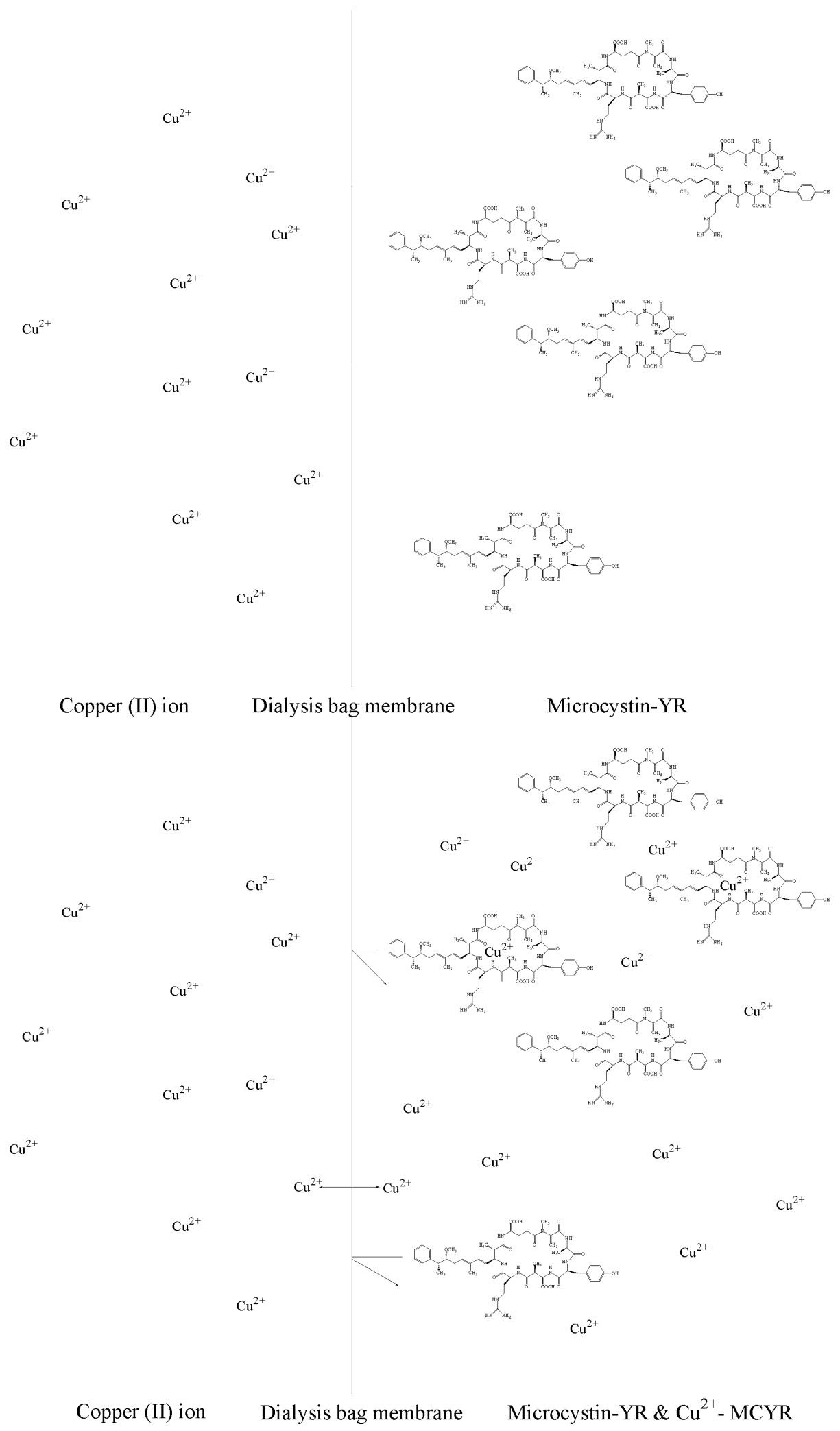

Figure 20. Equilibrium dialysis model 


\subsection{Determination of distribution ratio of iron using ultrafiltration technique}

\subsubsection{Procedures}

A centrifugal ultrafiltration technique was employed for studying the toxin-iron interactions due to the difficulty of using equilibrium dialysis method. $\mathrm{As} \mathrm{Fe}^{2+}$ has the potential to be oxidized to $\mathrm{Fe}^{3+}$, decrease in the exposure time of $\mathrm{Fe}^{2+}$ in air would reduce the oxidization. Microsep ${ }^{\mathrm{TM}}$ Centrifugal Devices with a molecular weight cutoff (MWCO) of 1000 Dalton were used to characterize the toxin-Fe ${ }^{2+}$ complexes. The optimized centrifugal force and the length of time were obtained according to the manual of the device. Three combinations of different centrifugal force $(\mathrm{g})$ and length of time (min) were tested to find an optimal condition at which ferrous ion had the highest recovery. The recovery was calculated using the following equation:

$$
\text { Recovery }=\left(\mathrm{C}_{\mathrm{s}} \mathrm{M}_{\mathrm{s}}+\mathrm{C}_{\mathrm{f}} \mathrm{M}_{\mathrm{f}}\right) / \mathrm{C}_{0} /\left(\mathrm{M}_{\mathrm{s}}+\mathrm{M}_{\mathrm{f}}\right) * 100 \%
$$

Where $C_{s}(\mu g / L)$ and $C_{f}(\mu g / L)$ were the concentration of iron in the sample reservoir and filtrate receiver, respectively; $\mathrm{M}_{\mathrm{s}}(\mathrm{g})$ and $\mathrm{M}_{\mathrm{f}}(\mathrm{g})$ were the mass of solutions in the sample reservoir and filtrate receiver, respectively.

The fresh ferrous ion solution with a concentration of $100 \mathrm{ppb}$ was prepared by hydrochloric acid $(\mathrm{pH}=4.93)$ in order to avoid the precipitation of $\mathrm{Fe}^{2+}$. A total of $3 \mathrm{~mL}$ solution composed of $\mathrm{Fe}^{2+}$ solution $(2660 \mu \mathrm{L})$ and methanol $(40 \mu \mathrm{L})$ for method optimization or algal toxin solution $(40 \mu \mathrm{L})$ for determination of toxin- $\mathrm{Fe}^{2+}$ complexes ware pipetted into sample reservoir and then a cap was placed on the reservoir in order to prevent evaporation and loss during centrifugation. The centrifugal device tube was hand-shaken for $5 \mathrm{~min}$ and then placed into the Marathon 21000R centrifuge and the samples were centrifuged using the three different conditions listed in Table 9. After 
centrifugation, $0.5 \mathrm{~mL}$ liquid samples from both the sample reservoir and filtrate receiver were transferred separately to different tubes using a pipette. Nitric acid $(2 \%, 2900 \mu \mathrm{L})$ and internal standard yttrium solution $(1 \mathrm{ppm}, 100 \mu \mathrm{L})$ were added to the tubes and then covered with parafilm until analysis. All the experiments were performed in duplicate.

\subsubsection{Results}

According to the recovery results listed in Table 9, the optimized centrifugal force and the length of time were set to 5,000 $\mathrm{g}$ and $30 \mathrm{~min}$, respectively.

\begin{tabular}{|c|c|c|c|c|}
\hline Group & $\begin{array}{l}\text { Length of } \\
\text { time (min) }\end{array}$ & $\begin{array}{l}\text { Centrifugal force } \\
\text { (g) }\end{array}$ & Recovery (\%) & $\begin{array}{c}\text { Distribution ratio } \\
\text { of iron }\left(K_{d}\right)\end{array}$ \\
\hline 1 & 20 & 7000 & 79 & 1.83 \\
\hline 2 & 30 & 5000 & 84 & 1.89 \\
\hline 3 & 45 & 3000 & 76 & 3.19 \\
\hline Microcystin-YR & 30 & 5000 & 85 & 2.31 \\
\hline Pahayokolide A & 30 & 5000 & 85 & 5.61 \\
\hline Okadaic acid & 30 & 5000 & 79 & 8.31 \\
\hline
\end{tabular}

A distribution ratio of iron, defined as $K_{d}=\mathrm{C}_{\mathrm{s}} \mathrm{M}_{\mathrm{s}} / \mathrm{C}_{\mathrm{f}} \mathrm{M}_{\mathrm{f}}$, was used for characterizing the interaction of iron with algal toxins. The result of ultrafiltration experiment showed that the distribution ratio of iron changed with the addition of algal toxin (Table 9). Assuming the free $\mathrm{Fe}^{2+}$ was capable of penetrating into the filtrate receiver freely in the control group (group 1, 2 and 3), the formation of toxin- $\mathrm{Fe}^{2+}$ complex would result in a portion of free $\mathrm{Fe}^{2+}$ being trapped on the sample reservoir rather than being filtered into the receiver. Once the ratio of the quantity of iron in these two sections was calculated, the roles of the algal 
toxins played in this process could be assessed.

The following conclusions could be obtained: 1) both the centrifugal force and the length of time of the centrifugation would affect the $K_{d} ; 2$ ) the addition of algal toxin would affect the distribution of the free $\mathrm{Fe}^{2+}$; and 3) the effects of the algal toxin on the distribution of $\mathrm{Fe}^{2+}$ were various depending on the types of toxins. All three algal toxins showed affinities to $\mathrm{Fe}^{2+}$, as indicated by the increase in $K_{d}$ with the addition of algal toxins. However, as the molarities of toxins added into the sample reservoir were different, it is difficult to compare the affinities of these toxins to the $\mathrm{Fe}^{2+}$ ion.

\subsection{Discussion on metal-toxin complexation}

The results have shown that the stability of the toxin-metal complexes varied depending on both the algal toxins and the metal ions used in the experiments. A number of factors and parameters could affect the stability of these toxin-metal complexes. These factors may include the radii of metal ion, the Lewis acid-base properties, atomic sub-shell structure and redox potential of metals, the toxin's radii of cavity in some cyclic polypeptides, the functional groups present in the toxins, and the accessibility of these functional groups. The effects of some of these factors on the stability of metal-toxin complexes are discussed below.

\subsubsection{Effects of ionic radius of metals and cavity radius of toxin molecules}

Previous work demonstrated that cyclic peptides, for example microcystins, could be functioning as the ligands by enveloping the metal ion in a two- or three-dimensional cavity. Moreover, the configuration analysis of one of these complexes indicated that the minimum energy configuration of the metal ion binding to microcysin-LR was located in the cavity region (Yan et al. 2000). The minimum energy implied that the most stable 
complex compound would form as the favorable configuration. In the current study, both microcystin-YR and pahayokolide A (cyclic peptides) were capable of forming the cavity through the conformational changes. Previous work has shown that the transition metal cations, such as $\mathrm{Cu}^{2+}, \mathrm{Co}^{2+}, \mathrm{Cd}^{2+}, \mathrm{Fe}^{2+}$ and $\mathrm{Mn}^{2+}$, were favorable to form an octahedral for six-coordination (Kertesz and Hoffmann 1984; Halasyamani 2004). If the cavity of the toxin molecule was larger or smaller compared to the volume of the metal ions, it would be hard for the toxin to bind with the metal ions in order to form a stable structure. Although the size of the cavity formed by algal toxin molecules could not be measured in the current work, the results of the experiment indicated that the algal toxin molecules tended to chelate with the small metal cations, especially $\mathrm{Cu}^{2+}$. The size of the cavity could be estimated to be approximately $4.89 \AA$ by summing up the lengths of coordination bond of $\mathrm{Cu}(\mathrm{II})-\mathrm{N}(1.75 \AA$ ) and $\mathrm{Cu}(\mathrm{II})-\mathrm{O}(1.68 \AA$ ) (Thorp 1992) (supposing that both the nitrogen and oxygen atoms participated in the binding with the copper(II) ion) as well as the radius of the copper(II) ion. In this case, if the radii of the ions were too large, for example, as in the case of the manganese(II) ion where the radius was more than 30\% larger than that of the copper(II) ion's, the formation of complexes with these specific algal toxin molecules would be impossible or if formed, the complex would be unstable.

\subsubsection{Effects of $d$-orbital electron configuration of metal cations}

Half a century ago, Irving and Williams (1953) proposed a theory to explain the relative stabilities of the complexes of the transition metals, particularly, for these six metals of interest, the order would be as follows:

$$
\mathrm{Mn}(\text { II) }<\mathrm{Fe}(\text { II) }<\mathrm{Co}(\text { II) }<\mathrm{Ni}(\text { II) }<\mathrm{Cu}(\text { II) }>\mathrm{Zn}(\text { II) }
$$

In the current work, four of them, $\mathrm{Mn}^{2+}, \mathrm{Fe}^{2+}, \mathrm{Co}^{2+}$ and $\mathrm{Cu}^{2+}$ were selected to 
determine their capability of complexing with algal toxin molecules. Except for $\mathrm{Fe}^{2+}$, in which case quantitated data could not be obtained for comparison, the formed complexes of the other three metal cations agreed well with the order above. The results indicate that the stability of the toxin-metal complexes follows the order below:

$$
\text { toxin- } \mathrm{Cu}^{2+}>\text { toxin- } \mathrm{Co}^{2+}>\text { toxin- } \mathrm{Mn}^{2+}
$$

$\mathrm{Cu}^{2+}$ could complex with three algal toxin molecules with a strong affinity while the $\mathrm{Mn}^{2+}$ could in theory only form weak complexes with toxin molecules, and their existence could not be confirmed (they could not be detected). Cobalt(II) ion could form a relatively stable complex with one of the toxin molecules which could be determined. The stability of these toxin-metal complexes could be explained by the crystal field theory (CFT) (Donia and El-Boraey 1997). The CFT is based on that electrostatic interaction exists between the central metal ion and the ligands. The stability of the complexes is related to their crystal field stabilization energy (CFSE), which resulted from placing a transition metal ion in the crystal field generated by a set of ligands. The CFSE increases from Mn(II) to Ni(II) corresponding to the stability of their complexes with algal toxin molecules which serve as the ligands in the formed complex. The CFSE of copper(II) is lower than that of nickel(II), however, the octahedral copper(II) complexes are subject to the Jahn-Teller effect therefore enhance the stability of complex by formation of four short bonds and two long bonds resulting from the distortion of the $d$-orbitals. Since the electron configuration of $\mathrm{Fe}^{3+}$ and $\mathrm{Mn}^{2+}$ are the same, their behavior in the crystal field would be similar; and it could be helpful to explain why the formation of microcystin- $\mathrm{Fe}^{3+}$ complex was not detectable (Saito et al. 2008). Although the work was not performed to determine the stability of the complex formed by toxin molecules with $\mathrm{Ni}(\mathrm{II})$ and $\mathrm{Zn}(\mathrm{II})$, the stability of the toxin- $\mathrm{Ni}^{2+}$ 
and toxin- $\mathrm{Zn}^{2+}$ could be predicted according to the Irving and Williams series.

In the case of $\mathrm{Hg}^{2+}$ and $\mathrm{Cd}^{2+}$, which belong to group 12, their $d$-orbitals, $4 d$ and $5 d$ respectively, are fully occupied with no incomplete $d$ sub-shell. Once they form complexes with toxin molecules, the electrons originating from the $\mathrm{N}$ or $\mathrm{O}$ atoms would occupy $s$-orbitals, and as a consequence, the formation of these complexes are favorable and are stable as a result of the decreases of the shielding effect of electrons occupied in the $d$ and $f$ orbitals to the nucleus and increases of the attractive force of the nucleus to the electrons in the $s$-orbital (inert pair effect).

\subsubsection{Effects of structures and functional groups of algal toxin molecules}

The results have shown that $\mathrm{PbTx}-2$, a polyether compound, in this experiment could not form any detectable complex with the selected metals. It could be explained by the fact that the hydroxyl group contained in the molecule is incapable of complexing with metal ions. On the other hand, the three other algal toxin molecules that contain phenol, carboxyl, and amino groups showed the ability to form metal complexes. Especially, for microcystin-YR and pahayokolide A, it was found that they readily complex with metal ions. The stability of these cyclic toxins-metal complexes could be attributed to their cyclic structures which play an important role in forming the complexes by applying six coordinators to the metal ions making it more stable(Yan et al. 2000). The results indicated that cobalt(II) ion $\left(\mathrm{Co}^{2+}\right)$, which has a relatively higher CFSE, was capable of complexing with pahayokolide A, a large cyclic molecule. Moreover, it has been observed that some of these selected metals could also complex with okadaic acid which is a linear toxin molecule rather than a cyclic one. The complexation of okadaic acid with the metal cation could be attributed to the presence of the hydroxyl and carboxyl groups in the molecule, 
especially the latter, as it had a strong affinity to metal cation after its deprotonation. Furthermore, due to the inert pair effect of mercury, the result of its specific electron configuration, the strong affinity of toxin molecule to mercury(II) ion $\left(\mathrm{Hg}^{2+}\right)$ could be attributed to the presence of phenol group in the microcystin-YR in addition to the hydroxyl and the carboxyl groups that are present in the pahayokolide A. These binding

sites have the potential to lead to the formation of stable toxin- $\mathrm{Hg}^{2+}$ complexes because of the occupancy of $6 s$-orbital of mercury by the incoming electrons from the toxin molecules resulted in an even more stable electron configuration of mercury.

\subsubsection{Effects of redox potential of metals}

According to the generalized oxidation-reduction theory, the density of electron cloud of the atoms would be re-distributed when the chemical reaction occurred (Gong et al. 2004). Therefore, the formation of toxin-metal complex was not a classical oxidation-reduction reaction; the oxidation state of the central atom (metal cation) and the ligands (coordination atoms) would be changed during the process of the electrons transfer. The electrode potential of the overall reaction depends on the half-cell reactions related to both the electron(s) donor strength of the toxin molecule and the electron(s) acceptor strength of metal cation. As a given algal toxin molecule, the relative magnitude of overall reaction electrode potential depends on the redox potential of half-cell reactions of the metal cation. The formation of the toxin-metal complex occurs when the metal cation accepts the electron(s) as the anode while the oxygen or nitrogen group donates the electron(s) as the cathode. Suppose the values of the electrode potential of these metal cations in the formation of the toxin-metal complexes were directly proportional to their standard electrode potential. Therefore, the conditional stability constants $\left(K_{c s c}\right)$ could be 
expressed as the equation below which built up a relationship between the difference of the electrode potential and the equilibrium constant $(K)$ the value of which was equal to that of $K_{c s c}$

$$
\begin{gathered}
\Delta G=-R T \ln K \\
\Delta G=-\mathrm{n} \Delta E F=-\mathrm{n}\left(\varphi_{O x}-\varphi_{R e d}\right) F \\
\mathrm{n}\left(\varphi_{O x}-\varphi_{R e d}\right) F=R T \ln K
\end{gathered}
$$

where the $\Delta G$ is the change of Gibbs free energy of the reaction, $R$ is the universal gas constant $\left(8.314 \mathrm{~J} \cdot \mathrm{K}^{-1} \cdot \mathrm{mol}^{-1}\right), T$ is the absolute temperature $(\mathrm{K}), \Delta E$ is the change of the standard electrode potential at the temperature of interest, $\varphi_{O x}$ is the redox potential of the oxidant, $\varphi_{\text {Red }}$ is the redox potential of the reductant, $\mathrm{n}$ is the number of electrons transferred and $F$ is the Faraday's constant $\left(96485 \mathrm{C} \cdot \mathrm{mol}^{-1}\right)$.

The redox potential of mercury and copper is summarized in Table 7. Both have a positive redox potential value, thus these metal cations have a great tendency to accept electron(s) and thereby be reduced. In other words, the mercury ion(II) $\mathrm{Hg}^{2+}$ and copper(II) $\left(\mathrm{Cu}^{2+}\right)$ accepted electron(s) from toxin molecules resulting in the formation of stable complex compounds. The results have shown that $\mathrm{Cu}^{2+}$ complexed with all the toxins except $\mathrm{PbTx}-2$ (see Table 7). Moreover, $\mathrm{Hg}^{2+}$, as the metal cation whose redox potential value was the largest amongst the selected metal cations, was able to form more stable complexes with the algal toxins, as evidenced by the higher conditional stability constants of the $\mathrm{Hg}^{2+}$-toxin complexes. On the other hand, $\mathrm{Mn}^{2+}$, as the metal cation with the smallest redox potential in the experimental group, could not show any capability of forming the complex with the algal toxin molecules. 


\subsubsection{Effects of softness-hardness of metal cations}

No large difference in ionic electronegativity of the metal ions was found (Table 7). Thus it appears that the ionic electronegativity of metal ions would not be directly related to the stability of the complexes. However, the ionic electronegativity, one of the most important parameters of the cations, relates to the Lewis acid strength ( ) which could be calculated from the following equation:

$$
=\mathrm{z} / \mathrm{r}_{\mathrm{k}}^{2}-7.7 \mathrm{X}_{\mathrm{z}}+8.0
$$

where $\mathrm{z}$ is the charge number of the atomic core, $\mathrm{r}_{\mathrm{k}}$ is the ionic radius and $\mathrm{X}_{\mathrm{z}}$ is the electronegativity of elements in valence states (Zhang 1982).

The metal cations were generally thought as the Lewis acid in the Lewis acid-base electron-pair theory. Because of the characters of the outer-shell electron configuration of the metal cations, the algal toxin molecules were capable of donating the electron pair(s) to occupy the empty orbitals. The unfilled orbitals or the unpaired electrons (lone electron) of the metal cations have the potential to accept the electron(s) from the toxin molecules. Some functional groups, such as amino, carboxyl, phenol and hydroxyl, are generally the moieties present in algal toxins. These groups can act as the Lewis base by the way of donating electron(s) to the Lewis acid resulting in the formation of conjugate acid-base pair. In order to form the Lewis base, these moieties need to be deprotonated in the aqueous media. Deprotonation was favorable to occur under strong basic condition in order to stabilize the Lewis base once it formed. However, in the presence of the metal cations, the deprotonized compound could form and be stabilized by attacking the electrophilic metal cations surrounding it.

For a given algal toxin, the stability of its complexes with the metal cations depends on 
the electron-acceptor strength of the metal cations, namely Lewis acid strength. The results have shown that the $\mathrm{Cd}^{2+}, \mathrm{Cu}^{2+}$ and $\mathrm{Hg}^{2+}$, which served as the soft Lewis acids, exhibited strong affinities with the selected algal toxin molecules. On the other hand, $\mathrm{Co}^{2+}$, as a borderline cation, whose Lewis acid strength was between the soft and hard in the Pearson classification (Zhang 1982), exhibited a weak affinity toward the toxin molecules and could only be capable of binding with one of the selected toxin molecules. Moreover, it could be easier to explain why the $\mathrm{Fe}^{2+}$ was able to bind with microcystin while $\mathrm{Fe}^{3+}$ failed to form the complex with microcystin by applying the soft-hard acid-base theory and using the data of Lewis acid strengths of $\mathrm{Fe}^{3+}$ and $\mathrm{Fe}^{2+}$ ions.

\subsubsection{Effects of ionic species}

The result indicated that the arsenate $\left(\mathrm{HAsO}_{4}{ }^{2-}\right)$, the only anion tested in this work, showed no affinity to any of the selected algal toxins. All the previously published articles focused on the algal toxin interacting with metal cations and it was the first time involving an anion in this study. As both the arsenate and toxin molecules were potentially negatively charged species, it could be predicted that the formation of complex between them would be difficult. The arsenic speciation analysis demonstrated that inorganic arsenate (iAs ${ }^{\mathrm{V}}$ ) was the only arsenic species present in both inside and outside solution and the conversion of iAs ${ }^{\mathrm{V}}$ to iAs ${ }^{\mathrm{III}}$ did not occurred. The coexistence of arsenate with the selected algal toxins in our experiment could not cause the arsenic speciation conversion during the equilibrium dialysis. This result was supportive of the conclusion that the $\mathrm{As}^{\mathrm{V}}$ was unable to bind with the toxin as an anionic specie.

\subsubsection{Comparison with previous studies}

The $K_{c s c}$ values of toxin-metal complexes obtained in the current work were lower than 
previously reported in the literature. The following may help to explain these deviations from the current literature results: 1) the matrices employed in the experiments were different; 2) the sensitivity of the methods in characterizing the complexes was not the same; 3) the manners in the expression and calculations of conditional stability constants were different.

The compositions of matrix used have a great effect on the experimental results. One of the most important factors is $\mathrm{pH}$. The previous studies have shown that the stability of the labile compounds, for example the toxin-metal complex, was vastly affected by $\mathrm{pH}$ of the system (Humble et al. 1997). The effects of $\mathrm{pH}$ could affect both the algal toxin molecules and the metal cations. First of all, the binding sites of the toxin molecules could be blocked by lowering the $\mathrm{pH}$. Each of the twenty different natural amino acids and their side chains has its own $p K_{a}$ values and their speciation could be affected by changing the $\mathrm{pH}$. The amino, carboxyl, nitrogen and oxygen groups which are generally present in the toxin molecules would be incapable of forming the deprotonated species or have the potential to be re-protonated as a result of lowering the $\mathrm{pH}$. Moreover, the toxin-metal complexes, although were able to form, would be unstable and have the potential to be decomposed through the solvent effects caused by the high concentration of the hydrate ion $\left(\mathrm{H}^{+}\right)$resulting in substituting the $\mathrm{H}^{+}$for metal cation and leading to the formation of the toxin-metal complex reversibly. Assume the processes of complexation occurred by a two -step reaction:

$$
\begin{gathered}
\mathrm{T}+\mathrm{H}_{2} \mathrm{O} \rightarrow \mathrm{T}^{-}+\mathrm{H}_{3} \mathrm{O}^{+} \\
\mathrm{T}^{-}+\mathrm{M} \rightarrow \mathrm{T}-\mathrm{M}
\end{gathered}
$$


First of all, the toxin molecule needs to be deprotonated and form the negatively charged species. Secondly, the deprotonated toxin molecule forms complex compounds with metal ions. The equilibrium constants for these reactions could be described as below:

$$
\begin{aligned}
& K_{l}=\left[\mathrm{T}^{-}\right]\left[\mathrm{H}_{3} \mathrm{O}^{+}\right] /[\mathrm{T}] \\
& K_{2}=[\mathrm{T}-\mathrm{M}] /\left[\mathrm{T}^{-}\right][\mathrm{M}]
\end{aligned}
$$

Thus,

$$
K_{1} K_{2}=[\mathrm{T}-\mathrm{M}]\left[\mathrm{H}_{3} \mathrm{O}^{+}\right] /[\mathrm{M}][\mathrm{T}]
$$

The conditional stability constant $\left(K_{c s c}\right)$ could be described as

$$
K_{c s c}=[\mathrm{T}-\mathrm{M}] /[\mathrm{M}][\mathrm{T}]=K_{1} K_{2} /\left[\mathrm{H}_{3} \mathrm{O}^{+}\right]
$$

Since the $\mathrm{pH}=-\log \left[\mathrm{H}_{3} \mathrm{O}^{+}\right]$, the modified equation of $K_{c s c}$ could be obtained as

$$
K_{c s c}=K_{1} K_{2} * 10^{\mathrm{pH}}
$$

From the above equation, the relationship between $K_{c s c}$ of the toxin-metal complex and $\mathrm{pH}$ of the solution could be quantified. With the increase of one $\mathrm{pH}$ unit, the $K_{\text {csc }}$ increases ten times. Therefore, high $\mathrm{pH}$ condition is favorable to form more stable complexes. In the current work, the selected $\mathrm{pH}$ was about 5.7, which is normally lower than the $\mathrm{pH}$ value of the natural aquatic environment. In this case, the conditional stability constant of the toxin-metal complexes obtained in this work would be increased by several order of magnitude (to $10^{5}-10^{6}$ ) if $\mathrm{pH}$ effects is considered. The previous works have shown that the humic substances could complex with some metal ions (in the order of magnitude about $10^{5}-10^{6}$ ) and significantly affect their transformation, transport and biological uptake processes in the environment (Mohapatra et al. 2006; Hirose 2007; Ko et al. 2007; Selwood 
et al. 2007). Therefore, it is expected that the presence of algal toxins in aquatic environment could also play a role in trace metal cycling.

The previous experiments were mainly conducted using electrochemical methods, for example, polarography and voltammetry (Humble et al. 1997; Yan et al. 2000). In brief, both of the electrochemical methods were established for measuring the differences of the currents with or without addition of the microcystins. The principle of these electrochemical methods was the charge transfer during the oxidation caused by the formation of the toxin-metal complex. Because of the complexation of algal toxin with metal cation, the redox potential of the metal cation would become higher than that of the free species. Nuclear magnetic resonance (NMR) (Saito et al. 2008) and mass spectrometry (MS) (Norte et al. 1998) were also employed to qualitatively study the complexation of the algal toxin with the metal cation in the previous studies. In the current work, the traditional equilibrium dialysis was used to determine the differences of the metal ion concentration in both the inside and the outside solutions. Moreover, the ultrafiltration device was employed to study the toxin- $\mathrm{Fe}^{2+}$ complexes.

The variation of methods could lead to different results. Therefore, differences in expression and values of the stability constants could be found from the literature (Table 1). Consequently, it is very difficult to compare these results. Unlike the previous work, in which the studies only focused on the limited species of algal toxins and ions, the current study took a view of a group of different algal toxins and a series of metal ions.

\subsection{Summary}

The results of this study indicate that $\mathrm{PbTx}-2$ is incapable of forming complexes with

all selected metal ions. Microcytin-YR could form complexes with $\mathrm{Cd}^{2+}, \mathrm{Cu}^{2+}$ and $\mathrm{Hg}^{2+}$; 
pahayokolide A could form complexes with $\mathrm{Cd}^{2+}, \mathrm{Co}^{2+}, \mathrm{Cu}^{2+}$ and $\mathrm{Hg}^{2+}$; okadaic acid could form complexes with $\mathrm{Cd}^{2+}$ and $\mathrm{Cu}^{2+}$.

Some of the algal toxins were studied for their complexation with metals for the first time. For example, pahayokolide A, one of the recently isolated compounds, and brevetoxin ( $\mathrm{PbTx}-2$ used in this study) were studied for the first time for their complexation with metals. Although microcytins have been studied by a few research groups (Humble et al. 1997; Yan et al. 2000; Saito et al. 2008; Norte et al. 1998), complexation of microcystin-YR with metal ions has never been previously studied. In addition to metal ions, metalloid, such as anion $\mathrm{HAsO}_{4}{ }^{2-}$ was also included in the current study.

This comprehensive study of the complexation of algal toxins with metal ions would be helpful to predict the interactions of these algal toxins with other elements. The stability constants of these complexes could be used to evaluate the toxicity of these contaminants when they co-occur in aquatic environments. Previous studies have shown that the sorption of humic substances on solid particles may reduce or increase the sorption of metals depending on the specific environmental conditions (Mohapatra et al. 2006; Hirose 2007; Ko et al. 2007; Selwood et al. 2007). Similarly, it is likely to observe a similar phenomenon with algal toxins because they contain similar functional groups as humic substances. The alteration in distribution of algal toxins and metals among dissolved phases could significantly affect their transformation, transport and biological uptake processes because the dissolved species is generally the reactive and bioavailable form that can be taken up (Schild and Moczydlowski 1991; Stevens and Krieger 1991; Koukal et al. 2007; Bouillon et al. 2008). It has been reported that both algal toxins and metals could be accumulated in 
biological tissue, such as fish body through food chains and reach harmful levels (Cullen et al. 1994; Mason et al. 1995; Downs et al. 1998; Watras et al. 1998; Mehra et al. 2010). Interactions between algal toxins and toxic metals could alter the bioaccumulation of toxins and/or metal ions and consequently affect the toxicity of algal toxins and/or toxic metals. 


\section{CHAPTER 3}

\section{THE EFFECTS OF ARSENIC AND COPPER ON \\ THE GROWTH OF KARENIA BREVIS}

\subsection{Introduction}

As a secondary metabolic product, algal toxins have been widely investigated because of their toxicity which threaten the health of humans and survival of other animals (Pierce et al. 2003; Plakas et al. 2004; Pierce et al. 2005; Plakas and Dickey 2010). The triggers of algal toxin production by algal species remain unclear currently, however, previous studies have shown that the toxin-producing ability of the specific algal species were likely to be affected by various environmental factors, including temperature, $\mathrm{pH}$, lumination, salinity, nitrate, phosphate, metals and even microgravity (Vezie et al. 2002; Gouvea et al. 2008; Gong et al. 2009; Gong et al. 2009; Li et al. 2009; Qian et al. 2010; Xiao et al. 2010).

The input of metals leading to changes in the environmental conditions has been shown to have effects on production of algal toxins by some researchers (Gouvea et al. 2008; Gong et al. 2009; Gong et al. 2009; Li et al. 2009; Qian et al. 2010). The behavior of algal species responding to metal exposure could be explained by the acquisition of nutritional metals, such as iron, or detoxification of toxic metals, such as copper, or the result of responding to the environmental stress caused by metals (Humble et al. 1997; Rue and Bruland 2001; Maldonado et al. 2002; Gouvea et al. 2008; Li et al. 2009). Gong et al. (2009) reported that microcystis strain PCC7806 could tolerant arsenic up to $10^{-4} \mathrm{M}$ in its growth conditions (Gong et al. 2009). Kenefick et al. (2009) demonstrated that copper sulfate could induce the loss of cell wall integrity of $M$. aeruginosa and accelerated the release of microcystin-LR into the medium. The influence of trace metals on the growth 
and toxin production of M. aeruginosa were studied by Lukac and Aegerter (1993). They demonstrated that zinc was required for optimal growth as well as toxin production to the selected microcystis strain, M. aeruginosa PCC 7806 while aluminum, cadmium, chromium, copper, manganese, nickel and tin did not significantly affect toxin yield below tolerable concentrations of metals. In addition, they found that iron affect M. aeruginosa growth and toxin production. More interestingly, they observed that the cell grew much more slowly in the absence or at low concentrations of iron (lower than $2.5 \mu \mathrm{M}$ ); however, the toxin production was increased by $20-40 \%$. In contrast to these findings, Utkilen and Gjolme (1995) observed that the toxin content increased while the iron concentration increased by treating a different M. aeruginosa strain (CYA 228/1).

In this work, arsenic and copper were selected as the representative elements becaue: 1) Arsenic as an anion in form of arsenate $\left(\mathrm{AsO}_{4}{ }^{3-}\right)$ while copper as a cation in form of copper(II) $\left.\left(\mathrm{Cu}^{2+}\right) ; 2\right)$ arsenic is generally thought of as toxic element and exists in many different chemical species in aquatic environments. The four major species include two inorganic species arsenite (iAs $\left.{ }^{\prime \prime \prime}\right)$ and arsenate $\left(\mathrm{iAs}^{\mathrm{V}}\right)$, and two organic species, monomethylarsonic acid (MMA) and dimethylarsinic acid (DMA). The species of arsenic could be transformed under different chemical and biological conditions in the environment. Since arsenic pollution is prominent environmental issues in global water pollution (Mazumder et al. 1988), it is important to understand the effects of arsenic on $K$. brevis growth and toxin production to assess potential ecological risk of arsenic pollution with the harmful algal blooms of $K$. brevis; 3) As a common element in aquatic environment, copper ion $\left(\mathrm{Cu}^{2+}\right)$ has been well studied for its ecological effects and toxicity. 
A very low $\left(10^{-9} \mathrm{M}\right)$ concentration of $\mathrm{Cu}^{2+}$ could have highly toxic to marine organisms. Besides, copper (II) sulfate $\left(\mathrm{CuSO}_{4}\right)$ is widely used as an economical, effective algaecide. Brevetoxin ( $\mathrm{PbTx}-2)$, used in current study, a dominant brevetoxin type, was isolated from K. brevis during its exponential growth period. As mature cell of K. brevis is about 20-40 $\mu \mathrm{m}$ in diameter, it can be counted easily by Z1 coulter particle counter (Beckman coulter, GMI Inc., MN) to evaluate the growth rate. The objective of my work was to determine the effects of arsenic and copper on the growth of $K$. brevis.

\subsection{Experimental}

\subsubsection{Instrumentation}

A Z1 coulter particle counter (Beckman coulter, GMI Inc., MN) was used for counting cells or particles in the 1 to 120 micron size range by electrical sensing zone technique. This instrument is based on the measurable changes in electrical resistance produced by non-conductive particles suspended in an electrolyte. A small opening aperture between electrodes where the suspended particles pass through was the sensing zone. Every single cell displaced its own volume of electrolyte measuring as a voltage pulse in the sensing zone. The height of the each pulse was proportional to the volume of the cell.

\subsubsection{Chemicals and reagents}

All reagents used were of analytical level. Sodium arsenate heptahydrate $\left(\mathrm{Na}_{2} \mathrm{HAsO}_{4} \cdot 7 \mathrm{H}_{2} \mathrm{O}\right)$ and copper (II) sulfate pentahydrate $\left(\mathrm{CuSO}_{4} \cdot 5 \mathrm{H}_{2} \mathrm{O}\right)$ were purchased from Fisher Scientific (Fairlawn, NJ, USA). Z-TRI-PAK solution, as the electrolyte solution, was purchased from Beckman Coulter. All glassware was soaked in 10\% $\mathrm{HNO}_{3}$ overnight and then thoroughly rinsed with DDI water (18.2 mega-ohm $\cdot \mathrm{cm}$, Barnstead Nanopure Diamond Lab Water System). 
Table 10. Artificial seawater for RE media

\begin{tabular}{|c|c|c|c|}
\hline \multicolumn{4}{|c|}{ Artificial seawater for RE media } \\
\hline Salt & \multicolumn{2}{|l|}{ Molarity } & Quantity (g) for $2 \mathrm{~L}$ \\
\hline $\mathrm{NaCl}$ & \multicolumn{2}{|l|}{$400 \mathrm{mM}$} & 46.76 \\
\hline $\mathrm{KBr}$ & \multicolumn{2}{|l|}{$1.7 \mathrm{mM}$} & 0.4 \\
\hline $\mathrm{KCl}$ & \multicolumn{2}{|l|}{$10 \mathrm{mM}$} & 1.5 \\
\hline $\mathrm{MgSO}_{4} \cdot 7 \mathrm{H}_{2} \mathrm{O}$ & \multicolumn{2}{|l|}{$20 \mathrm{mM}$} & 9.86 \\
\hline $\mathrm{MgCl}_{2} \cdot 6 \mathrm{H}_{2} \mathrm{O}$ & \multicolumn{2}{|l|}{$20 \mathrm{mM}$} & 8.12 \\
\hline $\mathrm{H}_{3} \mathrm{BO}_{3}(6 \mathrm{~g} / \mathrm{L})$ & \multicolumn{2}{|l|}{$0.2 \mathrm{mM}$} & 4.12 \\
\hline \multicolumn{4}{|c|}{ Stock solutions for RE media and required volume in $2 \mathrm{~L}$ RE seawater } \\
\hline Components & Concentration & Concentration & Volume $(\mathrm{mL})$ \\
\hline $\mathrm{CaCl}_{2} \cdot 2 \mathrm{H}_{2} \mathrm{O}$ & $147 \mathrm{~g} / \mathrm{L}$ & $1 \mathrm{M}$ & $20 \mathrm{~mL}$ \\
\hline $\mathrm{FeSO}_{4} \cdot 7 \mathrm{H}_{2} \mathrm{O}$ & $3.06 \mathrm{~g} / \mathrm{L}$ & $11 \mathrm{mM}$ & $2 \mathrm{~mL}$ \\
\hline $\mathrm{NaNO}_{3}$ & $75 \mathrm{~g} / \mathrm{L}$ & $880 \mathrm{mM}$ & $2 \mathrm{~mL}$ \\
\hline $\mathrm{NaH}_{2} \mathrm{PO}_{4} \cdot 2 \mathrm{H}_{2} \mathrm{O}$ & $5 \mathrm{~g} / \mathrm{L}$ & $36 \mathrm{mM}$ & $2 \mathrm{~mL}$ \\
\hline $\mathrm{NaHCO}_{3}$ & $84 \mathrm{~g} / \mathrm{L}$ & $1 \mathrm{M}$ & $4 \mathrm{~mL}$ \\
\hline RE Vitamins & (per L) & & $2 \mathrm{~mL}$ \\
\hline $\mathrm{B}_{12}$ (cyanocobalamin) & $200 \mathrm{mg}$ & $148 \mu \mathrm{M}$ & \\
\hline Biotin & $100 \mathrm{mg}$ & $410 \mu \mathrm{M}$ & \\
\hline Thiamine- $\mathrm{HCl}$ & $200 \mathrm{mg}$ & $590 \mu \mathrm{M}$ & \\
\hline RE Trace Metals & (per L) & $($ per L) & $2 \mathrm{~mL}$ \\
\hline $\mathrm{CuSO}_{4} \cdot 5 \mathrm{H}_{2} \mathrm{O}$ & $80 \mu \mathrm{M}$ & $20 \mathrm{mg}$ & \\
\hline $\mathrm{Na}_{2} \mathrm{MoO}_{4} \cdot 2 \mathrm{H}_{2} \mathrm{O}$ & $825 \mu \mathrm{M}$ & $200 \mathrm{mg}$ & \\
\hline $\mathrm{ZnSO}_{4} \cdot 7 \mathrm{H}_{2} \mathrm{O}$ & $350 \mu \mathrm{M}$ & $100 \mathrm{mg}$ & \\
\hline $\mathrm{CoCl}_{2} \cdot 6 \mathrm{H}_{2} \mathrm{O}$ & $84 \mu \mathrm{M}$ & $20 \mathrm{mg}$ & \\
\hline $\mathrm{MnSO}_{4} \cdot \mathrm{H}_{2} \mathrm{O}$ & $1.2 \mathrm{mM}$ & $200 \mathrm{mg}$ & \\
\hline $\mathrm{NiSO}_{4} \cdot 6 \mathrm{H}_{2} \mathrm{O}$ & $74 \mu \mathrm{M}$ & $20 \mathrm{mg}$ & \\
\hline $\mathrm{Na}_{3} \mathrm{VO}_{4}$ & $10 \mu \mathrm{M}$ & $1.84 \mathrm{mg}$ & \\
\hline $\mathrm{Na}_{2} \mathrm{SeO}_{3}$ & $10 \mu \mathrm{M}$ & $1.73 \mathrm{mg}$ & \\
\hline Trizma 8.1-8.2(10\%) & & & $28 \mathrm{~mL}$ \\
\hline TrisHCl & & $48.5 \mathrm{~g} / \mathrm{L}$ & \\
\hline Tris Base & & $51.5 \mathrm{~g} / \mathrm{L}$ & \\
\hline
\end{tabular}


Richard Eaton (RE) media was prepared by following the optimized standard operation procedure which was optimized by Dr. Kathleen Rein's research laboratory. The components of RE media were shown in Table 10.

The arsenic and copper solutions were prepared by following the steps below. In details, two Pyrex glass volumetric flasks $(100 \mathrm{~mL})$ were soaked in $10 \%$ nitric acid for $24 \mathrm{~h}$ and then rinsed with DDI water to wash away all the potential contaminants. The arsenic and copper stock solutions were prepared by dissolving solid sodium arsenate heptahydrate and copper (II) sulfate pentahydrate in DDI water, separately. The concentrations of stock solution were $100 \mathrm{ppm}$ for arsenic and $1000 \mathrm{ppm}$ for copper. The prepared solutions needed to be filtered by BD $10 \mathrm{~mL}$ Luer-Lok syringes (Becton Dickinson \& CO., Frankin Lakes, NJ) with the $0.2 \mu \mathrm{m}$ sterile nylon filters purchased from Fisher Scientific and then placed in the sterile storage bottle (Corning, NY). To avoid potential contamination by organisms, the solution was freshly prepared before the experiment. An algae culture (100 $\mathrm{mL}$ ) with a primary concentration of 5000 cells $/ \mathrm{ml}$ was incubated in $250 \mathrm{~mL}$ flask. Arsenic $(10,25,50,100 \mathrm{ppb})$ in the form of $\mathrm{Na}_{2} \mathrm{HAsO}_{4}$ while copper $(50,250,500,1000 \mathrm{ppb})$ in the form of $\mathrm{CuSO}_{4}$ were spiked into the algae culture, separately. Algae culture $(1 \mathrm{ml})$ was sampled at different time points for determination of the density of cell by using Z1 coulter particle counter. The cell growth curves with addition of different concentration of arsenic/ copper are shown in Figure 21 and 22. The control groups, compared to the metal treated groups, were performed without addition of the copper/arsenic.

\subsection{Results and discussion}

\subsubsection{The effects of arsenic on the growth of Karenia brevis}

Figure 21 has shown that the growth of K. brevis was inhibited when the concentration 
of arsenate was 50 and $100 \mathrm{ppb}$. The slope of the cell growth curve could reflect on the growth rate of the cell during the period of the incubation. Comparing the experimental groups to the control groups, the larger growth rate for the larger groups indicate facilitation of the growth, while the smaller growth rate implied the inhibition of the growth. The experimental results demonstrated that the growth of $K$. brevis was completely inhibited during the whole growth process when the arsenate concentration was $100 \mathrm{ppb}$ in the media. Moreover, the addition of $50 \mathrm{ppb}$ arsenate also revealed a slight inhibition of the growth of the algae while lower arsenate concentrations (10 ppb and 25 ppb) showed no obvious inhibition of the growth of the algae. These results suggest that $K$. brevis could tolerant arsenate up to $50 \mathrm{ppb}$. Once the arsenate concentration was further increased to levels where it became toxic, first the growth rate slowed down, and at even higher concentrations of arsenate, the complete inhibition of $K$. brevis growth was observed.

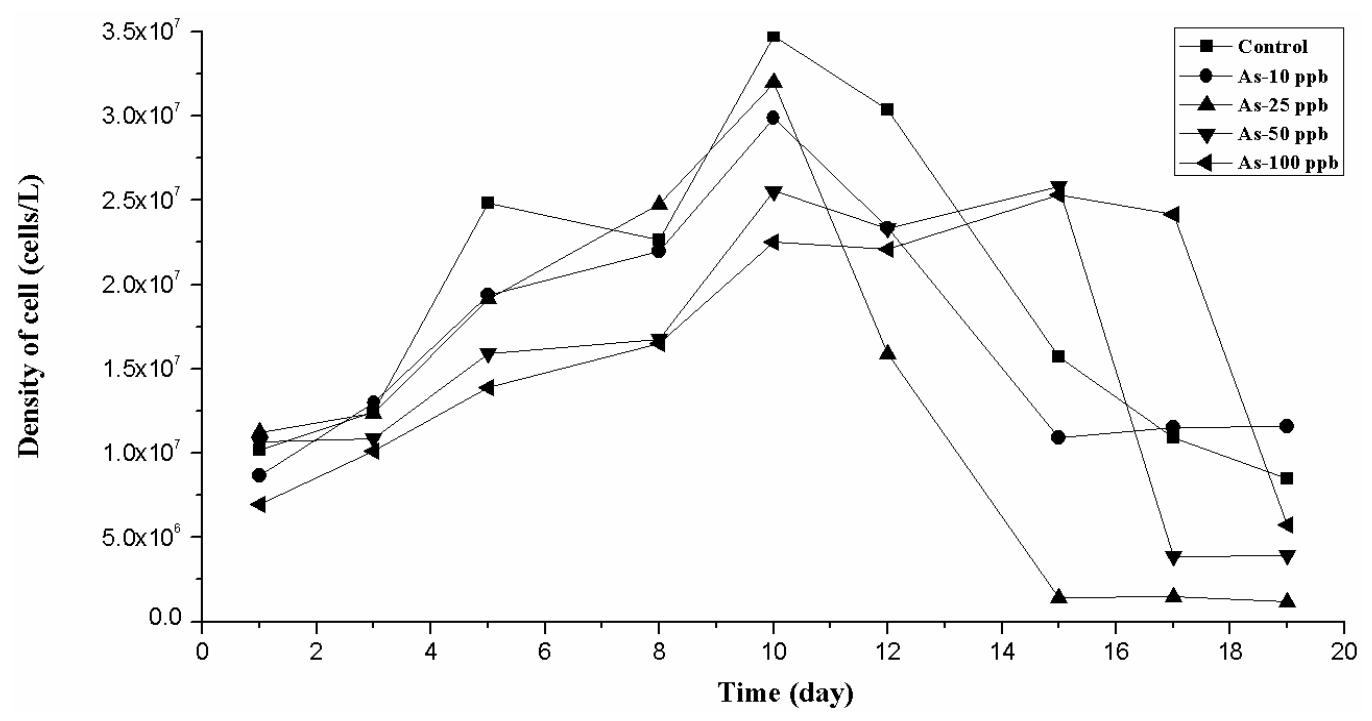

Figure 21. The effects of arsenic $\left(\mathrm{AsO}_{4}{ }^{3-}\right)$ on the growth of Karenia brevis 
Interestingly, it was observed in this study that, although the addition of high concentration of arsenic inhibited the growth of the cells (resulting in the slower growth rate at the exponential phase), this highly toxic element could extend the time for the cell growth in their exponential phase. As shown in Figure 21, the rates of cell growth were greater for the control groups than for the groups treated with high concentrations of arsenate. There was a rapid exponential growth in population displayed as the increase of cell numbers, however, the maximum number of cells was reached within 10 days. After that, there was no further increase in cell number; instead, the decease of cell number occurred. The decrease of cell number could be caused by the faster depletion of nutrients by the higher number of cells present. In addition, the limited growth space could also result in cellular death as the potentially toxic metabolic waste could reach an elevated concentration and constrain the further increase of the population density. Conversely, for the groups treated with high concentrations of arsenate, the cell number increased relatively slower due to the inhibition effect of arsenic. The growth of algal cells in a low growth rate was helpful to relieve the potential pressure induced by the limited nutrients and environment, leading to an extended period for cell growth in the exponential phase. Therefore, the arsenate spiked into the medium could play a dual role. On one hand it inhibited the growth of the cell; on the other hand it expanded the period of time for growth through the regulation of the population density.

\subsubsection{The effects of copper on the growth of Karenia brevis}

Since the traditional RE algae culture media contains copper (II) sulfate (20 ppb) in the algae culture media, a newly prepared RE trace metal stock solution without addition of copper (II) sulfate pentahydrate $\left(\mathrm{CuSO}_{4} \cdot 5 \mathrm{H}_{2} \mathrm{O}\right)$ was applied in the experiment (medium 


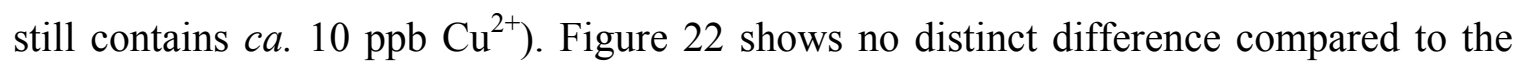
control groups of the growth rate of $K$. brevis with the addition of copper in the low concentrations (50 ppb and $250 \mathrm{ppb}$ ). However, the inhibition of the algae growth could be observed for the experimental groups which were spiked with high concentrations of copper (1000 ppb). It is suggested that the high concentration of free copper (II) ion in the aquatic system would play a role in the inhibition of the algae growth. The results demonstrated that although the algae species of $K$. brevis was capable of resisting the low concentration of free copper (II) ion or even the copper in this quantity was required for growth, the high concentration of free copper (II) ion could definitely toxic to the K. brevis resulting in the lower rate of growth. Interestingly, K. brevis under the condition of exposure to $500 \mathrm{ppb}$ copper exhibited an astonishing growth capability in highly growth rate and the extension of period of time for growth in the exponential phase. This phenomenon would be probably due to the potential resistance of a section of $K$. brevis specie to the addition of free copper (II) ion.

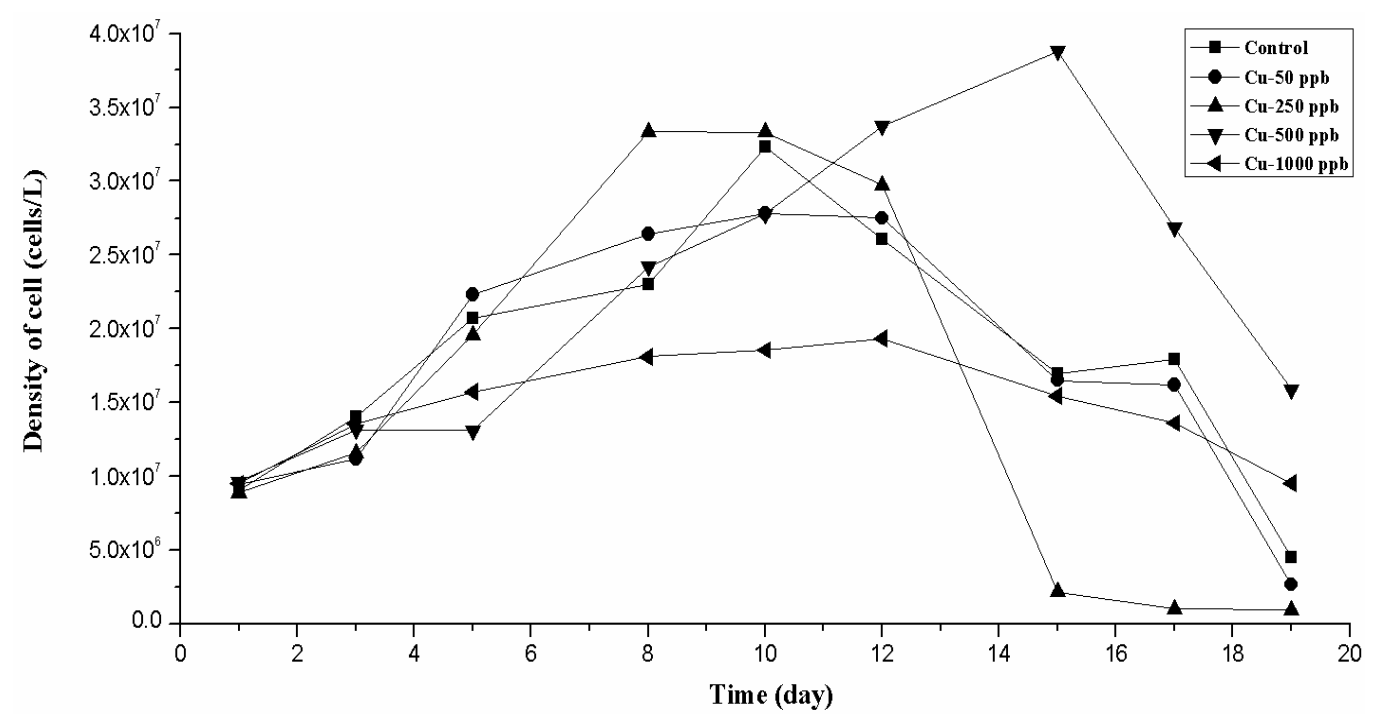

Figure 22. The effects of copper $\left(\mathrm{Cu}^{2+}\right)$ on the growth of Karenia brevis 


\subsection{Summary}

In conclusion, the toxic elements of copper and arsenic at high concentration levels could affect the growth of the K. brevis, specifically, they retard growth. The usage of copper or arsenic contained substances to inhibit the growth of algae species would not be a good selection because these toxic materials could potentially increase the time for their growth by adjusting the population density. Even worse, these elements were highly toxic to the environmental and ecological system. The experiment results could be helpful to understand the relationship between the harmful algal blooms of the $K$. brevis and the toxic elements, such as copper and arsenic. Moreover, monitoring the concentration of some specific toxic elements could be helpful to predict the potential occurrence of the HABs in the aquatic environment. 


\section{Chapter 4}

\section{PERSPECTIVES}

The stability constants obtained in this work would be helpful to study the bioavailability of metals with the presence of algal toxins. The stability constants of toxin-metal complexes could be used to predict the behavior of both algal toxins and metal ions in aquatic environment. These data could be employed to build a database which could be used to estimate the stability of complexes formed by other metal ions as well as other algal toxins.

In addition, the effects of metal ions, such as arsenic and copper, on the toxin production of $K$. brevis should be determined in future studies. As the most dominated toxic product released by $K$. brevis, brevetoxins, result in vast economic losses for fisheries and serious public health issues. In addition, harmful algal blooms caused by K. brevis in Gulf of Mexico would result in a high concentration of brevetoxins present in marine water and lead to the local life directly exposed to these toxins. Understanding the effects of the metals on the toxin production would be helpful to re-estimate the potential risk, thereby addressing this problem in an effective way. 


\section{REFERENCES}

Adam, A., N. Mohammad-Noor, A. Anton, E. Saleh, S. Saad and S. R. M. Shaleh (2011). "Temporal and spatial distribution of harmful algal bloom (HAB) species in coastal waters of Kota Kinabalu, Sabah, Malaysia." Harmful Algae 10(5): 495-502.

An, T. Y., T. K. S. Kumar, M. L. Wang, L. Liu, J. O. Lay, R. Liyanage, J. Berry, M. Gantar, V. Marks, R. E. Gawley and K. S. Rein (2007). "Structures of pahayokolides A and B, cyclic peptides from a Lyngbya sp." Journal of Natural Products70(5): 730-735.

Anderson, D. M., J. M. Burkholder, W. P. Cochlan, P. M. Glibert, C. J. Gobler, C. A. Heil, R. M. Kudela, M. L. Parsons, J. E. J. Rensel, D. W. Townsend, V. L. Trainer and G. A. Vargo (2008). "Harmful algal blooms and eutrophication: Examining linkages from selected coastal regions of the United States." Harmful Algae8(1): 39-53.

Anderegg, G., L'Eplattenier, F. and Schwarzenbach, G. (1963). "Hydroxamatkomplexe II. Die anwendung der pH-methode." Helvetica ChimicaActa46(4): 1400-1408.

Backer, L. C., L. E. Fleming, A. Rowan, Y. S. Cheng, J. Benson, R. H. Pierce, J. Zaias, J. Bean, G. D. Bossart, D. Johnson, R. Quimbo and D. G. Baden (2003). "Recreational exposure to aerosolized brevetoxins during Florida red tide events." Harmful Algae2(1): $19-28$.

Backer, L. C., B. Kirkpatrick, L. E. Fleming, Y. S. Cheng, R. Pierce, J. A. Bean, R. Clark, D. Johnson, A. Wanner, R. Tamer, Y. Zhou and D. G. Baden (2005). "Occupational exposure to aerosolized brevetoxins during Florida red tide events: Effects on a healthy worker population." Environmental Health Perspectives 113(5): 644-649.

Baden, D. G. (1989). "Brevetoxins-unique polyether dinoflagellate toxins." Faseb Journal3(7): 1807-1817.

Baden, D. G., A. J. Bourdelais, H. Jacocks, S. Michelliza and J. Naar (2005). "Natural and derivative brevetoxins: Historical background, multiplicity, and effects." Environmental Health Perspectives113(5): 621-625.

Bajpai, R., N. K. Sharma, L. A. Lawton, C. Edwards and A. K. Rai (2009). "Microcystin producing cyanobacterium Nostoc sp BHU001 from a pond in India." Toxicon53(5): 587-590.

Balogh, S. J., Y. B. Huang, H. J. Offerman, M. L. Meyer and D. K. Johnson (2002). "Episodes of elevated methylmercury concentrations in prairie streams." Environmental Science \& Technology36(8): 1665-1670.

Baran, E. J., C. C. Wagner and M. H. Torre (2002). "Synthesis and characterization of 
EDTA complexes useful for trace elements supplementation." Journal of the Brazilian Chemical Society13(5): 576-582.

Barrow, N. J. and V. C. Cox (1992). "The effects of $\mathrm{pH}$ and chloride concentration of mercury sorption. 1. By goethite." Journal of Soil Science43(2): 295-304.

Barrow, N. J. and V. C. Cox (1992). "The effects of $\mathrm{pH}$ and chloride concentration on mercury sorption. 2. By a soil." Journal of Soil Science43(2): 305-312.

Berry, J. P., M. Gantar, R. E. Gawley, M. L. Wang and K. S. Rein (2004). "Pharmacology and toxicology of pahayokolide A, a bioactive metabolite from a freshwater species of Lyngbya isolated from the Florida Everglades." Comparative Biochemistry and Physiology C-Toxicology \& Pharmacology139(4): 231-238.

Bienvenue, E., A. Boudou, J. P. Desmazes, C. Gavach, D. Georgescauld, J. Sandeaux, R. Sandeaux and P. Seta (1984). "Transport of mercury-compounds across bimolecular lipid-membranes-effect of lipid-composition, $\mathrm{pH}$ and chloride concentration." Chemico-Biological Interactions 48(1): 91-101.

Bittencourt-Oliveira, M. C., M. C. Oliveira, and E. Pinto (2011). "Diversity of microcystin-producing genotypes in Brazilian strains of Microcystis (Cyanobacteria)." Brazilian Journal of Biology71(1): 209-216.

Bocio, A., M. Nadal and J. L. Domingo (2005). "Human exposure to metals through the diet in Tarragona, Spain - Temporal trend." Biological Trace Element Research104(3): 193-201.

Bouillon, R. C., R. J. Kieber, S. A. Skrabal and J. L. C. Wright (2008). "Photochemistry and identification of photodegradation products of the marine toxin domoic acid." Marine Chemistry110(1-2): 18-27.

Bourdelais, A. J., H. M. Jacocks, J. L. C. Wright, P. M. Bigwarfe and D. G. Baden (2005). "A new polyether ladder compound produced by the dinoflagellate Karenia brevis." Journal of Natural Products68(1): 2-6.

Braga, M. C. B., G. Shaw and J. N. Lester (2000). "Mercury modeling to predict contamination and bioaccumulation in aquatic ecosystems." Reviews of Environmental Contamination and Toxicology, Vol 164164: 69-92.

Brand, L. E. and A. Compton (2007). "Long-term increase in Karenia brevis abundance along the Southwest Florida Coast." Harmful Algae6(2): 232-252.

Bremner, I. (1987). "Involvement of metallothionein in the hepatic-metabolism of copper." Journal of Nutrition117(1): 19-29. 
Bruno, M., P. M. B. Gucci, E. Pierdominici, P. Sestili, A. Ioppolo, N. Sechi, and L. Volterra (1992). "Microcystin-like toxins in different fresh-water species of Oscillatoria." Toxicon30(10): 1307-1311.

Bury, N. R., F. B. Eddy, and G. A. Codd (1995). "The effects of the cyanobacterium Microcystis-aeruginosa, the cyanobacterial hepatotoxin microcystin-LR, and ammonia on growth-rate and ionic regulation of brown trout." Journal of Fish Biology 46(6): 1042-1054.

Campos, A. and V. Vasconcelos (2010). "Molecular mechanisms of microcystin toxicity in animal cells." International Journal of Molecular Sciences11(1): 268-287.

Carmichael, W. W., V. Beasley, D. L. Bunner, J. N. Eloff, I. Falconer, P. Gorham, K. I. Harada (1988). "Naming of cyclic heptapeptide toxins of cyanobacteria (blue-green-algae)." Toxicon26(11): 971-973.

Carvalho, G. A., P. J. Minnett, V. F. Banzon, W. Baringer, and C. A. Heil (2011). "Long-term evaluation of three satellite ocean color algorithms for identifying harmful algal blooms (Karenia brevis) along the west coast of Florida: A matchup assessment." Remote Sensing of Environment115(1): 1-18.

Casas, J. S. and M. M. Jones (1980). "Mercury(II) complexes with sulfhydryl containing chelating-agents-stability constant inconsistencies and their resolution." Journal of Inorganic \& Nuclear Chemistry42(1): 99-102.

Chen, Z. R., Y. Cai, H. Solo-Gabriele, G. H. Snyder, and J. L. Cisar (2006). "Interactions of arsenic and the dissolved substances derived from turf soils." Environmental Science \& Technology40(15): 4659-4665.

Cheng, Y. S., Y. Zhou, C. M. Irvin, R. H. Pierce, J. Naar, L. C. Backer, L. E. Fleming, B. Kirkpatrick, and D. G. Baden (2005). "Characterization of marine aerosol for assessment of human exposure to brevetoxins." Environmental Health Perspectives113(5): 638-643.

Cheng, Y. S., Y. Zhou, J. Naar, C. M. Irvin, W. C. Su, L. E. Fleming, B. Kirkpatrick (2010). "Personal exposure to aerosolized red tide toxins (brevetoxins)." Journal of Occupational and Environmental Hygiene7(6): 326-331.

Crist, R. H., K. Oberholser, N. Shank, and M. Nguyen (1981). "Nature of bonding between metallic-ions and algal cell-walls." Environmental Science \& Technology15(10): 1212-1217.

Cullen, W. R., L. G. Harrison, H. Li and G. Hewitt (1994). "Bioaccumulation and excretion of arsenic compounds by a marine unicellular alga, polyphysa-peniculus." Applied Organometallic Chemistry8(4): 313-324. 
Daly, R. I., L. Ho, and J. D. Brookes (2007). "Effect of chlorination on Microcystis aeruginosa cell integrity and subsequent microcystin release and degradation." Environmental Science \& Technology41(12): 4447-4453.

Dave, G. and R. Q. Xiu (1991). "Toxicity of mercury, copper, nickel, lead, and cobalt to embryos and larvae of zebrafish, Brachydanio-rerio." Archives of Environmental Contamination and Toxicology21(1): 126-134.

Dean, J. A. (1972). Lange's handbook of chemistry. Solubility product constants.

Dean, J. A. (1972). Lange's handbook of chemistry. Potential of the elements and their compounds at $298.15 \mathrm{~K}$.

Dechraoui, M. Y., J. Naar, S. Pauillac, and A. M. Legrand (1999). "Ciguatoxins and brevetoxins, neurotoxic polyether compounds active on sodium channels." Toxicon37(1): 125-143.

Dehghani, H. and A. R. A. Sardrood (2007). "Molecular complexation of free base meso-tetraarylporphyrins with antimony(III) chloride in free solvent media." Polyhedron26(15): 4263-4268.

Delnomdedieu, M., A. Boudou, D. Georgescauld and E. J. Dufourc (1992). "Specific interactions of mercury-chloride with membranes and other ligands as revealed by mercury-NMR." Chemico-Biological Interactions81(3): 243-269.

Donia, A. M., H. A. El-Boraey (1997). "Thermal investigation of cobalt, nickel and copper complexes with 8-aminoquinoline: Correlation between thermal stability and crystal field splitting energy." Journal of Thermal Analysis and Calorimetry 48(6): $1325-1336$.

Dickey, R. W., S. C. Bobzin, D. J. Faulkner, F. A. Bencsath and D. Andrzejewski (1990). "Identification of okadaic acid from a caribbean dinoflagellate, Prorocentrum-concavum." Toxicon28(4): 371-377.

Downs, S. G., C. L. Macleod and J. N. Lester (1998). "Mercury in precipitation and its relation to bioaccumulation in fish: A literature review." Water Air and Soil Pollution108(1-2): 149-187.

Ellis, S. (1985). "Brevetoxins-chemistry and pharmacology of red tide toxins from Ptychodiscus-brevis (formerly Gymnodinium-breve)-Introduction." Toxicon23(3): 469-472.

Engstrom, K. S., K. Broberg, G. Concha, B. Nermell, M. Warholm, and M. Vahter (2007). "Genetic polymorphisms influencing arsenic metabolism: Evidence from 
Argentina." Environmental Health Perspectives115(4): 599-605.

Erdner, D. L., J. Dyble, M. L. Parsons, R. C. Stevens, K. A. Hubbard, M. L. Wrabel, S. K. Moore (2008). "Centers for oceans and human health: a unified approach to the challenge of harmful algal blooms." Environmental Health7.

Etheridge, S. M. (2010). "Paralytic shellfish poisoning: Seafood safety and human health perspectives." Toxicon56(2): 108-122.

Faulkner, D. J. (2002). "Marine natural products." Natural Product Reports19(1): 1-48.

Faust, M. A. (1991). "Morphology of ciguatera-causing Prorocentrum-lima (Pyrrophyta) from widely differing sites." Journal of Phycology27(5): 642-648.

Fewer, D. P., K. Halinen, H. Sipari, K. Bernardova, M. Manttari, E. Eronen, and K. Sivonen (2011). "Non-autonomous transposable elements associated with inactivation of microcystin gene clusters in strains of the genus Anabaena isolated from the Baltic Sea." Environmental Microbiology Reports3(2): 189-194.

Fewer, D. P., M. Koykka, K. Halinen, J. Jokela, C. Lyra, and K. Sivonen (2009). "Culture-independent evidence for the persistent presence and genetic diversity of microcystin-producing Anabaena (Cyanobacteria) in the Gulf of Finland." Environmental Microbiology11(4): 855-866.

Fewer, D. P., A. Tooming-Klunderud, J. Jokela, M. Wahsten, L. Rouhiainen, T. Kristensen, T. Rohrlack, K. S. Jakobsen, and K. Sivonen (2008). "Natural occurrence of microcystin synthetase deletion mutants capable of producing microcystins in strains of the genus Anabaena (Cyanobacteria)." Microbiology-Sgm154: 1007-1014.

Fire, S. E., L. J. Flewelling, J. Naar, M. J. Twiner, M. S. Henry, R. H. Pierce, D. P. Gannon (2008). "Prevalence of brevetoxins in prey fish of bottlenose dolphins in Sarasota Bay, Florida." Marine Ecology-Progress Series368: 283-294.

Fischer, A., S. J. Hoeger, K. Stemmer, D. J. Feurstein, D. Knobeloch, A. Nussler, and D. R. Dietrich (2010). "The role of organic anion transporting polypeptides (OATPs/SLCOs) in the toxicity of different microcystin congeners in vitro: A comparison of primary human hepatocytes and OATP-transfected HEK293 cells." Toxicology and Applied Pharmacology245(1): 9-20.

Fischer, W. J. and D. R. Dietrich (2000). "Pathological and biochemical characterization of microcystin-induced hepatopancreas and kidney damage in carp (Cyprinus carpio)." Toxicology and Applied Pharmacology 164(1): 73-81.

Fitzgerald, W. F., D. R. Engstrom, R. P. Mason and E. A. Nater (1998). "The case for atmospheric mercury contamination in remote areas." Environmental Science \& 
Technology32(1): 1-7.

Fitzgerald, W. F., C. H. Lamborg, and C. R. Hammerschmidt (2007). "Marine biogeochemical cycling of mercury." Chemical Reviews 107(2): 641-662.

Fleming, L. E., B. Kirkpatrick, L. C. Backer, C. J. Walsh, K. Nierenberg, J. Clark, A. Reich (2011). "Review of Florida red tide and human health effects." Harmful Algae 10(2): 224-233.

Foulkes, E. C. and S. Blanck (1992). "Affinity of cellular-binding sites for cadmium and mercury, and acute Hg effects on amino-acid-transport in the rabbit kidney.." Faseb Journal6(5): A1855-A1855.

Fourest, B., J. Duplessis, and F. David (1982). "Hydrated radii determination for some trivalent actinide ions." Comptes Rendus De L Academie Des Sciences Serie Ii294(19): 1179-1181.

Friedly, J. C., D. B. Kent, and J. A. Davis (2002). "Simulation of the mobility of metal-EDTA complexes in groundwater: The influence of contaminant metals." Environmental Science \& Technology36(3): 355-363.

Fujiki, H. and M. Suganuma (2011). "Tumor promoters - microcystin-LR, Nodularin and TNF-alpha and human cancer development." Anti-Cancer Agents in Medicinal Chemistry11(1): 4-18.

Furst, P., S. Hu, R. Hackett, and D. Hamer (1988). "Copper activates metallothionein gene-transcription by altering the conformation of specific DNA-binding protein." Cell55(4): 705-717.

Gan, N. Q., X. Y. Sun, and L. R. Song (2010). "Activation of Nrf2 by microcystin-LR provides advantages for liver cancer cell growth." Chemical Research in Toxicology23(9): 1477-1484.

Garcia, A. C., S. Bargu, P. Dash, N. N. Rabalais, M. Sutor, W. Morrison, and N. D. Walker (2010). "Evaluating the potential risk of microcystins to blue crab (Callinectes sapidus) fisheries and human health in a eutrophic estuary." Harmful Algae9(2): 134-143.

Gehringer, M. M., P. Milne, F. Lucietto, and T. G. Downing (2005). "Comparison of the structure of key variants of microcystin to vasopressin." Environmental Toxicology and Pharmacology19(2): 297-303.

Genuario, D. B., M. E. Silva-Stenico, M. Welker, L. A. B. Moraes, and M. F. Fiore (2010). "Characterization of a microcystin and detection of microcystin synthetase genes from a Brazilian isolate of Nostoc." Toxicon55(4): 846-854. 
Gong, Y., H. N. Chou, C. D. Tu, X. Liu, J. T. Liu, and L. R. Song (2009). "Effects of arsenate on the growth and microcystin production of Microcystis aeruginosa isolated from Taiwan as influenced by extracellular phosphate." Journal of Applied Phycology21(2): 225-231.

Gong, Y., L. R. Song, X. Q. Wu, B. D. Xiao, T. Fang, and J. T. Liu (2009). "Effects of arsenate on microcystin content and leakage of Microcystis strain PCC7806 under various phosphate regimes." Environmental Toxicology24(1): 87-94.

Gong, Z. S., Z. P. Zhao, and H. P. Huang (2004). "The generalized oxidation and reduction reactions in soil chemistry." Journal of Yunnan Agricultural University 19(3): 349-352.

Gouvea, S. P., G. L. Boyer, and M. R. Twiss (2008). "Influence of ultraviolet radiation, copper, and zinc on microcystin content in Microcystis aeruginosa (Cyanobacteria)." Harmful Algae7(2): 194-205.

Grubisic, S., M. Gruden, S. R. Niketic, N. Sakagami-Yoshida, and S. Kaizaki (2002). "Conformational analysis of EDTA-type chromium(III) complexes with beta-propionato metal chelate rings." Journal of Molecular Structure609(1-3): 1-9.

Gupta, N., S. C. Pant, R. Vijayaraghavan, and P. V. L. Rao (2003). "Comparative toxicity evaluation of cyanobacterial cyclic peptide toxin microcystin variants (LR, RR, YR) in mice." Toxicology188(2-3): 285-296.

H. Irving and R. J. P. Williams (1953). "The stability of transition-metal complexes." Journal of the Chemical Society (Resumed)(0): 3192-3210.

Halasyamani, P. S. (2004). "Asymmetric cation coordination in oxide materials: Influence of lone-pair cations on the intra-octahedral distortion in $\mathrm{d}(0)$ transition metals." Chemistry of Materials 16(19): 3586-3592.

Hallegraeff, G. M. (1993). "A revies of harmful algal blooms and their apparent global increase." Phycologia32(2): 79-99.

Herschman, H. R., R. W. Lim, D. W. Brankow, and H. Fujiki (1989). "The tumor promoters 12-o-tetradecanoylphorbol-13-acetate and okadaic acid differ in toxicity, mitogenic activity and induction of gene-expression." Carcinogenesis 10(8): 1495-1498.

Heyrovska, R. (2007). "Dependences of molar volumes in solids, partial molal and hydrated ionic volumes of alkali halides on covalent and ionic radii and the golden ratio." Chemical Physics Letters436(1-3): 287-293.

Hirata, S. and H. Toshimitsu (2005). "Determination of arsenic species and arsenosugars in marine samples by HPLC-ICP-MS." Analytical and Bioanalytical 


\section{Chemistry383(3): 454-460.}

Hirose, K. (2007). "Metal-organic matter interaction: ecological roles of ligands in oceanic DOM." Applied Geochemistry22(8): 1636-1645.

Hooser, S. B., V. R. Beasley, R. A. Lovell, W. W. Carmichael, and W. M. Haschek (1989). "Toxicity of microcystin-LR, a cyclic heptapeptide hepatotoxin from Microcystis-aeruginosa, to rats and mice." Veterinary Pathology26(3): 246-252.

Hopman, A. H. N., J. Wiegant, and P. Vanduijn (1986). "A new hybridocytochemical method based on mercurated nucleic-acid probes and sulfhydryl-hapten ligands. 1. Stability of the mercury-sulfhydryl bond and influence of the ligand structure on immunochemical detection of the hapten." Histochemistry84(2): 169-178.

Horner, R. A., D. L. Garrison, and F. G. Plumley (1997). "Harmful algal blooms and red tide problems on the US west coast." Limnology and Oceanography42(5): 1076-1088.

Hughes, M. F. (2002). "Arsenic toxicity and potential mechanisms of action." Toxicology Letters 133(1): 1-16.

Humble, A. V., G. M. Gadd, and G. A. Codd (1997). "Binding of copper and zinc to three cyanobacterial microcystins quantified by differential pulse polarography." Water Research31(7): 1679-1686.

Hummert, C., A. Ruhl, K. Reinhardt, G. Gerdts, and B. Luckas (2002). "Simultaneous analysis of different algal toxins by LC-MS." Chromatographia55(11-12): 673-680.

Ishida, H., A. Nozawa, H. Nukaya, and K. Tsuji (2004). "Comparative concentrations of brevetoxins PbTx-2, PbTx-3, BTX-B1 and BTX-B5 in cockle, Austrovenus stutchburyi, greenshell mussel, Perna canaliculus, and Pacific oyster, Crassostrea gigas, involved neurotoxic shellfish poisoning in New Zealand." Toxicon43(7): 779-789.

James, K. J., B. Carey, J. O'Halloran, Fnam van Pelt, and Z. Skrabakova (2010). "Shellfish toxicity: human health implications of marine algal toxins." Epidemiology and Infection138(7): 927-940.

Jasionek, G., A. Zhdanov, J. Davenport, L. Blaha, and D. B. Papkovsky (2010). "Mitochondrial toxicity of microcystin-LR on cultured cells: application to the analysis of contaminated water samples." Environmental Science \& Technology44(7): 2535-2541.

Jensen, W. B. (2003). "The place of zinc, cadmium, and mercury in the periodic table." Journal of Chemical Education 80(8): 952-961.

Jones, G. J. and P. T. Orr (1994). "Release and degradation of microcystin following algicide treatment of a Microcystis-aeruginosa bloom in recreational lake, as determined 
by HPLC and protein phosphatase inhibition assay." Water Research 28(4): 871-876.

Kaido, T., H. Hashimoto, H. Okamura, and K. Tsukaguchi (2005). "Progressive severe anemia due to copper deficiency five years after subarachnoid hemorrhage." Journal of Clinical Neuroscience12(2): 205-206.

Kenefick, S. L., S. E. Hrudey, H. G. Peterson, and E. E. Prepas (1993). "Toxin release from microcystis-aeruginosa after chemical treatment." Water Science and Technology27(3-4): 433-440.

Kent, D. B., J. A. Davis, L. C. D. Anderson, B. A. Rea, and J. A. Coston (2002). "Effect of adsorbed metal ions on the transport of Zn- and Ni-EDTA complexes in a sand and gravel aquifer." Geochimica Et Cosmochimica Acta66(17): 3017-3036.

Kertesz, M. and R. Hoffmann (1984). "Octahedral vstrigonal-prismatic coordination and clustering in transition-metal dichalcogenides." Journal of the American Chemical Society 106(12): 3453-3460.

Khan, U., N. Benabderrazik, A. J. Bourdelais, D. G. Baden, K. Rein, P. R. Gardinali, L. Arroyo, and K. E. O'Shea (2010). "UV and solar TiO(2) photocatalysis of brevetoxins (PbTxs)." Toxicon55(5): 1008-1016.

Kirkpatrick, B., R. Currier, K. Nierenberg, A. Reich, L. C. Backer, R. Stumpf, L. Fleming, and G. Kirkpatrick (2008). "Florida red tide and human health: A pilot beach conditions reporting system to minimize human exposure." Science of the Total Environment402(1): 1-8.

Kiviranta, J., M. Namikoshi, K. Sivonen, W. R. Evans, W. W. Carmichael, and K. L. Rinehart (1992). "Structure determination and toxicity of a new microcystin from Microcystis-aeruginosa strain-205." Toxicon30(9): 1093-1098.

Klinman, J. P., D. M. Dooley, J. A. Duine, P. F. Knowles, B. Mondovi, and J. J. Villafranca (1991). "Status of the cofacter identity in copper oxidative-enzymes." Febs Letters282(1): 1-4.

Ko, I., A. P. Davis, J. Y. Kim and K. W. Kim (2007). "Effect of contact order on the adsorption of inorganic arsenic species onto hematite in the presence of humic acid." Journal of Hazardous Materials 141(1): 53-60.

Kolrep, F., A. Ehlers, S. Hassel, and A. Lampen (2011). "Toxicity of the marine biotoxin okadaic acid after in vitro phase I metabolism in V79 and HepG2 cells." Naunyn-Schmiedebergs Archives of Pharmacology383: 87-87.

Konoki, K., K. Saito, H. Matsuura, N. Sugiyama, Y. Cho, M. Yotsu-Yamashita, and K. Tachibana (2010). "Binding of diarrheic shellfish poisoning toxins to okadaic acid binding 
proteins purified from the sponge Halichondria okadai." Bioorganic \& Medicinal Chemistry18(21): 7607-7610.

Koukal, B., P. Rosse, A. Reinhardt, B. Ferrari, K. J. Wilkinson, J. L. Loizeau and J. Dominik (2007). "Effect of Pseudokirchneriella subcapitata (Chlorophyceae) exudates on metal toxicity and colloid aggregation." Water Research41(1): 63-70.

Kuramoto, M., C. Tong, K. Yamada, T. Chiba, Y. Hayashi, and D. Uemura (1996). "Halichlorine, an inhibitor of VCAM-1 induction from the marine sponge Halichondria okadai Kadota." Tetrahedron Letters37(22): 3867-3870.

Kurmayer, R. (2011). "The toxic cyanobacterium Nostoc sp. strain 152 produces highest amounts of microcystin and nostophycin under stress conditions." Journal of Phycology47(1): 200-207.

Kurmayer, R., E. Dittmann, J. Fastner, and I. Chorus (2002). "Diversity of microcystin genes within a population of the toxic cyanobacterium Microcystis spp. in Lake Wannsee (Berlin, Germany)." Microbial Ecology43(1): 107-118.

Lafay, B., R. Ruimy, C. R. Detraubenberg, V. Breittmayer, M. J. Gauthier, and R. Christen (1995). "Roseobacter-algicola sp-nov, a new marine bacterium isolated from the phycosphere of the toxin-producing dinoflagellate Prorocentrum-lima." International Journal of Systematic Bacteriology 45(2): 290-296.

Landsberg, J. H., L. J. Flewelling, and J. Naar (2009). "Karenia brevis red tides, brevetoxins in the food web, and impacts on natural resources: Decadal advancements." Harmful Algae8(4): 598-607.

Leopold, K., M. Foulkes, and P. Worsfold (2010). "Methods for the determination and speciation of mercury in natural waters-A review." Analytica Chimica Acta663(2): $127-138$.

Lerch, K. (1980). "Copper metallothionein, a copper-binding protein from neurospora-crassa." Nature284(5754): 368-370.

Li, H. L., T. Murphy, J. Guo, T. Parr, and C. Nalewajko (2009). "Iron-stimulated growth and microcystin production of Microcystis novacekii UAM 250." Limnologica39(3): 255-259.

Li, Y. B., M. A. Trush, and J. D. Yager (1994). "DNA-damage caused by reactive oxygen species originating from a copper-dependent oxidation of the 2-hydroxy catechol of estradiol." Carcinogenesis 15(7): 1421-1427.

Liu, X. W., Z. L. Chen, N. Zhou, J. M. Shen, and M. M. Ye (2010). "Degradation and detoxification of microcystin-LR in drinking water by sequential use of UV and ozone." 
Journal of Environmental Sciences-China22(12): 1897-1902.

Lukac, M. and R. Aegerter (1993). "Influence of trace-metals on growth and toxin production of Microcystis-aeruginosa." Toxicon31(3): 293-305.

Lundqvist, R., E. K. Hulet, and P. A. Baisden (1981). "Electromigration method in tracer studies of complex chemistry. 2. Hydrated radii and hydration numbers of trivalent actinides." Acta Chemica Scandinavica Series a-Physical and Inorganic Chemistry35(9): 653-661.

Luukkainen, R., K. Sivonen, M. Namikoshi, M. Fardig, K. L. Rinehart, and S. I. Niemela (1993). "Isolation and identification of 8 microcystins from 13 Oscillatoria-agardhii strains and structrue of a new microcystin." Applied and Environmental Microbiology59(7): 2204-2209.

MacKenzie, L., V. Beuzenberg, P. Holland, P. McNabb, T. Suzuki, and A. Selwood (2005). "Pectenotoxin and okadaic acid-based toxin profiles in Dinophysis acuta and Dinophysis acuminata from New Zealand." Harmful Algae4(1): 75-85.

Magana, H. A., C. Contreras, and T. A. Villareal (2003). "A historical assessment of Karenia brevis in the western Gulf of Mexico." Harmful Algae2(3): 163-171.

Maldonado, M. T., M. P. Hughes, E. L. Rue, and M. L. Wells (2002). "The effect of Fe and $\mathrm{Cu}$ on growth and domoic acid production by Pseudo-nitzschia multiseries and Pseudo-nitzschia australis." Limnology and Oceanography47(2): 515-526.

Manger, R. L., L. S. Leja, S. Y. Lee, J. M. Hungerford, Y. Hokama, R. W. Dickey, H. R. Granade (1995). "Detection of sodium-channel toxins-directed cytotoxicity assays of purified ciguatoxins, brevetoxins, saxitoxins, and seafood extracts." Journal of Aoac International78(2): 521-527.

Manger, R. L., L. S. Leja, S. Y. Lee, J. M. Hungerford, Y. Hokama, R. W. Dickey, H. R. Granade (2003). "Polymorphisms in the human monomethylarsonic acid (MMA(V)) reductase/hGSTO1 gene and changes in urinary arsenic profiles." Chemical Research in Toxicology16(12): 1507-1513.

Mason, R. P., J. R. Reinfelder, and F. M. M. Morel (1995). "Bioaccumulation of mercury and methylmercury." Water Air and Soil Pollution 80(1-4): 915-921.

Mazumder, D. N. G., A. K. Chakraborty, A. Ghose, J. D. Gupta, D. P. Chakraborty, S. B. Dey, and N. Chattopadhyay (1988). "Chronic arsenic toxicity from drinking tubewell water in rural west-bengal." Bulletin of the World Health Organization66(4): 499-506.

McSheehy, S., P. Pohl, D. Velez, and J. Szpunar (2002). "Multidimensional liquid chromatography with parallel ICP MS and electrospray MS/MS detection as a tool for the 
characterization of arsenic species in algae." Analytical and Bioanalytical Chemistry372(3): 457-466.

Mehra, R., A. S. Thakur, and S. Punia (2010). "Accumulation of lead, cadmium, nickel and copper in hair of people living near heavy traffic area." Journal of the Indian Chemical Society87(6): 751-755.

Meyer, G. and P. Nockemann (2003). "Affinity of divalent mercury towards nitrogen donor ligands." Zeitschrift Fur Anorganische Und Allgemeine Chemie629(9): 1447-1461.

Mez, K., K. A. Beattie, G. A. Codd, K. Hanselmann, B. Hauser, H. Naegeli, and H. R. Preisig (1997). "Identification of a microcystin in benthic cyanobacteria linked to cattle deaths on alpine pastures in Switzerland." European Journal of Phycology32(2): 111-117.

Meza, M. M., L. Z. Yu, Y. Y. Rodriguez, M. Guild, D. Thompson, A. J. Gandolfi, and W. T. Klimecki (2005). "Developmentally restricted genetic determinants of human arsenic metabolism: Association between urinary methylated arsenic and CYT19 polymorphisms in children." Environmental Health Perspectives 113(6): 775-781.

Mohapatra, D., D. Mishra, G. R. Chaudhury and R. P. Das (2006). "Effect of dissolved organic matter on the adsorption and stability of $\mathrm{As}(\mathrm{V})$ on manganese wad." Separation and Purification Technology49(3): 223-229.

Moore, J. K., S. C. Doney, D. M. Glover, and I. Y. Fung (2002). "Iron cycling and nutrient-limitation patterns in surface waters of the World Ocean." Deep-Sea Research Part Ii-Topical Studies in Oceanography49(1-3): 463-507.

Morton, S. L. and J. W. Bomber (1994). "Maximizing okadaic acid content from Prorocentrum-hoffmannianum faust." Journal of Applied Phycology6(1): 41-44.

Morton, S. L., P. D. R. Moeller, K. A. Young, and B. Lanoue (1998). "Okadaic acid production from the marine dinoflagellate Prorocentrum belizeanum Faust isolated from the Belizean coral reef ecosystem." Toxicon36(1): 201-206.

Mukhopadhyay, C. K., B. Mazumder, P. F. Lindley, and P. L. Fox (1997). "Identification of the prooxidant site of human ceruloplasmin: A model for oxidative damage by copper bound to protein surfaces." Proceedings of the National Academy of Sciences of the United States of America94(21): 11546-11551.

Murakami, Y., Y. Oshima, and T. Yasumoto (1982). "Identification of okadaic acid as a toxic component of a marine dinoflagellate Prorocentrum-lima." Bulletin of the Japanese Society of Scientific Fisheries48(1): 69-72.

Murrell, R. N. and J. E. Gibson (2009). "Brevetoxins 2, 3, 6, and 9 show variability in potency and cause significant induction of DNA damage and apoptosis in Jurkat E6-1 
cells." Archives of Toxicology83(11): 1009-1019.

Naar, J. P., L. J. Flewelling, A. Lenzi, J. P. Abbott, A. Granholm, H. M. Jacocks, D. Gannon (2007). "Brevetoxins, like ciguatoxins, are potent ichthyotoxic neurotoxins that accumulate in fish." Toxicon50(5): 707-723.

Nakanishi, K. (1985). "The chemistry of brevetoxins-a review." Toxicon23(3): 473-479.

Nikol, H. and A. Vogler (1991). "Photoluminescence of antimony(III) and bismuth(III) chloride complexes in solution." Journal of the American Chemical Society113(23): 8988-8990.

Nishiwakimatsushima, R., T. Ohta, S. Nishiwaki, M. Suganuma, K. Kohyama, T. Ishikawa, W. W. Carmichael, and H. Fujiki (1992). "Liver-tumor promotion by the cyanobacterial cyclic peptide toxin microcystin-LR." Journal of Cancer Research and Clinical Oncology118(6): 420-424.

Niwa, H., K. Wakamatsu, and K. Yamada (1989). "Halicholactone and Neohalicholactone, 2 novel fatty-acid metabolites from the marine sponge Halichondria-okadai kadota." Tetrahedron Letters30(34): 4543-4546.

Norte, M., J. J. Fernandez, M. L. Souto, J. A. Gavin, M. L. Candenas, and P. Ausina (1998). "Complexation of okadaic acid: A preliminary study." Bioorganic \& Medicinal Chemistry Letters8(9): 1007-1012.

Oelkers, E. H., D. M. Sherman, K. V. Ragnarsdottir, and C. Collins (1998). "An EXAFS spectroscopic study of aqueous antimony(III)-chloride complexation at temperatures from 25 to 250 degrees C." Chemical Geology151(1-4): 21-27.

Oh, H. M., S. J. Lee, M. H. Jang, and B. D. Yoon (2000). "Microcystin production by Microcystis aeruginosa in a phosphorus-limited chemostat." Applied and Environmental Microbiology66(1): 176-179.

Oliveira, A. C. R., V. F. Magalhaes, R. M. Soares, and Smfo Azevedo (2005). "Influence of drinking water composition on quantitation and biological activity of dissolved microcystin (cyanotoxin)." Environmental Toxicology20(2): 126-130.

Orr, P. T. and G. J. Jones (1998). "Relationship between microcystin production and cell division rates in nitrogen-limited Microcystis aeruginosa cultures." Limnology and Oceanography43(7): 1604-1614.

Owen, E. D. and K. J. Msayib (1985). "Catalyzed degradation of polyvinyl-chloride. 2. antimony(III) chloride photocatalysis." Journal of Polymer Science Part a-Polymer Chemistry23(6): 1833-1838. 
Peng, L. A., Y. M. Liu, W. Chen, L. M. Liu, M. Kent, and L. R. Song (2010). "Health risks associated with consumption of microcystin-contaminated fish and shellfish in three Chinese lakes: Significance for freshwater aquacultures." Ecotoxicology and Environmental Safety73(7): 1804-1811.

Persson, I., M. Sandstrom, and P. L. Goggin (1987). "On the coordinating properties of some solvents- a vibrational spectroscopic study of mercury(II) halides and antimony(V) chloride in solution- new concepts for Lewis basicity scales of solvents." Inorganica Chimica Acta129(2): 183-197.

Petsko, G. A. (1995). "Cancer-chemotherapy-heavy-metal revival." Nature377(6550): 580-581.

Philbert, M. A., C. M. Beiswanger, D. K. Waters, K. R. Reuhl, and H. E. Lowndes (1991). "Cellular and regional distribution of reduced glutathione in the nervous-system of the rat-histochemical-localization by mercury orange and ortho-phthaldialdehyde-induced histofluorescence." Toxicology and Applied Pharmacology107(2): 215-227.

Pierce, R. H., M. S. Henry, P. C. Blum, S. L. Hamel, B. Kirkpatrick, Y. S. Cheng, Y. Zhou (2005). "Brevetoxin composition in water and marine aerosol along a Florida beach: Assessing potential human exposure to marine biotoxins." Harmful Algae4(6): 965-972.

Pierce, R. H., M. S. Henry, P. C. Blum, J. Lyons, Y. S. Cheng, D. Yazzie, and Y. Zhou (2003). "Brevetoxin concentrations in marine aerosol: Human exposure levels during a Karenia brevis harmful algal bloom." Bulletin of Environmental Contamination and Toxicology70(1): 161-165.

Plakas, S. M. and R. W. Dickey (2010). "Advances in monitoring and toxicity assessment of brevetoxins in molluscan shellfish." Toxicon56(2): 137-149.

Plakas, S. M., Z. H. Wang, K. R. El Said, E. L. E. Jester, H. R. Granade, L. Flewelling, P. Scott, and R. W. Dickey (2004). "Brevetoxin metabolism and elimination in the Eastern oyster (Crassostrea virginica) after controlled exposures to Karenia brevis." Toxicon44(6): 677-685.

Poli, M. A., T. J. Mende, and D. G. Baden (1986). "Brevetoxins, unique activators of voltage-sensitive sodium-channels, bind to specific sites in rat-brain synaptosomes." Molecular Pharmacology30(2): 129-135.

Poste, A. E., R. E. Hecky, and S. J. Guildford (2011). "Evaluating microcystin exposure risk through fish consumption." Environmental Science \& Technology45(13): 5806-5811.

Pouria, S., A. de Andrade, J. Barbosa, R. L. Cavalcanti, V. T. S. Barreto, C. J. Ward, 
W. Preiser (1998). "Fatal microcystin intoxication in haemodialysis unit in Caruaru, Brazil." Lancet352(9121): 21-26.

Prasanna, R., V. Gupta, C. Natarajan, and V. Chaudhary (2010). "Bioprospecting for genes involved in the production of chitosanases and microcystin-like compounds in Anabaena strains." World Journal of Microbiology \& Biotechnology26(4): 717-724.

Qian, H. F., S. Q. Yu, Z. Q. Sun, X. C. Xie, W. P. Liu, and Z. W. Fu (2010). "Effects of copper sulfate, hydrogen peroxide and N-phenyl-2-naphthylamine on oxidative stress and the expression of genes involved photosynthesis and microcystin disposition in Microcystis aeruginosa." Aquatic Toxicology99(3): 405-412.

Rajanna, B., C. S. Chetty, S. Rajanna, E. Hall, S. Fail, and P. R. Yallapragada (1995). "Modulation of protein kinase C by heavy metals." Toxicology Letters81(2-3): 197-203.

Raju, K. S., G. Alessandri, M. Ziche, and P. M. Gullino (1982). "Ceruloplasmin, copper ions, and angiogenesis." Journal of the National Cancer Institute69(5): 1183-1188.

Rao, P. V. L., R. Bhattacharya, M. M. Parida, A. M. Jana, and A. S. B. Bhaskar (1998). "Freshwater cyanobacterium Microcystis aeruginosa (UTEX 2385) induced DNA damage in vivo and in vitro." Environmental Toxicology and Pharmacology5(1): 1-6.

Refsvik, T. (1986). "Mechanism of N-acetylpenicillamine (NAPA) potentiation of biliary-excretion of methyl mercury in the rat-influence of glutathione depletors, and metabolization of NAPA and of cysteine in relation to1-chloro-2,4-dinitrobenzene (DNB) and bromosulphophtalein (BSP) conjugation." Acta Pharmacologica Et Toxicologica59: 498-501.

Riordan, J. R. and V. Richards (1980). "Human-fetal liver contains both zinc-rich and copper-rich forms of metallothionein." Journal of Biological Chemistry255(11): $5380-5383$.

Rue, E. and K. Bruland (2001). "Domoic acid binds iron and copper: a possible role for the toxin produced by the marine diatom Pseudo-nitzschia." Marine Chemistry76(1-2): 127-134.

Saito, K., Y. Sei, S. Miki, and K. Yamaguchi (2008). "Detection of microcystin-metal complexes by using cryospray ionization-Fourier transform ion cyclotron resonance mass spectrometry." Toxicon51(8): 1496-1498.

Sano, T. and K. Kaya (1995). "A 2-amino-2-Butenoic acid(DHB)-containing microcystin isolated from Oscillatoria-agardhii." Tetrahedron Letters36(47): 8603-8606.

Satarug, S., J. R. Baker, S. Urbenjapol, M. Haswell-Elkins, P. E. B. Reilly, D. J. Williams, and M. R. Moore (2003). "A global perspective on cadmium pollution and 
toxicity in non-occupationally exposed population." Toxicology Letters 137(1-2): 65-83.

Sato, M. and J. D. Gitlin (1991). "Mechanisms of copper incorporation during the biosynthesis of human ceruloplasmin." Journal of Biological Chemistry266(8): 5128-5134.

Schild, L. and E. Moczydlowski (1991). "Competitive-binding interaction between $\mathrm{Zn}^{2+}$ and saxitoxin in cardiac $\mathrm{Na}^{+}$channels-evidence for a sulfhydryl-group in the $\mathrm{Zn}^{2+}$ saxitoxin binding-site." Biophysical Journal59(3): 523-537.

Selwood, A. I., P. T. Holland, S. A. Wood, K. F. Smith, and P. S. McNabb (2007). "Production of anatoxin-a and a novel biosynthetic precursor by the cyanobacterium Aphanizomenon issatschenkoi." Environmental Science \& Technology41(2): 506-510.

Shaikh, Z. A., T. T. Vu, and K. Zaman (1999). "Oxidative stress as a mechanism of chronic cadmium-induced hepatotoxicity and renal toxicity and protection by antioxidants." Toxicology and Applied Pharmacology154(3): 256-263.

Shigemori, H., M. A. Bae, K. Yazawa, T. Sasaki, and J. Kobayashi (1992). "Alteramide-A, a new tetracyclic alkaloid from a bacterium-alteromonas sp. associated with the marine sponge Halichondria-okadai." Journal of Organic Chemistry57(15): 4317-4320.

Shimizu, Y., H. Bando, H. N. Chou, G. Vanduyne, and J. C. Clardy (1986). "Absolute-configuration of brevetoxins." Journal of the Chemical Society-Chemical Communications(22): 1656-1658.

Sivonen, K., W. W. Carmichael, M. Namikoshi, K. L. Rinehart, A. M. Dahlem, and S. I. Niemela (1990). "Ioslation and characterization of hepatotoxic microcystin homologs from the filamentous fresh-water cyanobacterium Nostoc sp. strain-152." Applied and Environmental Microbiology56(9): 2650-2657.

Stankovich, M. T. and A. J. Bard (1977). "Electrochemistry of proteins and related substances. 1. Cystine and cysteine at mercury-electrode." Journal of Electroanalytical Chemistry 75(2): 487-505.

Stevens, D. K. and R. I. Krieger (1991). "Stability studies on the cyanobacterial nicotinic alkaloid anatoxin-A." Toxicon29(2): 167-179.

Stoichev, T., D. Amouroux, R. C. R. Martin-Doimeadios, M. Monperrus, O. F. X. Donard, and D. L. Tsalev "Speciation analysis of mercury in aquatic environment." Applied Spectroscopy Reviews 41(6): 591-619.

Sugiyama, N., K. Konoki, and K. Tachibana (2007). "Isolation and characterization of okadaic acid binding proteins from the marine sponge Halichondria okadai." 
Biochemistry46(40): 11410-11420.

Sun, B. G., M. Macka, and P. R. Haddad (2002). "Separation of organic and inorganic arsenic species by capillary electrophoresis using direct spectrophotometric detection." Electrophoresis23(15): 2430-2438.

Suzuki, T., V. Beuzenberg, L. Mackenzie, and M. A. Quilliam (2004). "Discovery of okadaic acid esters in the toxic dinoflagellate Dinophysis acuta from New Zealand using liquid chromatography tandem mass spectrometry." Rapid Communications in Mass Spectrometry18(10): 1131-1138.

Svircev, Z., V. Baltic, M. Gantar, M. Jukovic, D. Stojanovic, and M. Baltic (2010). "Molecular aspects of microcystin-induced hepatotoxicity and hepatocarcinogenesis." Journal of Environmental Science and Health Part C-Environmental Carcinogenesis \& Ecotoxicology Reviews 28(1): 39-59.

Tansel, B., J. Sager, T. Rector, J. Garland, R. F. Strayer, L. F. Levine, M. Roberts, M. Hummerick, and J. Bauer (2006). "Significance of hydrated radius and hydration shells on ionic permeability during nanofiltration in dead end and cross flow modes." Separation and Purification Technology51(1): 40-47.

Taylor, N. J. and A. J. Carty (1977). "Nature of $\mathrm{Hg}^{2+}$-cysteine complexes implicated in mercury biochemistry." Journal of the American Chemical Society99(18): 6143-6145.

Tett, P., R. Gowen, D. Mills, T. Fernandes, L. Gilpin, M. Huxham, K. Kennington (2007). "Defining and detecting undesirable disturbance in the context of marine eutrophication." Marine Pollution Bulletin55(1-6): 282-297.

Thorp, H. H. (1992). "Bond valence sum analysis of metal-ligand bond lengths in metalloenzymes and model complexes." Inorganic Chemistry31(9): 1585-1588.

Torigoe, K., M. Murata, T. Yasumoto, and T. Iwashita (1988). "Prorocentrolide, a toxic nitrogenous macrocycle from amarine dinoflagellate Prorocentrum-lima." Journal of the American Chemical Society110(23): 7876-7877.

Trainer, V. L., R. A. Edwards, A. M. Szmant, A. M. Stuart, T. J. Mende, and D. G. Baden (1990). "Brevetoxins-unique activators of voltage-sensitive sodium channels." Acs Symposium Series 418: $166-175$.

Trasande, L., P. J. Landrigan, and C. Schechter (2005). "Public health and economic consequences of methyl mercury toxicity to the developing brain." Environmental Health Perspectives113(5): 590-596.

Trogen, G. B., U. Edlund, G. Larsson, and I. Sethson (1998). "The solution NMR structure of a blue-green algae hepatotoxin, microcystin-RR - A comparison with the 
structure of microcystin-LR." European Journal of Biochemistry258(2): 301-312.

Truman, P., D. J. Stirling, P. Northcote, R. J. Lake, C. Seamer, and D. J. Hannah (2002). "Determination of brevetoxins in shellfish by the neuroblastoma assay." Journal of Aoac International 85(5): 1057-1063.

Turkdogan, M. K., F. Kilicel, K. Kara, I. Tuncer, and I. Uygan (2003). "Heavy metals in soil, vegetables and fruits in the endemic upper gastrointestinal cancer region of Turkey." Environmental Toxicology and Pharmacology13(3): 175-179.

Twiner, M. J., M. Y. B. Dechraoui, Z. H. Wang, C. M. Mikulski, M. S. Henry, R. H. Pierce, and G. J. Doucette (2007). "Extraction and analysis of lipophilic brevetoxins from the red tide dinoflagellate Karenia brevis." Analytical Biochemistry369(1): 128-135.

Utkilen, H. and N. Gjolme (1995). "Iron-stimulated toxin production in Microcystis-aeruginosa." Applied and Environmental Microbiology61(2): 797-800.

Vahter, M. (2000). "Genetic polymorphism in the biotransformation of inorganic arsenic and its role in toxicity." Toxicology Letters 112: 209-217.

Vandal, G. M., R. P. Mason, and W. F. Fitzgerald (1991). "Cycling of volatile mercury in temperate lakes." Water Air and Soil Pollution56: 791-803.

Vasconcelos, Mtsd, M. F. C. Leal, and C. M. G. van den Berg (2002). "Effect of nitrogen and phosphorus on growth of toxic and nontoxic Microcystis strains and on intracellular microcystin concentrations." Microbial Ecology43(4): 443-454.

Wakisaka, Y., Y. Chu, J. D. Miller, G. A. Rosenberg, and D. D. Heistad (2010). "Critical Role for Copper/Zinc-Superoxide Dismutase in Preventing Spontaneous Intracerebral Hemorrhage During Acute and Chronic Hypertension in Mice." Stroke41(4): $790-797$.

Wang, K. Q. and R. Y. Feng (2004). "The method of calculating the atomic radius and positive ionic radius of meta." Journal of Pingdingshan Teachers Colleg19(2): 14-17.

Wang, Q., Y. A. Niu, P. Xie, J. Chen, Z. M. Ma, M. Tao, M. Qi, L. Y. Wu, and L. G. Guo (2010). "Factors Affecting Temporal and Spatial Variations of Microcystins in Gonghu Bay of Lake Taihu, with Potential Risk of Microcystin Contamination to Human Health." Thescientificworldjournal10: 1795-1809.

Wang, Q. R., D. Kim, D. D. Dionysiou, G. A. Sorial, and D. Timberlake (2004). "Sources and remediation for mercury contamination in aquatic systems - a literature review." Environmental Pollution131(2): 323-336.

Watras, C. J., R. C. Back, S. Halvorsen, R. J. M. Hudson, K. A. Morrison, and S. P. 
Wente (1998). "Bioaccumulation of mercury in pelagic freshwater food webs." Science of the Total Environment219(2-3): 183-208.

White, A. R., X. D. Huang, M. F. Jobling, C. J. Barrow, K. Beyreuther, C. L. Masters, A. I. Bush, and R. Cappai (2001). "Design and preparation of serine-threonine protein phosphatase inhibitors based upon the nodularin and microcystin toxin structures. Part 3." Journal of the Chemical Society-Perkin Transactions 1(14): 1673-1695.

White, C. W., K. B. Avraham, P. F. Shanley, and Y. Groner (1991). "Transgenic mice with expression of elevated levels of copper-zinc superoxide-dismutase in the lungs are resistant to pulmonary oxygen-toxicity." Journal of Clinical Investigation87(6): 2162-2168.

White, C. W., K. B. Avraham, P. F. Shanley, and Y. Groner (1997). "Comparative toxicity of the diarrhetic shellfish poisons, okadaic acid, okadaic acid diol-ester and dinophysistoxin-4, to the diatom Thalassiosira weissflogii." Toxicon35(11): 1591-1603.

Winner, R. W. (1984). "The toxicity and bioaccumulation of cadmium and copper as affected by humic-acid." Aquatic Toxicology5(3): 267-274.

Woolf, A., R. Wright, C. Amarasiriwardena, and D. Bellinger (2002). "A child with chronic manganese exposure from drinking water." Environmental Health Perspectives 110(6): 613-616.

Wren, C. D. (1986). "A review of metal accumulation and toxicity in wild mammals. 1. mercury." Environmental Research40(1): 210-244.

Xiao, Y. A., Y. D. Liu, G. H. Wang, Z. J. Hao, and Y. J. An (2010). "Simulated microgravity alters growth and microcystin production in Microcystis aeruginosa (cyanophyta)." Toxicon56(1): 1-7.

Yamaoka, Y., M. L. Carmona, J. M. Oclarit, K. Z. Jin, and Y. Shibata (2001). "Arsenic compounds in marine sponge (Haliclona permolis, Halichondria japonica, Halichondria okadai and Haliclona sp white) from Seto Inland Sea, Japan." Applied Organometallic Chemistry15(4): 261-265.

Yan, F., M. Ozsoz, and O. A. Sadik (2000). "Electrochemical and conformational studies of microcystin-LR." Analytica Chimica Acta409(1-2): 247-255.

Yehiayan, L., M. Pattabiraman, K. Kavallieratos, X. T. Wang, L. H. Boise, and Y. Ca (2009). "Speciation, formation, stability and analytical challenges of human arsenic metabolites." Journal of Analytical Atomic Spectrometry24(10): 1397-1405.

Yim, M. B., P. B. Chock, and E. R. Stadtman (1990). "Copper, zinc superoxide-dismutase catalyzes hydroxyl radical production from hydrogen-peroxide. " 
Proceedings of the National Academy of Sciences of the United States of America87(13): 5006-5010.

Yuan, M., W. W. Carmichael, and E. D. Hilborn (2006). "Microcystin analysis in human sera and liver from human fatalities in Caruaru, Brazil 1996." Toxicon48(6): 627-640.

Zahir, F., S. J. Rizwi, S. K. Haq, and R. H. Khan (2005). "Low dose mercury toxicity and human health." Environmental Toxicology and Pharmacology20(2): 351-360.

Zeng, J., L. Y. Yang, and W. X. Wang (2009). "Cadmium and zinc uptake and toxicity in two strains of Microcystis aeruginosa predicted by metal free ion activity and intracellular concentration." Aquatic Toxicology91(3): 212-220.

Zhang, L. and M. H. Wong (2007). "Environmental mercury contamination in China: Sources and impacts." Environment International33(1): 108-121.

Zhang, Y. G. (1982). "Electronegativities of elements in valence states and their applications. 1. Electronegativities of elements in valence states." Inorganic Chemistry21(11): 3886-3889.

Zhang, Y. G. (1982). "Electronegativities of elements in valence states and their applications. 2. A scale for strengths of Lewis-acids." Inorganic Chemistry21(11): 3889-3893.

Zhou, J. and L. Fritz (1993). "Ultrastructure of two toxic marine dinoflagellates, Prorocentrum-LimaandProrocentrum-maculosum." Phycologia32(6): 444-450.

Zhou, L., H. Yu, and K. Chen (2002). "Relationship between microcystin in drinking water and colorectal cancer." Biomedical and Environmental Sciences15(2): 166-171.

Zillioux, E. J., D. B. Porcella, and J. M. Benoit (1993). "Mercury cycling and effects in fresh-water wetland ecosystems." Environmental Toxicology and Chemistry12(12): 2245-2264. 